\title{
62nd Annual Meeting of the Irish Otorhinolaryngology/ Head and Neck Society
}

\author{
Abstract Booklet
}

\section{$1.0900-0908$}

\section{Surgical Management of Combined Paediatric Head and Neck and Thoracic Pathology}

N Elsafty, R Mehanna, L Nolke, J McGuinness, J Russell

Aim and objective: The management of paediatric cervical pathology extending below the neck poses a significant challenge to the Paediatric Otolaryngologist. Cervicothoracic lesions extend through the thoracic inlet and can be extensive, involving multiple spaces and vital structures simultaneously.

Materials and methods: We conducted a case series over 5 years of all head and neck and mediastinal lesions requiring shared surgical operative management. Operative log-books, radiology, and chart review were undertaken. Endoscopic imaging and video recordings were also obtained. Results: A total of 17 cases were identified within 5 years $-41.1 \%$ males, 58.8\% females. The median age at diagnosis was 9 months. The most common presenting complaint was stridor (29.4\%), lower respiratory symptoms (23.5\%), and neck swelling (17.6\%). Nearly half of all cases were due to tracheostenosis ( $n=8,47 \%)$ with neoplastic lesions $(n=4,23.5 \%)$, lymphangiomas $(n=3,17.6 \%)$ iatrogenic tracheoesophageal fistulae $(n=3,17.6 \%)$ comprising the remaining cases. Eighty-two percent underwent preoperative imaging with at least one imaging modality. All cases underwent combined surgery under both ENT and cardiothoracic teams, with all cases undergoing sternotomy. Fifty-two percent $(n=9)$ underwent concurrent slide tracheoplasty and $29.4 \%(n=5)$ underwent concurrent neck dissection. The average stay in the intensive care unit (ICU) was 13.5 days and the average total length of hospital stay (LOHS) was 58.9 days. The average length of follow-up was 25 months. One death was recorded on follow-up.

Conclusion: Experienced multidisciplinary input is essential for the safe and optimal surgical management of children with cervicothoracic lesions. Multisurgeon collaborative input allows for specialised teams to optimize treatment outcomes.

\subsection{8-0916}

\section{Totally Endoscopic Cartilage Tympanoplasty; A Hierarchical Task Analysis}

R Fahy, M Corbett, T Crotty, L Chadwick, I Keogh

Aim and objective: Totally endoscopic ear surgery (TEES) is a novel method of conducting otologic surgery that offers a unique perspective with operative and non-operative challenges. This study sought to conduct a technical and human factors analysis of endoscopic tragal cartilage tympanoplasty using the hierarchical task analysis (HTA) methodology, and identify potential pitfalls or errors using the systematic human error reduction and prediction approach (SHERPA).

Materials and methods: A literature review of publications describing endoscopic tympanoplasty was conducted. Eighteen endoscopic tragal cartilage tympanoplasties were observed over 12 months to identify the tasks and subtasks required for successful completion of TEES. The SHERPA approach was used to identify the potential operative risks and intervention methods to reduce or remediate these risks.

Results: An HTA was created identifying 8 tasks and 49 subtasks for a safe approach to completing totally endoscopic cartilage tympanoplasty. A risk score for each subtask was calculated from a suitable risk matrix to produce a SHERPA. SHERPA highlighted errors that have a major impact on patient outcomes including damage to middle ear structures. The majority of errors are rare or unlikely to occur.

(o) The Author(s). 2021 Open Access This article is distributed under the terms of the Creative Commons Attribution 4.0 International License (https://creativecommons. org/licenses/by-nc/4.0/), which permits unrestricted use, distribution, and non-commercial reproduction in any medium, provided you give appropriate credit to the original author(s) and the source, provide a link to the Creative Commons license, and indicate if changes were made. The Creative Commons Public Domain Dedication waiver (http://creativecommons.org/publicdomain/zero/1.0/) applies to the data made available in this article, unless otherwise stated. 
Conclusion: HTA and SHERPA methodology are valuable tools that can effectively deconstruct the technical and non-technical skills required to complete a successful surgery. Our HTA, possibly the first for TEES, allows for quick reference to a correct method of endoscopic tympanoplasty and allows evaluation of a standard technique. The SHERPA aims to reduce the risks associated with undergoing endoscopic tympanoplasty to improve patient safety, particularly in a training environment.

\title{
3. 0916-0924
}

\section{The Use of P-Possum Scores to Predict Morbidity in Patients Undergoing Surgery with Reconstruction for Malignancies Involving the Temporal Bone}

\author{
H Jones, A Gendre, A McHugh, B O'Sullivan, F Martin, R McConn-Walsh, JP O'Neill, N Shine
}

\begin{abstract}
Aim and objective: The Portsmouth-Physiological and Operative Severity Score for the Enumeration of Mortality and Morbidity (P-POSSUM) is a two-part scoring system that includes a physiological assessment and a measure of operative severity. We sought to determine whether P-POSSUM risk estimates could be used in major head and neck reconstructive surgery.

Materials and methods: We reviewed 67 patients who were diagnosed with a temporal bone malignancy in a single centre between 2000 and 2021, 34 patients undergoing surgical resection were included. We assessed the correlation between the P-POSSUM score and its application in patients undergoing major surgical resection of the head and neck with flap reconstruction.

Results: The 30-day mean \pm SD morbidity estimate calculated using P-POSSUM was $47.6 \pm 19.5 \%$, with a range of 14.9 to $89.9 \%$. The actual rate of overall complications was $47 \%$. We compared the actual complication rate with calculated estimates and a receiver operating characteristic (ROC) curve was obtained. The optimal cut-off for POSSUM was calculated from this at $40.5 \%$, the sensitivity and specificity at this point were 75 and $67 \%$, respectively.

Conclusion: Our study indicates that POSSUM is a useful tool for predicting morbidity in high risk in patients undergoing head and neck resection with reconstruction for malignancies of the temporal bone.
\end{abstract}

\section{0924-0932}

\section{Transcanal Tragal Cartilage Myringoplasty; Our Experience of Different Views}

\author{
E Cleere, M Corbett, IJ Keogh
}

Introduction: The advent of endoscopic ear surgery (EES) has allowed otologists a different, improved view of the surgical field when compared with conventional microscopic ear surgery (MES). The purpose of this study was to compare the efficacy of EES and MES for transcanal tragal cartilage myringoplasty.

Materials and methods: We retrospectively analysed patients who have undergone push through transcanal tragal cartilage myringoplasty in our institution in the last 10 years. Exclusion criteria were defined as patients with prior tympanic membrane repair, non-tragal cartilage tympanic membrane graft, ossicular chain reconstruction, and patients with insufficient follow-up. EES and MES groups were compared using outcomes such as graft success rate, changes in pure tone audiometry (PTA), and complications.

Results: Seventy-four patients met inclusion criteria (MES $=38$, EES $=36$ ). The mean age of included patients was 29.3 years with no significant demographic differences between groups. All EES cases were Cohen class 3 (total EES). The graft success rate at 12 months was higher among the EES group (94.5\%) vs MES (89.5\%). Twenty-four patients (66.7\%) in the EES group had improved hearing on postoperative PTA while 25 patients $(65.7 \%)$ in the MES group had improved hearing on postoperative PTA. There were no major operative complications in either group.

Conclusion: EES offers a superior view of the surgical field but can be technically more challenging for the surgeon when compared with MES. Outcomes were better in the EES group which supports that for tragal cartilage myringoplasty EES offers an otologic choice that can complement established practice. 


\title{
$5.0932-0940$
}

\section{Point of Care Eustachian Tube Functional Testing: A Prospective Feasibility Study}

\author{
R Hill, T Melrose, SG Khoo
}

\begin{abstract}
Aim and objective: Eustachian tube (ET) dysfunction is a common presentation in ENT clinics, with aural fullness and type $C$ tympanograms being a hallmark. Many patients with aural fullness however have both normal audiograms and type A normal tympanograms, leading to false reassurance. The function of the ET can be assessed via measuring the middle ear pressures following Valsalva and swallowing. Our aim with the present study is to quantify the sensitivity and specificity of eustachian tube function testing (ETF testing) as a diagnostic tool in ET dysfunction in the context of a type A tympanogram.

Materials and methods: Patient selection began with a full history and examination, and inclusion into the study was as a result of aural fullness being the primary complaint. Audiometry and tympanometry were performed, and abnormal results were excluded from the study. Our patient selection criteria were, therefore; aural fullness associated with normal audiometry and tympanometry. A control group was selected from patients undergoing audiometric testing who did not complain of aural fullness, had a normal audiogram, and had a type A tympanogram.

Results: Of our patient cohort, ETF testing showed abnormal results in $80 \%$ of cases, with no increase in peak pressures as expected in normal ET function. Less than $10 \%$ of the control group showed abnormal results in ETF testing.

Conclusion: ETF testing is a simple and effective way to highlight the presence of ET dysfunction. For patients with traditionally normal testing, ETF testing can identify ET dysfunction and allow access to specific treatments.
\end{abstract}

\section{0940-0948}

\section{Mastoid Cavity Obliteration Techniques: A Review of 189 Cases}

\author{
N McHugh, A Nae, R McConn Walsh
}

\begin{abstract}
Aim and objective: Canal wall down (CWD) mastoidectomy is a well-established surgical technique undertaken to eradicate cholesteatoma. Whilst providing excellent risk reduction in disease recurrence over alternatives, postoperative otorrhea and accumulation of debris in the exteriorised cavity may become problematic. Traditionally, mastoid cavity obliteration (MCO) has subsequently been used to treat this. However, it is now common practice to obliterate cavities during the primary procedure. This method is also utilised in lateral skull base surgery, particularly in the context of CSF leak. We describe our experience with various obliteration techniques.

Materials and methods: The database in a tertiary otorhinolaryngology department was reviewed for patients undergoing MCO following CWD mastoidectomies and lateral skull base surgery. Selected patients underwent various combinations of cartilage graft, bone pate, middle temporal artery (MTA) flap, and fascia lata graft closure techniques. The primary outcome was to ascertain the effectiveness of performing these surgeries in relation to the aforementioned post-operative sequelae.

Results: One hundred and eighty-nine eligible patients were identified, all of whom had undergone MCO with either cartilage graft, bone pate, or an MTA flap. Eighty-five of the patients had fascia lata graft-assisted closure. There was a significant improvement in postoperative otorrhea and problematic sequelae in all groups.

Conclusion: There is a benefit to primarily performing MCO post-CWD mastoidectomy and lateral skull base surgery. This can be effectively performed in various ways including bone pate, MTA flap, and fascia lata graft. However, residual disease detection may prove more difficult postoperatively.
\end{abstract}




\title{
7.0948-0956
}

\section{Outcomes From 7 Years of Direct to Audiology Referral Pathway}

\author{
A Noone, R Katiri, N Sivan, E Farrell, L McLoughlin, B Lang, S Kieran
}

\begin{abstract}
Aim and objective: The direct to audiology via ENT referral pathway was designed to enhance patient access to audiology services. The pathway is recommended in the model of care for ENT and has been in use for several years in many institutions. Here, we outline our outcomes over the last 7 years.

Materials and methods: A retrospective review of the direct to audiology referral service was conducted. The time frame was 2014 to 2021. Outcomes were defined by the pathway each patient took following attendance at the audiology clinic. Patients were either discharged, referred for hearing aids, or identified as candidates for further diagnostic assessments, including a follow-up at an ENT outpatient clinic.

Results: During the time frame, 445 patients were triaged to the direct to audiology initiative. The average wait time for patients was 13 days and ranged from 1 to 145 days, the median wait time was 10 days. The average age was 55 years. One hundred and fifty-five (35\%) patients required imaging and 241 (54\%) were referred for hearing aid amplification. Approximately $40 \%$ of all patients referred were discharged by the audiologist back to the GP.

Conclusion: The direct to audiology initiative has proven effective at reducing waiting times for ENT patients solely in need of audiological intervention. A large proportion of these referrals to the ENT service can be assessed comprehensively in the audiology clinic, thereby reducing the demand on ENT clinics, enhancing service provision, and onwards referral for amplification.
\end{abstract}

\section{0956-1004}

\section{A New Modified Combined Approach Tympanomastoidectomy Procedure: A Single Centre Method}

\author{
C Reinhardt, A Nae, JM Hintze, R McConn-Walsh
}

\begin{abstract}
Introduction: Cholesteatoma is a benign disease associated with significant morbidity. The operative management of cholesteatoma has evolved significantly over the past seven decades. The combined approach tympanoplasty (CAT) was first described in 1958 by Jansen for the management of cholesteatoma while maintaining a closed cavity by keeping the posterior canal wall intact. There have been many subsequent modifications of the CAT, most notably that of Tos (1982). Here, we present a new approach that aims to highlight a change of practice from the traditional radical mastoidectomy to predominantly CAT.

Materials and methods: A retrospective analysis was undertaken of a prospectively maintained database of all surgeries employing this new approach performed at a single tertiary referral centre for neuro-otology and lateral skull base surgery between September 2016 and August 2021. Data were collected and analysed for demographics, postoperative and hearing outcomes, and recurrence.

Results: A total of 23 procedures were performed, 18 males and 5 females (3.6:1). The mean age was $46.2 \pm 16.9$ years. The most common preoperative examination findings were tympanic membrane (TM) retraction or perforation, ossicle erosion, and hearing loss. Our approach involves a cortical mastoidectomy, epitympanotomy, atticotomy, and opening of the facial recess, aimed at removing cholesteatoma while keeping the posterior canal wall up. Attic closure is with cartilage reconstruction. The tegmen defect, if present, is closed with temporalis fascia \pm reconstruction of the TM with cartilage \pm total/partial ossicular replacement prosthesis.
\end{abstract}

Conclusion: Our data show good postoperative results with the newly described modified combined approach tympanomastoidectomy procedure.

\section{1004-1012}

\section{Trainee Perception of a New Digital Temporal Bone Laboratory Using the Voxel-man Simulator}

\author{
E Richards, C Leonard, C Dalton
}

Aim and objective: Temporal bone (TB) surgery is challenging to learn due to intricate anatomy and limited learning opportunities, particularly during the COVID-19 pandemic. TB skills can be acquired in theatre, or in a wet, dry, or digital laboratory. We aimed to assess trainee perception of the usefulness of TB drilling courses held in a newly established digital TB laboratory using the VOXEL-MAN Tempo Simulator. 
Materials and methods: Eleven junior ( $\leq \mathrm{ST} 3 \mathrm{~s}$ ) and 13 senior (>ST4) candidates, attended a 3-hour course, and completed pre- and post-course questionnaires relating to prior experience, aims for, and outcomes of the course.

Results: 13/24 (55\%) trainees had a clinical experience of cortical mastoidectomy. 18/24 (75\%) had wet, 0/24 had dry, and 2/24 (8\%) had prior digital laboratory experience. 11/11 (100\%) junior trainees wished to learn drilling techniques and TB anatomy, whilst 8/11 (73\%) wished to learn how to use the TB simulator. 9/13 (69\%) senior trainees wished to improve their surgical skill and anatomical understanding, and 8/13 (62\%) wished to use the simulator to gain further experience of otologic procedures. $24 / 24$ (100\%) found the digital TB course useful, $96 \%$ scoring it as "extremely useful". 24/24 (100\%) felt the VOXEL-MAN simulator would have a beneficial impact on all stages of training. $100 \%$ felt the simulator should be included in ENT boot camps, and desired fortnightly to 6-monthly access.

Conclusion: The newly established digital TB laboratory was perceived as extremely useful by trainees. Access to this type of facility should be easy and regular to enhance maximum benefit for training, particularly catch-up training.

\title{
10. $1012-1020$
}

\section{Efficacy and Benefits of Cone-beam Computed Tomography vs X-ray in Cochlear Implantation: Birmingham Experience}

\author{
E Richards, J Muzaffar, R Kumar, L Yates, A Nehikhare, S Colley, C Coulson
}

Aim and objective: Cochlear implant $(\mathrm{Cl})$ electrode optimal placement is crucial for successfully implant aided performance. The advent of conebeam computed tomography (CBCT) has aided in confirming position and troubleshooting difficult cases. We aimed to compare CBCT vs Modified Stenvers' view X-ray imaging for postoperative assessment of $\mathrm{Cl}$ electrode placement.

Materials and methods: Between April 2016 and September 2016, CBCT was used in our department following Cl. Retrospective data collection was performed to assess benefits over standard X-ray imaging.

Results: Two hundred and forty-four adults underwent $\mathrm{Cl}$ in this period. One hundred and fourteen had an analysable CBCT and $134 \mathrm{had}$ an X-ray. When formally reported, X-rays were described as satisfactory or not. CBCT showed an average electrode insertion depth of $22 \mathrm{~mm}$. Full insertion was achieved in 95 and $89 \%$ achieved $360^{\circ}$ rotation. Ninety-eight percent attained normal positioning into the scala tympani on the first procedure. Bamford-Kowal-Bench (BKB) scores after 12 months of rehabilitation ranged from 61 to $99 \%$ (mean 78\%). In general, BKB scores were good (mean $>85 \%$ ) in cases with normal CBCT, while scores were poorer (mean $<70 \%$ ) in those with abnormal CBCT and/or cochlea. A strong positive correlation was seen between BKB and normal CBCT findings $(p<0.05)$. Patients with normal cochlear anatomy, full electrode insertion, with evidence of apical electrode placement, in optimal scalar tympani position, had high BKB scores (mean $>85 \%$ ). BKB showed a moderate positive correlation with abnormal cochlea and/or with abnormal CBCT findings $(p<0.05)$.

Conclusion: CBCT offers considerably more valuable information to the operating team and audiologists following $\mathrm{Cl}$ than Modified Stenvers' view X-rays.

\section{1020-1028}

\section{Diagonal Ear Lobe Crease and Coronary Artery Disease: A Meta-analysis}

\author{
J Curtis, S Walford
}

Aim and objective: An association between a diagonal ear lobe crease (DELC) and cardiovascular disease was first suggested by Frank in 1973. Since then there have been numerous studies that have investigated the association of "Frank's Sign" with cardiovascular disease, although some have suggested it is a result of a confounding factor. This review looked to see if there is a significant association between the presence of a DELC and angiography-confirmed coronary artery disease (CAD) independent of other known cardiovascular risk factors.

Materials and methods: Systematic review and meta-analysis of selected studies, published between 1974 and 2017, using the PRISMA checklist. Results: Twelve studies involving 4,960 patients were included in the meta-analysis. Findings from our study suggest:

- Patients with DELC have a $4 \times$ increased likelihood of having CAD (OR 4.61; $<<0.00001)$.

- The relationship between DELC and CAD was independent of age and all other conventional cardiovascular risk factors.

- Bilateral DELC has a stronger association with CAD than unilateral DELC.

- The presence of DELC has insufficient sensitivity/specificity to be used as a diagnostic test for cardiovascular disease but instead should be used as a risk marker.

Conclusion: We found that DELC is associated with CAD independently of other known cardiovascular risk factors including age. Histology studies indicate that atherosclerosis is causing DELC and patients with DELC appear to have an increased risk of CAD. It has insufficient sensitivity or specificity to be used as a diagnostic test but instead should be used as a valuable risk marker to be aware of whilst examining ears. 


\title{
12. 1028-1036
}

\section{The Academic Impact of 20 Years of Irish Otolaryngology Society Meetings}

M Corbett, A Patil, E O’Mathuna, A Lloyd, T Crotty, J Munir

\begin{abstract}
Aim and objective: Medical research involves the dissemination of results through presentation and publication. We sought to analyze research presented at the Irish Otolaryngology Society meetings over the last 20 years. We sought to assess academic impact through analysis of publication rates, impact factor of journals, and citation rates.

Materials and methods: All oral presentations from IOS conferences were examined between 2000 and 2019. Presentation titles and each author were searched using PubMed, Google Scholar, and Research Gate to identify any publication which resulted from the research presented. Results: Of the 703 presentations made at the conferences spanning 20 years, 30.15\% went on to publish their research with an average of 19 citations per publication, the median time to publication was 2 years. The mean impact factor of the journals was 1.83. Each year there have been more oral presentations with a declining publication rate.

Conclusion: The Irish otolaryngology society meeting is a high-quality meeting with comparable publication rates to similar international conferences. Despite this, many research presentations do not have any lasting impact as they are not published. Year on year, there have been fewer oral presentations resulting in full-text publications. Increasing pressure for trainees to rapidly present multiple research projects at several meetings without emphasis on completion of projects may explain the drop in publication rates. We would urge the importance of completion of quality research including publication in journals so that meaningful conclusions can add to the body of knowledge and contribute to the best evidence-based practice.
\end{abstract}

\section{3. $1036-1044$}

\section{Outcomes of Preoperative Real-time Polymerase Chain Reaction for SARS-CoV-2 Virus in Elective Otolaryngology Surgical Patients during the Coronavirus Disease 2019 Pandemic: A Prospective Cohort Study}

F Kavanagh, D Brinkman, D James, S O’Neill, C Murphy, I O’Riordan, G O’Flanagan, B Lang, I Keogh, E Lang, P Casserly, J Russell, D O'Brien, ICE Collaborative Group, P Sheahan

\begin{abstract}
Aim and background: Real-time polymerase chain reaction (RT-PCR) preoperative testing is the widely established means of excluding SARS-CoV-2 in patients before elective surgery. However, few studies have examined the outcome of negative RT-PCR testing in the postoperative period. Materials and methods: A prospective cohort study of patients undergoing elective Otolaryngology surgery at five institutions in Ireland between September and December 2020 who had negative preoperative RT-PCR testing. Baseline community transmission was obtained from the national public health database. The primary outcome measure was the incidence of symptomatic COVID-19 or major respiratory complications in patients 14 days after surgery. Prospectively enrolled patients were contacted 14 days after surgery and enquiry was made regarding the development of postoperative symptoms, testing, or diagnosis of COVID-19.

Results: Four hundred and ninety-nine patients were enrolled (258 males), Mean age was 36.4 years (range 0.25 months to 90 years) from four institutions in the Republic of Ireland. The peak 14-day COVID-19 incidence in the population during the study was 302.9 cases per 100,000 population. No COVID-19 infections or major respiratory complications were reported in the 14-day follow-up period. Thirty-nine patients underwent repeat RT-PCR testing during the 14 postoperative days, all of whom were negative for detection of SARS-CoV-2.

Conclusion: These data support the effectiveness of preoperative RT-PCR testing in predicting a low risk of transitioning to symptomatic COVID19 in the postoperative period during periods of moderate to high community transmission.
\end{abstract}




\title{
14. 1044-1052
}

\section{Teams of the Future: Addressing the Waiting List Crisis}

\author{
K Munir, L Tighe, E Keane
}

\begin{abstract}
Aim and background: Since the publication of the Model of Care in 2019, our speciality has seen the unprecedented effects of the COVID-19 pandemic, web hacking, and looks to the future with the demands of Slaintecare. As of July 2020, over 68,000 patients were awaiting an ENT appointment. The involvement of the multidisciplinary team and forward-thinking initiatives will be essential in tackling this predicament. Objectives: To determine the level of interest in professional development in ENT amongst nurses and to promote awareness of postgraduate qualification. As we seek to establish the role of our own CNS, we present a report of her future competency-based training and her potential role in our unit.

Materials and methods: A prospective survey of staff nurses in several units was conducted and a breakdown of the training in specialist nursing roles is presented, particularly in the commencement of nurse-led tonsillectomy clinics.

Results: At the time of submission, there were 19 respondents to the survey. Seventy-nine percent were interested in progression to both CNS and ANP roles. The majority of respondents were unaware of opportunities for professional development in these skills and the actual competencies required to progress to these roles. In our unit, a significant number are waiting specifically to be considered for tonsillectomy and we anticipate our CNS seeing four patients per session in her own clinic running concurrently with the consultant.

Conclusion: This study demonstrates that there is a clear interest in professional development in ENT skills amongst nurses, with many unaware of opportunities to develop their skillset.
\end{abstract}

\section{5. $1052-1100$}

\section{Impact of the COVID-19 Pandemic on Ent Activity Across Northern Ireland}

\author{
R Shuttleworth, B Devlin
}

Aim and objective: COVID-19 has had a devastating effect on the ability of surgical specialties to deliver their services to patients. ENT is no exception. Between 2019 and 2020, the number of patients awaiting ENT admission in Northern Ireland has risen 12.6\%, whilst the number of patients awaiting ENT outpatient clinic has climbed by $13.1 \%$. This reflects a reduction in activity, which within ENT in Northern Ireland is yet to be assessed. This study aims to evaluate the impact of the COVID-19 pandemic on ENT activity across Northern Ireland.

Materials and methods: All five trusts were contacted to submit data on the number of new and review patients seen in outpatient clinics and the total number of ENT operations performed. Data were requested for the full year of 2019 and 2020.

Results: While comparing activity levels between 2019 and 2020 across trusts, there was a $72 \%$ reduction in the number of new patients seen in outpatients, a $65.8 \%$ reduction in the number of review patients seen in outpatients, and a $61.4 \%$ reduction in the number of operations performed. Conclusion: The delivery of ENT services across Northern Ireland has been severely impacted by the pandemic. With the need for these services not diminishing, the reduction of activity highlighted in this study does not reflect the increase in the number of people awaiting ENT services. This suggests that without meaningful intervention, both inpatient and outpatient waiting times are likely to continue to increase for some time yet.

\section{6. $1430-1438$}

\section{Physician Associates in Ent: An Opportunity for Development}

\author{
E Richards, J Muzaffar, N Khan, S Ahmed
}

Aim and objective: Physician associates (PA) are well established in the US but remain relatively new in the UK with no specific job description. There are approximately 1,400 in the UK, with most deployed to ward work. We have integrated a PA into a firm structure in our department since 2017. We wished to explore this further and consider the cost-benefits.

Materials and methods: We discuss our departments' experience of a PA integrated into the Rhinology and Skullbase team and explore the cost-benefits of this.

Results: A typical week includes three clinic sessions, two in theatre, two wards, and one MDT. Our PA performs key skills such as microsuction, flexible nasendoscopy, and nasal cautery as well as more specialist tests including smell testing, ciliary biopsies, and nasal biopsies under local anaesthesia. Our PA contributes to the smooth running of theatre lists and competently first assists in complex endoscopic pituitary and skull-base surgery. Our PA also retains and develops generalist skills covering the ENT ward which also helps free-up juniors to attend teaching, clinics, and 
theatres. Through clinic sessions and procedures performed, an average monthly generation of $£ 7,921$ was made in 2019 . It has also provided the team with a long-term colleague, unlike rotating junior doctors.

Conclusion: Given the likely continued constriction in the supply of doctors in training, innovative approaches to maximise the skill mix amongst clinical teams are crucial. A model such as we have implemented offers a rewarding, cost-effective, and long-term skilled colleague, enhancing the productivity and care provided by the department.

\title{
17. 1438-1446
}

\section{Transoral Laser Microsurgery in Early Glottic Carcinoma: An Egyptian Experience}

\author{
A El-Badrawy, M Amin, S Bahaa Elden, A Yousef
}

Aim and objective: Laryngeal carcinoma is representing $1 \%$ of all malignancies diagnosed annually. It is suspected by circumscribed areas of mucosal change, e.g., leucoplakia. Therefore, if we could deal with glottic cancer early, we would have great outcomes in the management of laryngeal carcinomas. This is what we evaluated in our study to assess the role of $\mathrm{CO}_{2}$ laser in early glottic carcinoma.

Materials and methods: A prospective study evaluating oncologic outcomes of early glottic carcinoma treated with transoral laser microlaryngeal (TLM) surgery in two tertiary referral hospitals. The study was conducted for 33 patients at the Otolaryngology Department and National Cancer Institute-Cairo University. Patients were followed up for 2 years after the procedure between (January 2016 and July 2019) to assess loco-regional control. Operative and postoperative complications were assessed.

Results: The median follow-up was 24 months. Disease-free survival was $97 \%$. Overall survival was $100 \%$. There were no operative complications. The median postoperative pain score was 3 . The median duration of the procedure was 15 minutes. None of the patients experienced postoperative bleeding or airway complications. There was no return to the hospital within 30 days for complications.

Conclusion: Preferences of TLM over others incorporate shorter hospitalization, lower morbidity, valuable results, and less harm to voice in some cases compared with RT. Also, an imperative advantage of utilizing TLM is that takes off all treatment choices open in patients with a recurrent tumor within a short period of follow-up. Recent studies showed NBI can add more advantages to TLM.

\section{8. $1446-1454$}

\section{Free Flap Microvascular Pharyngeal Closure Results in Improved Dysphagia Specific Quality of Life Following Total Laryngectomy}

\author{
E Cleere, S Mamdouh, E Devoy-Flood, MT O’Callaghan, F Martin, JB O’Sullivan, N Shine, JP O'Neill
}

Aim and objective: Total laryngectomy $(\mathrm{TL})$ as either a primary or salvage treatment strategy remains an effective oncologic operation in the management of laryngeal cancer. Dysphagia is the most common complication following TL and this has a significant impact on patients' quality of life (QOL). Following removal of the larynx, several pharyngeal closure techniques exist. We aimed to evaluate the effect pharyngeal closure techniques have on dysphagia-specific QOL postoperatively.

Materials and methods: We retrospectively reviewed patients who had undergone TL at our institution (2014-2019). Patients alive at the time of the study were invited to complete the MD Anderson Dysphagia Inventory (MDADI). Outcomes were compared among primary closure (PC), pedicled pectoralis major myocutaneous flap (PMMF), and free flap (FF) closure groups.

Results: There were 27 patients identified for inclusion. Eight patients (30\%) underwent PC, 10 patients (37\%) had PMMF assisted closure, and 9 patients (33\%) underwent FF-assisted closure. Patients within the FF group scored consistently higher MDADI scores across all subscales (emotional, functional, physical, global) as well as composite MDADI scores in comparison to the PC and PMMF groups. FF closure was associated with a reduced inpatient length of stay (LOS). Additionally, no significant differences in postoperative morbidity including rates of pharyngocutaneous fistula (PCF) were observed between groups.

Conclusion: We now advocate FF closure for our patients following salvage TL due to the improved dysphagia-specific QOL, reduced inpatient LOS, and lack of additional surgical morbidity. 


\title{
Laryngeal Dysplasia: A Systematic Review of Prognostic Factors in the Development of Malignancy
}

\author{
I O’Riordan, E Keane, B Clyne, H Rowley
}

\begin{abstract}
Introduction: Laryngeal dysplasia is a premalignant lesion of the larynx. Previous studies have indicated $14 \%$ of patients with laryngeal dysplasia will develop laryngeal cancer. This study aims to assess the role of risk factors in the progression of laryngeal dysplasia to laryngeal cancer. Materials and methods: A systematic review was performed following the PRISMA 2009 checklist. Prospective and retrospective observational studies of adults ( $\geq 18$ years) with laryngeal dysplasia, graded using the WHO 2005 criteria followed up for a minimum of 12 months were included. Where possible, a meta-analysis of results was conducted (Revman 5), and the remainder of the results are presented narratively due to study heterogeneity.

Results: From 3,576 studies reviewed, 15 studies were included. Overall, the mean weighted transformation rate was $18.1 \%$ across 10 studies. Weighted mean transformation rate in low-grade dysplasia was $7.8 \%$, moderate grade dysplasia was $18.3 \%$, high-grade dysplasia was $21.8 \%$, and carcinoma in situ $26.7 \%$. The pooled odds ratio for the development of laryngeal malignancy in patients with dysplasia who were smokers was $0.38(95 \% \mathrm{Cl} 0.11,1.25)$.

Conclusion: This review has identified a higher than previously reported rate of malignant transformation, which may impact our current surveillance of dysplasia. It confirms that the rate of transformation corresponds with the severity of dysplasia. Risk also increases with smoking, although this did not reach statistical significance. These outcomes confirm the importance of surveillance and emphasise that no modifiable factors can be accurately used to risk stratify these patients.
\end{abstract}

\section{0. $1502-1510$}

\section{Twenty-years Recurrence Rate of Parotid Gland Pleomorphic Adenoma}

\author{
A Nae, H Alhuwaish, M Abahussain, T Moran
}

Aims and objectives: Pleomorphic adenoma (PA) is the most common salivary gland tumour, and although benign, has malignant potential and can recur after surgical excision. The study aimed to review the parotid gland PA management and recurrence rate in our institution.

Materials and methods: A retrospective review of our patients diagnosed with parotid glands PA between 1998 and 2020 was conducted. The patient's medical records, surgical notes, and histopathology results were inspected.

Results: One hundred PA cases were included. Thirty-six males and 64 females. The median age was 57; the 5th decade was the most prevalent (25\%). The main presenting symptom was a parotid mass (70\%). The initial fine needle aspiration identified the PA in $76 \%$ of cases. Eighty percent of patients had surgery for their tumours. Superficial parotidectomy was performed in $69 \%$ of cases. All histopathology results confirmed PA, with one incidental Warthin's tumour. Surgical complications were recorded in $10 \%$ of patients. The most common one was facial nerve weakness (7\%), followed by Frey's syndrome and keloid scar with 2\% each. Three cases of PA recurrence (3\%) were recorded at 3, 16, and 20 years, respectively, post-surgery. One case presented with multiple recurrences at a short interval ( 3 years) and after completion of parotidectomy, the patient was referred for radiotherapy. No case of malignancy was noted.

Conclusion: Our low number of complications and recurrence rate demonstrated a good surgical technique. Recurrence can develop after 15 years, and long-term follow-up is recommended for PA.

\section{1510-1518}

\section{Correlating Radiological and Histological Staging of Advanced Laryngeal Cancer}

\author{
J Hintze, B Lang, A Hannigan, J Kinsella, P Lennon, C Timon
}

Aim and objective: The objective of the present study was to examine the correlation between preoperative imaging characteristics with postoperative histology of patients undergoing laryngectomy and determine the rate of occult metastatic disease. 
Materials and methods: One hundred and eighteen cases were available for final analysis. Only cases with SCC of the larynx were included. Age and sex of the patient, method of hospital admission, preoperative radiological staging, operative details, and final histological analysis and staging were recorded.

Results: The mean age at presentation was $62.05 \pm 10.5 .81 .7 \%(n=123)$ of patients were male. $40.3 \%(n=48)$ of patients had previously had radiotherapy for either the same or another head and neck malignancy. $60.5 \%$ were T4 on imaging, $17.6 \% \mathrm{~T} 3,11.8 \% \mathrm{~T} 2,7.6 \% \mathrm{~T} 1$, and $2.5 \%$ either T0 or Tx. $58.8 \%$ were N0 on imaging, followed by N1 in $16.0 \%, 24.4 \%$ N2, and $0.8 \%$ N3. All 119 patients underwent total laryngectomy and 112 (94.1\%) patients underwent lateral neck dissection at the time of laryngectomy. There was a good correlation between T-staging on imaging compared to histology, however, $\mathrm{N}$-staging showed a statistically significant difference $(p<0.000)$. Eleven percent of patients were upstaged from $\mathrm{NO}$ to $\mathrm{N}+$ disease on histology ( $14.3 \%$ for primary and $6 \%$ for salvage).

Conclusion: Although preoperative staging on imaging does correlate well with postoperative histological staging, there still is a large cohort of patients (11\%), who were upstaged from N0 to N+ disease on histology, highlighting the importance of concurrent neck dissection in laryngectomies.

\title{
22. $1518-1526$
}

\section{The COVID-19 Pandemic and Its Implications for Head and Neck Cancer Patients}

\author{
A Zuccarelli, C Leonard, J Smith, M Adams, C Dorris, M Black
}

Aim and objective: COVID-19 has placed a significant unexpected strain upon the health service. We aim to assess the impact of COVID-19 on head and neck cancer diagnoses and treatment.

Materials and methods: We performed a retrospective review of patients referred to a regional Head and Neck Cancer Multidisciplinary Team Meeting (MDT) between 2018 and 2020 inclusive. Patients were identified from a prospectively collated database. Site of origin, tumour-lymph node-metastatic spread (TNM) stage at presentation, treatment modality, and key time markers along treatment pathway were assessed.

Results: 1,959 discussions occurred, 1,315 new cancer presentations, and 644 reviews. New discussions dropped from 474 and 470 in 2018 and 2019 to 371 in 2020 ( $\mathrm{Chi}^{2} 8.1 ; p=0.018$ ). Monthly analysis indicated no drop related specifically to lockdowns but the variance in monthly referrals was significant in 2020 (Kruskal-Wallis $\mathrm{Chi}^{2} 22.3 ; p=0.02$ ). Advanced tumours (T3/T4) were more prevalent in $20^{2} 0\left(\mathrm{Chi}^{2}=12.61 ; p=0.002\right)$.

Conclusion: Patients referred to the Regional Head and Neck MDT were discussed and treated promptly despite the challenges of COVID-19 on healthcare services. However, the reduction in referrals suggests the presence of COVID, societal, and healthcare restrictions have resulted in a reduction of new presentations to the Head and Neck MDT, with a significant increase in advanced tumours. This raises concern of possible delayed diagnoses and poorer outcomes for the head and neck cancer cohort both during the pandemic and the knock-on impact on service provision as restrictions come to an end.

\section{3. $1526-1534$}

\section{Pattern of Lymph Node Metastasis of Cutaneous SCCs Requiring Lateral Temporal Bone Resections}

\author{
J Hintze, H Jones, A Gendre, R McConn-Walsh, N Shine, JP O’Neill
}

\begin{abstract}
Aim and objective: The objective of the present study was to explore the pattern of lymph node spread of cutaneous SCCs involving the lateral temporal bone, as well as determine the rate of spread to the parotid gland.

Materials and methods: We retrospectively reviewed all lateral temporal bone resections for cutaneous SCC involving the lateral temporal bone over 20 years in a single tertiary referral centre for lateral skull base and head and neck surgery. Thirty-two patients were available for final analysis. Type of neck dissection performed and adjunctive procedures such as parotidectomy and pinnectomy performed were recorded.

Results: The mean age was $70.31 \pm 12$ years. All cases were SCC $(n=32)$. All patients underwent a LTBR, while $65.6 \%(n=21)$ underwent a pinnectomy, $71.9 \%(n=23)$ had a parotidectomy, and $62.5 \%(n=20)$ had a neck dissection ( $45 \%$ of which were modified radical). Level 1 was positive in $3.1 \%$, level 2 in 12.5\%, level 3 in 9.4\%, level 4 in $6.3 \%$, and level 5 in $6.3 \%$. The parotid had a disease in $34.4 \%$ ( $n=11$ ), of which $54 \%$ was due to direct invasion. $56.3 \%$ of patients underwent free flap reconstruction. The pathological size of the main specimen did not influence the rate of nodal disease; however, the depth of the specimen did ( $p=0.324$ and 0.008 , respectively). Seventy-eight percent underwent adjuvant radiotherapy treatment. The overall survival of the cohort was 66.7. There was no statistically significant difference in survival based on nodal disease or parotid disease.

Conclusion: In the present study, the most common location for nodal metastasis was in level 2, while parotid involvement was present in $34 \%$ of cases. In cases of neck disease, a full modified radical neck dissection should be performed, while in cases where vessel preparation for free flap reconstruction is performed, a lateral neck dissection can also be considered. Due to the high rate of parotid disease, results from the present support consideration for performing a parotidectomy at the time of lateral temporal bone resection.
\end{abstract}




\title{
24. 1534-1542
}

\section{Did COVID-19 Impact Post Radiation Imaging in Head and Neck Cancer Patients?}

\author{
C Murphy, H Markey, O Young
}

\begin{abstract}
Aims and objectives: Guidelines recommend that imaging should be done within 16 weeks of the last day of radiotherapy treatment. This study investigates if there were a delay in post-treatment imaging for head and neck SCC (HNSCC) patients during the COVID-19 crisis.

Materials and methods: A retrospective review was conducted of the head and neck radiotherapy database of patients undergoing treatment for HNSCC in the year pre-COVID and post-COVID in our centre. Data collected included age, sex, diagnosis, treatment regime, date of completion of treatment, and date of post-treatment scan.

Results: Thirty-one patients were in the pre-COVID group, 32 patients were in the post-COVID group. The male to female ratio was 1:3 in pre-COVID, 1:6 in post COVID. The median age was 59 in pre-COVID, 70 in post-COVID. Seventy-one percent of patients in pre-COVID got a scan within 16 weeks while $34 \%$ got a scan within the same timeframe in the post-COVID group.

Conclusion: The COVID-19 crisis caused significant pressure on radiology services in Ireland with resultant delays in essential post-radiotherapy imaging for HNSCC patients. The potential negative impact of these delays will be borne by already stretched services and more importantly by individual patient outcomes.
\end{abstract}

\section{5. $1542-1550$}

\section{Laryngectomy in T3 Laryngeal Cancer: Who Gets it and Why?}

\author{
G Sexton, J Hintze, P Lennon
}

\begin{abstract}
Aim and objective: Laryngeal cancer is often managed with radiotherapy or chemoradiotherapy, which currently represent the standard of care for T3 lesions. Despite this, some patients with T3 lesions undergo surgical management. We aimed to investigate indications for and outcomes from surgical management of T3 laryngeal cancers.

Materials and methods: A retrospective cohort study of patients with T3 laryngeal cancer who underwent surgical management over 12 years. Results: Twenty-six patients were identified. The mean age was 60.8 years. $84.6 \%(n=22)$ were males. Fourteen received no prior radiotherapyhere borderline T4 radiological findings were the most prevalent indication $(n=9,34.6 \%)$, followed by bulky/airway threatening disease ( $n=4$, $15.4 \%)$. For those with the previous radiotherapy, primary radiation failure was the most prevalent indication $(n=7,26.9 \%)$, followed by previously irradiated field $(n=3,11.5 \%)$ and bulky/airway threatening disease $(n=2,7.7 \%)$. Oral feeding was reestablished in $65.4 \%(n=17)$. Eleven achieved independent tracheoesophageal puncture prosthesis (TEPP) speech, with four using TEPP and electrolarynx (57.7\%). Four (15.4\%) did not achieve voice rehabilitation. Ten (38.5\%) had disease recurrence; the mean time to recurrence was 7.2 months. Mean survival was 32 months. Mean survival was 31.9 months in the borderline imaging group and 29.5 months in the salvage group. The difference was not statistically significant $(p=0.88)$. Swallow and speech rehabilitation rates were similar in the borderline imaging group ( 55.6 and $77.8 \%$, respectively) and the salvage group (71.4 and 83.3\%).

Conclusion: Laryngectomies for T3 disease may occur where radiological ambiguity exists, and occasionally where there is a threatened airway. Rehabilitation of speech and swallow following laryngectomy remains challenging.
\end{abstract}

\section{6. $1550-1558$}

\section{Cervicofacial Non-tuberculous Mycobacterial Infection in Children: A 10-year Retrospective Review of Conservative and Surgical Management}

\author{
B Wright, P Moriarty, K Trimble
}

Aims and objectives: To retrospectively collect data on a regional basis for the management strategies and outcomes in cases of non-tuberculous mycobacterial (NTM) infection in the head and neck region in children over 10 years. 
Materials and methods: A search was performed in the regional microbiology lab records for all cases of NTM cultures in the head and neck region between 2008 and 2018 for children aged between 0 and 12 years old. Medical imaging records were also reviewed to identify cases of cervicofacial NTM infections in children. Electronic care records were reviewed to gather data on management and outcomes for patients.

Results: A total of 31 cases were identified with an average age of 4 years old. The most common Mycobacterium cultured was mycobacterial avium complex (MAC). Three cases involved the parotid region and the remainder involved the neck. Patients had symptoms for an average of 57 days before presentation to the ENT or infectious diseases team and 35\% were known to have been prescribed antibiotics in primary care. Various management strategies were identified including fine needle aspiration (4 patients), excision biopsy (11 patients), incision and drainage ( 3 patients), incision and curettage (13 patients), and neck dissection ( 2 patients). Most commonly, a macrolide with or without rifampicin was prescribed by the ENT or infectious diseases team. Several complications occurred including marginal mandibular weakness, fistula, and scar tissues. Conclusion: In this series of children with cervicofacial NTM infection, the presentation was often delayed and antibiotics were commonly prescribed. Various surgical interventions were observed and the preferred technique of incision and curettage in our unit appears to be a good option with low morbidity.

\title{
27. 1558-1606
}

\section{Disease-specific Quality of Life in Children with Otitis Media Effusion}

\author{
S Boyle, M Fitzsimons, I Keogh
}

Introduction: Otitis media with effusion (OME) is one of the most common diseases of childhood and causes significant morbidity for children. The benefits of ventilation tubes (VT) are well established, but the subjective impact of surgery on Irish children's quality of life (QOL) has not been studied.

Materials and methods: A prospective single unit cross-sectional study used a validated QOL survey [Otitis Media-6 (OM-6)] to determine the impact of VT placement on QOL.

Results: Seventy-six children with a mean (range) age of $6(0.5-13)$ years were recruited to this study. Fifty-four of the children were male. The overall mean OM- 6 score for the 76 children was 3.2. Twenty-six children proceeded to surgery. The mean OM- 6 score in this cohort preoperatively was 4.5 and reduced to 1.35 at 3 months post-VT placement.

Conclusion: This study highlights the morbidity experienced by Irish children with OME. There is a significant short-term improvement in the quality-of-life scores of those who had VT insertion. Clinicians should consider the routine use of OM- 6 as an adjunct to holistic patient management.

\section{8. $1606-1614$}

\section{The Incidence of COVID-19 in the of Asymptomatic Children Undergoing Adenoidectomy}

\author{
A Copperthwaite, R Fahy, A Patil, M Corbett, K Hickey, A Rueda Benito
}

\begin{abstract}
Aim and objective:The COVID-19 pandemic has had a marked impact on medical, economic, and social wellbeing across the world. Adenoidectomy is performed routinely in children complaining of obstructive sleep-disordered breathing symptoms to improve their quality of life. Adenoid tissue has been shown to harbor asymptomatic viral infections including adenovirus, Epstein-Barr virus, rhinovirus, and coronaviruses. The presence of these viruses in adenoid tissue correlates with worse airway obstruction symptoms. Our study investigated the presence of COVID-19 in the adenoid tissue of asymptomatic patients.

Materials and methods: Fifteen patients presented for adenoidectomy. All patients presenting for adenoidectomy were asymptomatic for COVID19 infection and complained of obstructive sleep-disordered breathing symptoms. All patients were tested preoperatively with a nasopharyngeal swab for COVID-19 with PCR testing. Adenoid tissue was sent to the laboratory post adenoidectomy and tested for COVID-19 with PCR testing. Patients were selected by consecutive convenience sampling.

Results: Fifteen patient samples are being analyzed for COVID-19. Ages range from 3 to 13 years old.

Conclusion: COVID-19 continues to have a longstanding impact on society across the world. Our study examines the presence of asymptomatic infection of COVID-19 in patients presenting for adenoidectomy. Increasing COVID-19 infections may increase the chance of COVID-19 presence in adenoid tissue and worse airway obstructive symptoms.
\end{abstract}




\title{
A Review of Children with Down Syndrome Who Underwent Bone-anchored Hearing Aid Implantation
}

\author{
C Murphy, F Fitzgerald, S Hone
}

\begin{abstract}
Aims and objectives: To look at the success rates and outcome measures of children with Down syndrome who use a Bone Anchored Hearing Aid (Baha $\left.{ }^{\circledR}\right)$.

Materials and methods: A review was performed on a prospectively maintained database in our centre. Age, sex, indication for the implant, date of implantation, type of implant, complications, hearing and speech outcomes, and assessment of benefits data were recorded. The CHILD questionnaire was used to measure the assessment of benefit.

Results: Twenty-seven children with Down syndrome underwent implantation. The male to female ratio was 1:1. The indication for Baha ${ }^{\circ}$ was in the majority otitis media with effusion, next was chronic suppurative otitis media. Seventy-two percent of children were implanted with the Baha ${ }^{\circledR}$ Attract, the remaining had the Baha ${ }^{\circledR}$ Connect. Two complications were recorded that caused the device to fail.

Conclusion:This study shows Baha ${ }^{\circledR}$ is a successful method to treat conductive hearing loss in children with Down syndrome. The attract technology has improved success rate and is now the preferred choice of device in most instances as it has less chance of falling out or causing skin reactions.
\end{abstract}

\section{0. $1622-1630$}

\section{Early Intervention of Paediatric Epistaxis}

\author{
A Zuccarelli, C Jackson
}

Aim and objective: During the COVID-19 pandemic, the number of face-to-face encounters was reduced dramatically. We developed a remote clinical pathway for the management of paediatric epistaxis at the time of referral, aiming to treat early and optimize utilization of clinic appointments for those patients requiring septal cautery.

Materials and methods: Following referral to ENT, a standardized clinical letter was sent to the GP and parents of the patient with a recommendation to try a course of topical antibiotic cream (Naseptin) as first-line treatment. Contact information for the ENT department was provided in the letter so that if symptoms persisted following initial treatment, a prompt face-to-face appointment could be arranged for examination and cautery. Results: Sixty-six paediatric patients with recurrent episodes of epistaxis were referred and managed for 5 months. Eight patients had already been commenced on an antibiotic cream at the time of referral, while 56 were sent the standardized letter. Of the 66 patients commenced on an antiseptic cream, 54 (81\%) were successfully treated with this first-line treatment and did not require a face-to-face ENT consultation for further treatment. Conclusion: Topical antibiotic cream is proven to be a simple and effective treatment in most patients with epistaxis. This management pathway allows treatment and advice to be instigated early. We reduced unnecessary patient attendances, whist selecting patients likely to require cauterization at a face-to-face appointment.

\section{1630-1638}

\section{Novel Use of Gore-Tex Sutures for Mustarde Pinnaplasty}

\author{
A Mallon, D McKenna, E Reddy
}

Aim and objective: Representing one of the most common congenital head and neck abnormalities, prominent ears can affect up to $5 \%$ of children. Perceived facial disfigurement can cause significant psychosocial distress, low self-esteem, and social isolation. Surgical correction can significantly improve quality of life and over 200 surgical techniques have been described, each with inherent advantages and disadvantages. We describe a novel approach to the Mustarde-Furnas technique using Gore-Tex》 stitches and ascertain the resultant complication rate and patient satisfaction outcomes.

Materials and methods: A retrospective review of all patient case notes was undertaken between July 2011 and February 2020 to record operation and complication details. Post-intervention change in the quality of life was assessed using the validated Glasgow Benefit Inventory (GBI) or Glasgow Children's Benefit Inventory (GCBI) which was posted to all patients. Non-responders were contacted via telephone.

Results: Twenty-nine operations in total were identified ( 7 adults, 22 children). The mean overall adult GBI score was +61 with the mean subdomain scores for psychological health status (+83), social support $(+15)$, and physical status $(+5)$ all positive. The mean overall GCBI score was +60 with the subdomains of psychological health $(+60)$, physical health $(+14)$, behaviour $(+10)$, and vitality $(+26)$ all positive. Overall satisfaction was $93 \%$ reflecting a low complication rate (2/29-loss of position after 1 year and a suture granuloma).

Conclusion: Pinnaplasty using Gore-Tex sutures placed using the Mustarde-Furnas technique is associated with high patient satisfaction, significant self-reported improvements in psychological health, and a low complication rate. 


\title{
32. $1638-1646$
}

\section{Effect of Post-fess Middle Turbinate Synechiae on Sinonasal Physiology: A Computational Fluid Dynamics Study}

\author{
H Khatri, H Salati, E Wong, K Bradshaw, K Inthavong, R Sacks, N Singh
}

\begin{abstract}
Aim and objective: Chronic rhinosinusitis (CRS) has an estimated prevalence between 5 and $12 \%$ of the general population. Functional endoscopic sinus surgery (FESS) is reserved for cases recalcitrant to medical treatment. Middle turbinate synechiae (MTS) is a common complication post FESS. MTS anecedotally results in persistent rhinologic symptoms and is a common indication for revision surgery, but objective physiological effects have not yet been modelled.

Materials and methods: A three-dimensional segmentation was created from a high-resolution CT sinus of a healthy 25 -year-old female. Virtual synechiae were added between the right middle turbinate and lateral nasal in locations representing the most common findings seen in clinical practice. A no-synechiae model formed the control. In each model, CFD analysis was performed, assessing airflow streamlines, mucosal surface temperatures, and relative humidity levels within the sinonasal cavities.

Results: Synechiae models all lead to aberrant airflow streamlines/ventilation patterns, altered mucosal surface temperatures, and relative humidity levels. These altered ventilation patterns lead to altered mucosal surface temperatures within the sinus cavities affected. All synechiae models in this study demonstrate aberrations of airflow patterns compared with the control at the level of the olfactory cleft.

Conclusion: Post-FESS synechiae lead to altered airflow streamlines, which secondarily leads to altered mucosal surface cooling. Further research is required to further validate the findings yielded in this pilot study. The alterations seen in airflow streamlines and resultant changes in regional mucosal surface temperatures provide insight into the basis for perceived nasal obstructive symptoms and hyposmia reported by patients with synechiae post-FESS.
\end{abstract}

\section{3. $1646-1654$}

\section{Epistaxis in the SARS-CoV-2 Era}

\author{
M Walsh, SL Gillanders, C Shiel, P Lacy
}

\begin{abstract}
Aim and objective:Treating epistaxis is invasive and healthcare professionals can be exposed to the SARS-CoV-2 virus via aerosolization of particles in the upper airway. Given this risk to both patients and healthcare professionals, the management paradigm for epistaxis changed overnight. The objective of the study is to compare pre- and intrapandemic audits of epistaxis management.

Materials and methods: Before the pandemic, a proforma for the assessment and management of patients presenting with epistaxis was created with 20 patients included. These data were collated and compared with 20 patients presenting with epistaxis during the pandemic. The contributing causative factors, comorbidities, and treatment modalities were compared. ANOVA statistical analysis was utilised to compare differences between two groups.

Results: There was a significant difference in the utilization of rigid endoscopy (70\% pre-pandemic and 5\% interpandemic), bipolar and chemical cauterization (100\% pre-pandemic and $20 \%$ interpandemic), and nasal packing modality (65\% nasopore pre-pandemic and $70 \%$ rapid rhino interpandemic) while comparing pre-pandemic and pandemic management of epistaxis.

Conclusion: SARS-CoV-2 has forced a paradigm shift in the management of Epistaxis, which is less invasive, has less morbidity for the patient, requires fewer hospital admissions, and lessens the nosocomial transmission of the SARS-CoV-2 virus to healthcare staff and patients.
\end{abstract}

\section{4. $1654-1702$}

\section{The Prevalence of Anosmia and Length of Time to Recovery in Patients with COVID-19 Infection}

\author{
A Copperthwaite, V Quinn, L O’Keeffe, C Wijaya
}

Aim and objective: Anosmia is a well-recognised symptom of COVID-19 infection. The prevalence of anosmia in patients with COVID-19 varies greatly with a range of 33.9-68\% described in the literature. There is also a significant variation in the length of time taken for olfactory sensation to return. Our objective was to gather data from a random sample of patients who had COVID-19 and to report the prevalence of anosmia along with the time taken for the return of olfactory function. 
Materials and methods: This multicentric cross-sectional study was conducted in January 2021. Patients with polymerase chain reaction (PCR) proven COVID-19 infection were asked to complete a questionnaire. Data including age, gender, smoking history, and symptoms of COVID were collected. Patients under the age of 18 years and with a prior history of anosmia or nasal/sinus diseases were excluded.

Results: A total of 485 responses were received with 16 excluded due to the previous history of anosmia leaving 469 for inclusion. A total of 433 (92\%) people reported anosmia due to COVID-19, 380 (81\%) of whom reported total loss and 53 (11\%) reported a partial loss of smell. Thirty-six (7.4\%) people reported no change. On average, the length of time to recovery (partial or total) was 5.5 weeks.

Conclusion: COVID-19 remains to be a significant burden on society and anosmia continues to have a considerable effect on patients' quality of life. Our objective was to report the prevalence of anosmia within a random group along with the average length of time to recovery to provide useful information for physicians to counsel patients experiencing this troublesome symptom.

\title{
35. $1702-1710$
}

\section{Anterior Nasal Valve: Concept and Surgical Options}

\author{
MY Mian, SG Krishnan
}

The nasal valve, first described in the early 20th century by Mink is a complex, three-dimensional, dynamically alternate structure that controls nasal airway resistance. Dysfunction of the nasal valve can lead to nasal dysfunction and a significant drop in the quality of life for patients as defined by Hagen-Poiseuille - the flow through a tube is proportional to the fourth power of the radius of the tube and inversely proportional to the pressure difference across the tube. Thus, even a small decrease in the valve area can contribute to a severe nasal obstruction the nasal valve collapse (NVC) can be static or dynamic. Static NVC consist of an anatomically narrow nasal valve region that causes obstruction. Dynamic NVC is caused by insufficient cartilaginous support of the lateral nasal wall, leading to lateral insufficiency. Anatomically it is bounded by the caudal nasal septum head of inferior turbinate, upper lateral cartilage, lower lateral cartilage, and nasal floor. Most of the nasal airflow in Caucasian's passes through the middle meatus, Chines and African through the inferior common meatus, Middle Eastern and Pakistani's through the middle meatus. Common causes of NVC are prior rhinoplasty, aging, nasal trauma, and congenital abnormalities. Therapy is to correct NVC include surgical procedures and nonsurgical procedures. The non-surgical solution is to temporarily dilate the nasal valve such as Breath-Right strips or nasal cones. Latera, a polylactic acid copolymer, an absorbable implant, commonly inserted as an office procedure, give more durable results, by strengthening the lateral nasal wall. Bipolar radiofrequency has been employed as well, as a non-surgical solution. The surgical strategy involves septoplasty, inferior turbinate reduction may reduce negative inspiratory pressure by enlarging the airways but do not address the weakness of the lateral nasal wall. Procedure intended to address the weakness of the lateral wall include the cartilaginous grafts typically harvested from the nasal septum, ear, or rib cartilage that can be placed as spreader grafts, alar grafts, sturt grafts, or butterfly grafts. Reversing the lower lateral cartilage in selected cases also helps to improve the NVC. Implants made from non-observable alloplastic material have also been used for the treatment of NVC but are associated with the risk of extrusion and infection. Two audits from 2009 to 2011 and 2019 to 2020 were carried out. In the 2009 audit, 51 patients were recruited and analysed. Eleven patients did not fill the criteria as enough data was not present. 2019 audit was a prospective audit. In a 2009 audit, 29 patients had the septorhinoplasty, Batton grafts, and sturt grafts, 6 patients has septoplasty and Batton grafts, 5 patients had a reversal of lower lateral cartilage and septoplasty, 1 had spreader graft and septoplasty. The questionnaire was developed and the prognosis was measured 6 months by examination, photographs, and findings of the questionnaire. The data are suggestive that there was a significant improvement in the majority of patients in the 2009 audit. The 2019 audit has recruited 21 patients with a 6 -month follow-up. It is being analysed and would be presented together. 


\section{Poster Booklet}

\section{A Review of Telephone Consultations for Head and Neck Cancer follow up; A Patient Satisfaction Survey}

Y Yassin, R Stewart, L Collins, G Gray, B Devlin, M Black, R Ullah

Royal Victoria Hospital Belfast

\section{BACKGROUND}

Due to its high transmissibility of COVID-19 outpatient clinics were reduced to allow re-allocation of staff

Services needed to adopt new strategies for care delivery to reduce the risk to patients and staff due to travel and faceto-face (F2F) contact in hospital

\section{Problem}

- With the goal of 'cancer survivorship' HNC follow-up is focused on early detection of recurrence

- Previously established standards of care required modification with telephone consults being most prevalent

\section{Methods}

- Structured telephone interviews with 219 patients under follow up at the regional head and neck cancer unit

- Modified Likhart scale used to assess patient's opinion of telephone consultations

Patient demographics:

\begin{tabular}{|l|l|l|}
\hline Age & Male & Female \\
\hline $0-40$ & 13 & 7 \\
\hline $14-60$ & 28 & 15 \\
\hline $61-79$ & 57 & 28 \\
\hline $80+$ & 47 & 14 \\
\hline
\end{tabular}

\section{RESULTS}

Chi squared analysis demonstrated significant interaction between:

- Journey time and happiness to receive telephone review $\left(x^{2}(1)=8.72 ; \mathrm{P}<0.001\right)$

- Journey time and convenience of telephone review $\left(x^{2}\right.$ $(1)=13.73 ; P<0.01)$

Whilst not significant, there is an increasing trend in satisfaction in lower stage disease and high time from treatment

\section{Satisfaction score}
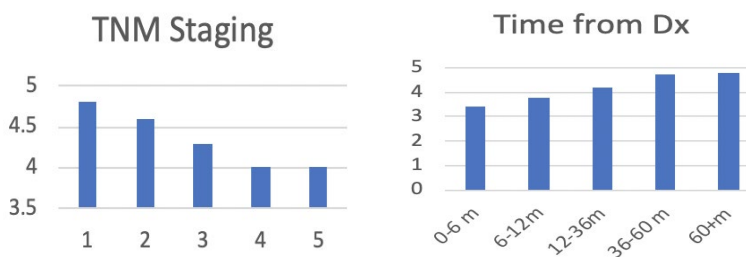

Journey Time (Minutes)

Age of patient
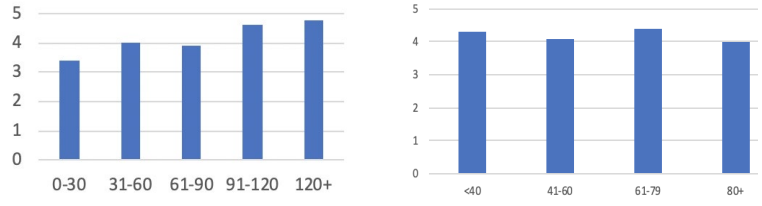

\section{CONCLUSIONS}

- $80 \%$ of patients preferred a telephone consultation during the pandemic

- $60 \%$ of patients would be happy to have telephone consultations become part of follow up

- Patients with lower stage disease, who are further from the date of their initial treatment and who live further from the hospital are more likely to be satisfied with telephone consultations

- An individualised approach is required as patient's clinical and emotional support requirements vary 


\author{
Endaural Myringoplasty Using Subcutaneous Tissue Graft: A Safe and Effective yet \\ Under Reported Technique \\ Authors: D Dick, C Soong ${ }^{1}$, E Reddy ${ }^{1}$
}

\title{
INTRODUCTION
}

Endaural incision for myringoplasty is well described. Most often, an underlay graft is take from temporalis fascia and used to scaffold the tympanic membrane. Reported take rates in adults are between $77-99 \%$ using this approach. ${ }^{1}$

It is also possible, though much less reported, to take graft material from subcutaneous tissue as part of an end aural incision approach. This requires no extra incisions and does not disturb the temporalis muscle. It also widens the external meatus to make follow up otoscopy easier in clinic.

\section{ОвJeCtive}

We aim to demonstrate our method of graft harvest then to review a single surgeon's practice, reporting success rates, hearing outcomes and complications from type 1 tympanoplasties performed using this technique.

\section{METHOD}

Using a prospectively maintained operative database on Microsoft Excel, we selected the myringoplasties which were performed using an endaural incision with incisional subcutaneous tissue graft, then analysed the data to look for complication rate and determine audiological outcomes.

VIDEO SHOWING ABRIDGED INCISION, GRAFT HARVEST AND PLACEMENT

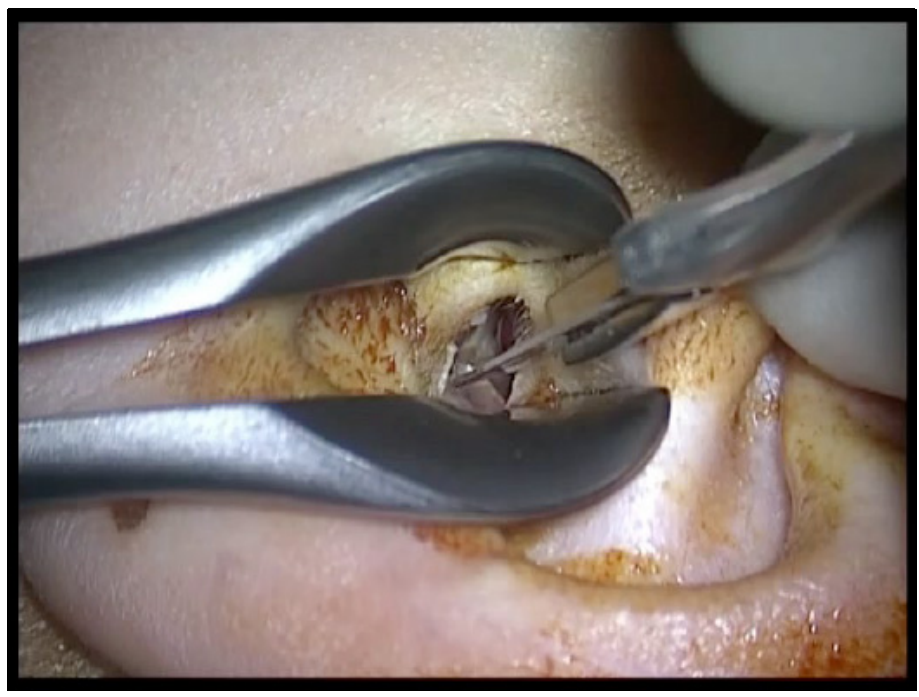

Video - click the image to play

\section{RESULTS}

We identified 119 type 1 myringoplasties spanning a period of 8 years, performed using the aforementioned technique. There were 51 males and 68 females, with a 1:1 right:left ratio

The average follow-up was 17 months (range 0.25-86 months).

The success rate was $87 \%$, with an intact drum at last clinic appointment.

The persistent perforation rate was $13 \%(n=11), 50 \%$ of which were pinhole, without hearing loss or infection. There were 3 cases with post operative granulations and 2 cases of myringitis, all treated conservatively in clinic and none of these ended up with perforations. There was no significance to age for complications however 11 of the residual perforations were right sided compared to 5 on the left.

There were no readmissions and no altered taste.

$80 \%(n=9)$ of these perforations had infection either pre or postoperatively.

In general, $93 \%$ of patients had improvement or no change in their hearing as demonstrated in pre and post operative audiograms. There was no new sensorineural hearing loss.

\section{CONCLUSION}

We conclude that this choice of incision and donor site is a safe and effective method for closing tympanic membrane perforations, with no need for head bandages, exposing muscle and subjectively less reported pain.

Our high-quality, prospective database has allowed a thorough analysis of complications and audiological outcomes, which were comparable to current literature for other methods of performing myringoplasty. As such we will continue to use this approach in order to reduce pain and discomfort for our patients whilst maintaining good outcomes.

\section{REFERENCES}

Sarkar S, Roychoudhury A, Roychaudhuri BK. Tympanoplasty in children. Eur Arch Otorhinolaryngol 2009; 266: 627-33. 


\section{INTRODUCTION}

- More than $60 \%$ of children will have a nosebleed before their $10^{\text {th }}$ birthday.

- Therefore, a common referral for tertiary ENT management.

- Anxiety provoking, however, rarely a sinister aetiology.

\section{OBjective}

- To assess the efficacy of Naseptin alone versus Naseptin and $\mathrm{AgNO}_{3}$ cautery for recurrent paediatric epistaxis.

- Primary outcome was the resolution of epistaxis.

- Secondary outcome was the occurrence of an adverse event in either cohort.

\section{MetHODS}

- All patients on the outpatient waiting list for epistaxis were telephoned.

- Patients with red-flag symptoms or multiple complaints were booked for face-to-face review.

- Patients that met the inclusion criteria were sent a prescription for Naseptin according to the NICE guidelines.

- At follow, if symptoms had resolved, the patient was discharged. If not, they were booked for a face-to-face review $+/$ - $\mathrm{AgNO}_{3}$ cautery.

\section{RESULTS}

- Average age 8.65 years (1-15 years).

- $\delta:$ : $123: 86$.

- 209 patients were contacted:

- 44 were discharged at the time of the initial phone call.

- 36 were booked directly for cautery (already had Naseptin).

- 129 remaining patients were prescribed Naseptin.

- 67/129 were discharged at follow due to treatment success.

- 28/81 who underwent $\mathrm{AgNO}_{3}$ cautery required further ipsilateral/contralateral cautery.

- There were no significant adverse events.

\section{Discussion/ConcLusion}

- Only $46.8 \%$ of patients on the outpatient waiting list warranted face-to-face review, which, during the COVID 19 era, represents a safe and efficient way of managing patients.

- Naseptin is an effective treatment for recurrent paediatric epistaxis.

- If Naseptin fails, $\mathrm{AGNO}_{3}$ cautery is a safe and effective secondary treatment for recalcitrant cases.

- Adequate first-line treatment of children in the community should be encouraged.

Outcome of initial contact

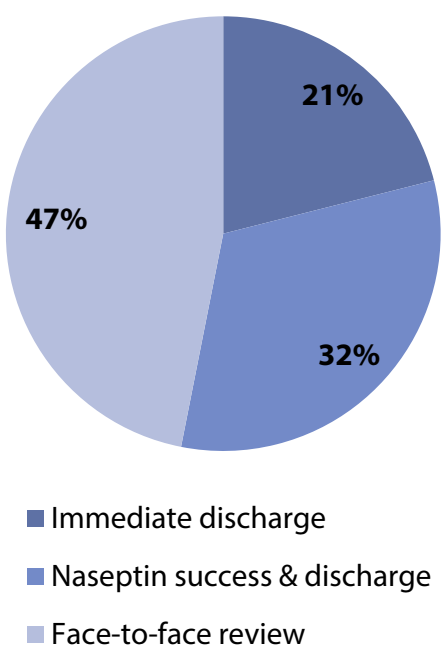

\section{Treatment Outcome}

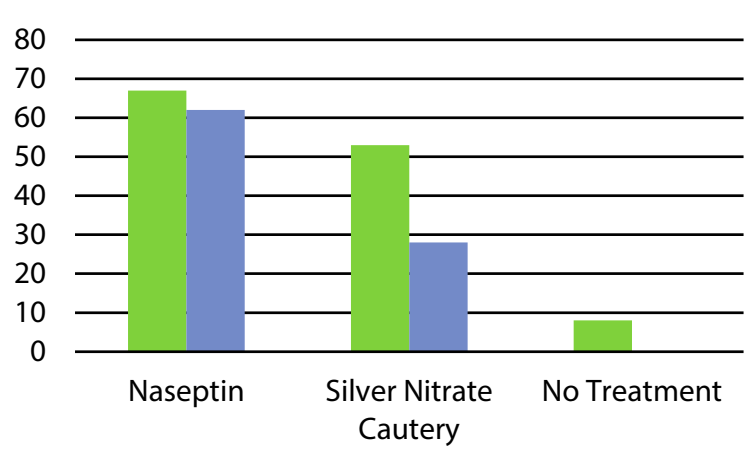

Resolution $\quad$ Further Treatment 


\section{yIOS \\ Irish Otorhinolaryngology / Head \& Neck Surgery Society

\section{Central Line Catheterisation as a Cause of Vocal Cord Palsy}

Emma Richards, Ravinder Suman, Nikoleta Skalidi and Christopher Jennings

\section{BACKGROUND}

Central venous catheterisation (CVC) is a commonly performed procedure, with over 5 million inserted annually in the US alone. ${ }^{1}$ It is most often achieved through the internal jugular veins (IJV) but can also be through the subclavian. ${ }^{2}$ The most frequently reported complications include cardiac arrhythmias, air emboli, haemothorax, pneumothorax and haematoma. Vocal cord palsy (VCP) is a rare and poorly recognised complication which we explore further. We report an unusual case of vocal cord palsy which developed following insertion of a central line.

\section{CASE Report}

A 46-year-old gentleman was admitted with seizures. Following failed attempts at establishing intravenous or intraosseous access, a central line was placed into the right internal jugular vein under ultrasound guidance. The patient was intubated for 9 days until a tracheostomy was performed to aid weaning. The patient was unable to phonate despite good airflow past the tracheostomy with a deflated cuff. Flexible nasendoscopy (FNE) showed a right VCP with an immobile, bowed vocal cord, with minimal compensation from the left true and false cords. Contemporaneous computed tomography (CT) imaging of the neck and thorax was performed on day 20 of admission to determine the cause of the palsy. Although this CT was clear, review of the original trauma CT (post CVC insertion) showed a haematoma within the right carotid sheath. A diagnosis of neuropraxia secondary to haematoma from CVC insertion was made. A second FNE demonstrated resolution of the VCP 29 days following admission.

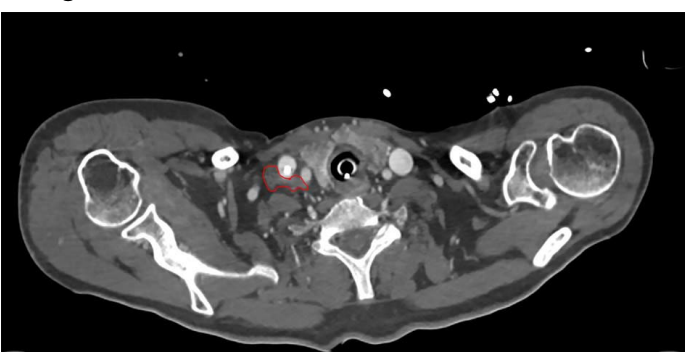

Fig. 1: CT showing haematoma in the right carotid sheath following insertion of central line.

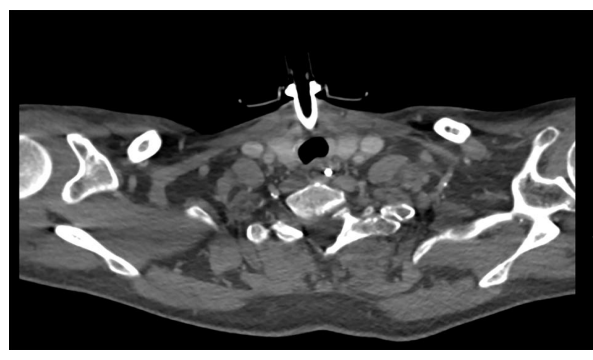

Fig. 2: CT showing resolution of the haematoma.

\section{Discussion}

Ten previous cases of VCP following CVC insertion were identified. Most involved placement via the IJV. The risk of injury is thought to be greatest with difficult insertions and repeated attempts. ${ }^{3}$ In our case the CVC was placed on the first attempt under ultrasound guidance.

Differentials considered included palsy secondary to direct trauma from intubation and neuropraxia from cuff pressure. However, the paramedial position of the palsied cord supported injury to the recurrent laryngeal nerve (RLN) rather than direct trauma. ${ }^{3}$

Review of the literature shows that most previously reported VCP after CVC insertion have been identified following development of hoarseness. Bruising is common but only Koduri et al demonstrated a proven haematoma. ${ }^{1}$ Other mechanisms include palsy secondary to local anaesthetic infiltration. Salman et al recommended pre-insertion VC check prior to CVC insertion where possible ${ }^{3}$. As illustrated by Butsch et $\mathrm{al}^{4}$ if hoarseness develops after difficult attempts to catheterise, further attempts should not be made on the contralateral side, unless absolutely necessary.

Literature shows almost all cases resolved with conservative management.

VCP is a rare but increasingly recognised potential complication of CVC. Our case and the previous literature highlight the importance of a developing a clear timeline of symptom history, examination findings and imaging to identify the cause. We recommend observation and supportive therapy in the first instance in such cases.

\section{REFERENCES}

1. Koduri S, Ng AKH, Roy D, Wong ECK. Ipsilateral vocal fold paralysis: an unusual complication of internal jugular tunnelled dialysis catheter insertion. J Vasc Access 2020;21:116-9.

2. Smith RN, Nolan JP. Central venous catheters. BMJ 2013;347:f6570.

3. Salman $M$, Potter $M$, Ethel $M$, Myint $F$. Recurrent aryngeal nerve injury: a complication of central venous catheterization: a case report. Angiology 2004;55: 345-6.

4. Butsch JL, Butsch WL, Da Rosa JF. Bilateral vocal cord paralysis: a complication of percutaneous cannulation of the internal jugular veins. Arch Surg 1976;111:828. 


\section{Facial Nerve Involvement During Temporal Bone Resection: Overall Survival and Locoregional Recurrence Outcomes}

Holly Jones ${ }^{1}$, A Gendre ${ }^{1}$, A McHugh ${ }^{1}$, B O'Sullivan ${ }^{2}$, F Martin², R McConn-Walsh ${ }^{1}$, J P O'Neill ${ }^{1}$, N Shine ${ }^{1}$

\section{Beaumont Hospital \\ Ospidéal Beaumont}

${ }^{1}$ Department of Otolaryngology, Beaumont Hospital, Dublin 9

${ }^{2}$ Department of Plastics and Reconstructive Surgery, Beaumont Hospital, Dublin 9

\section{BACKGROUND}

- Tumours of the lateral temporal bone are rare and account for $0.2 \%$ of Head and Neck cancers

- Facial nerve resection is often required in lateral temporal bone resection for tumours extending to the lateral skull base

- Limited data exists to guide facial nerve reanimation strategies in these patients

\section{Methods}

- We performed a single institution retrospective review of temporal bone malignancies managed surgically between 2000 and 2020

- Patients were divided into two groups: facial nerve preservation or facial nerve resection

\section{RESULTS}

- 39 patients were included with 20 having facial nerve resection at the time of surgery

- Squamous cell carcinoma was the most common pathology

- $48 \%$ of patients died during follow up

- Mean overall survival was 27 months and mean time to locoregional recurrence was 23 months in the facial nerve preservation group

- Mean overall survival was 16 months and mean time to locoregional recurrence was 13 months in the facial nerve resection group

- $75 \%$ of patients in the facial nerve resection group had static facial nerve reanimation using tarsorraphy, goldweight eyelid implant and fascia lata sling

\section{CONCLUSIONS}

- Facial nerve resection during lateral temporal bone surgery is associated with poor overall survival and locoregional control outcomes

- Multidisciplinary surgical management and static facial reanimation should be offered to maintain function and quality of life in this group of patients

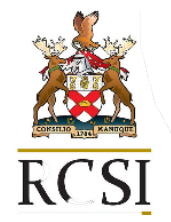

\section{Facial Reanimation Strategies}

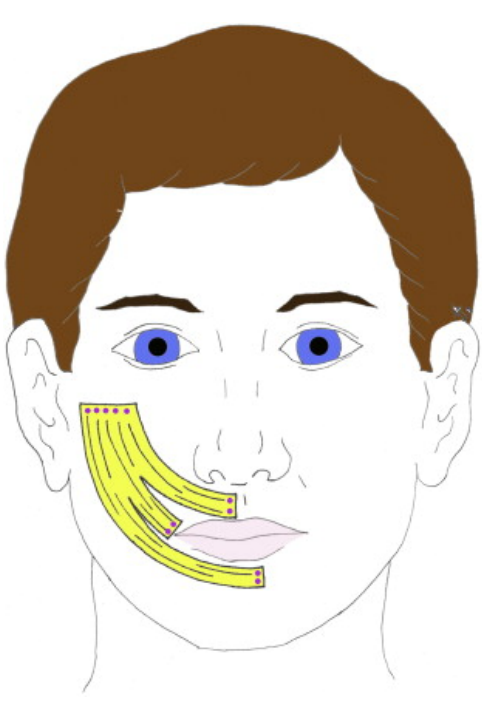

Fascia Lata Sling
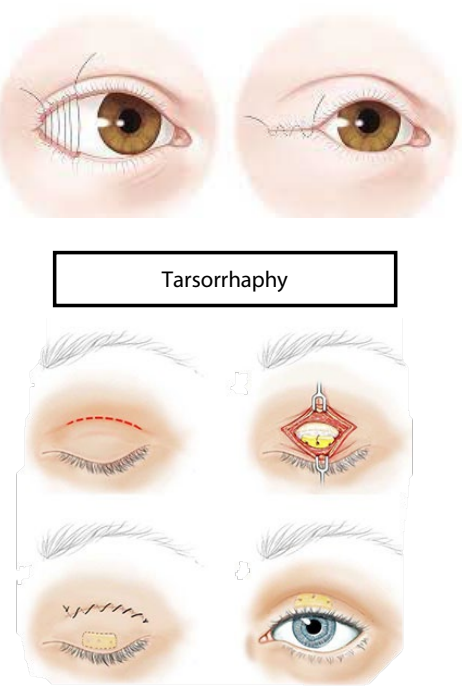

Gold Weight Insertion
Survival Outcomes
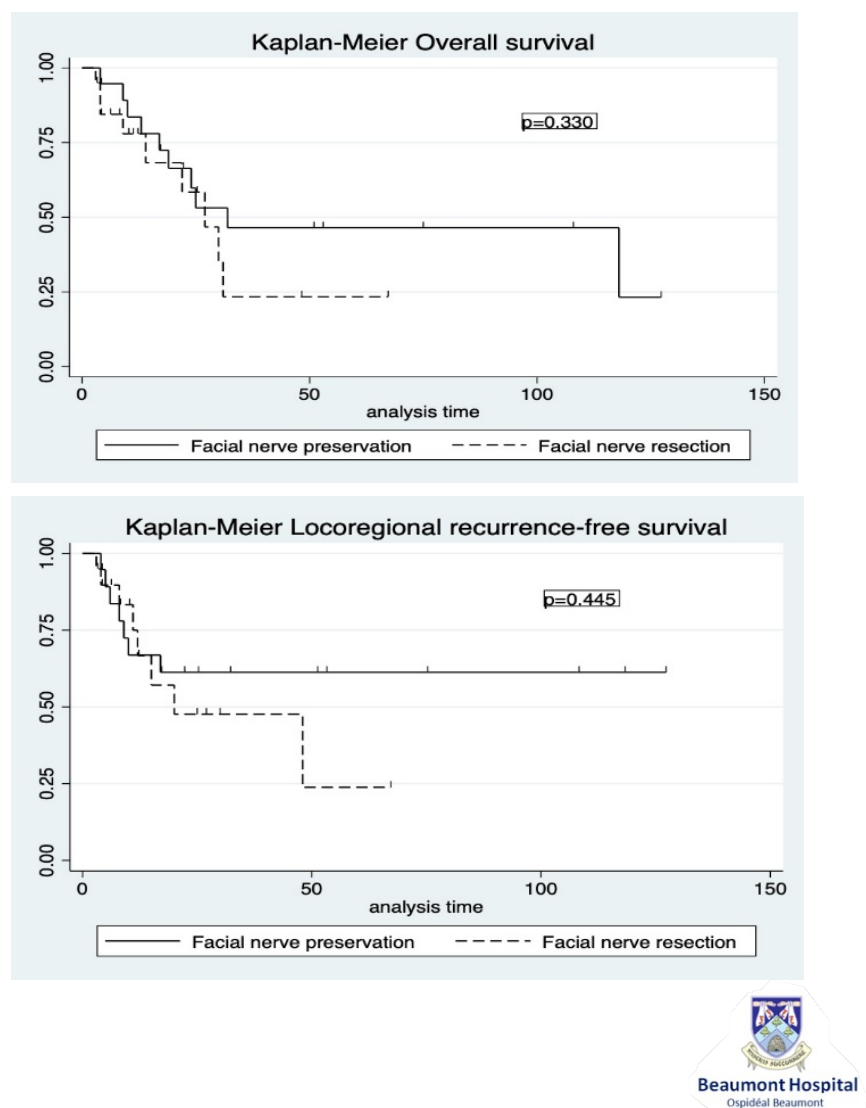


\section{A Complete Loop Audit: How the COVID Pandemic has Changed the Management of Epistaxis for the Good.}

Dr Rachael Collins MBBS BSC (Hons), Ms Sheneen Meghi MBBS MRCS (ENT), Mr Kaso Ari MBBS, Mr John Phillips BSc(Hons) MBBS MRCS (Eng) FRCS (ORL-HNS)

\section{BACKGROUND}

- Epistaxis is a very common ENT emergency ${ }^{1,2}$. Of those admitted to hospital with epistaxis approximately $75 \%$ require nasal packing ${ }^{2}$.

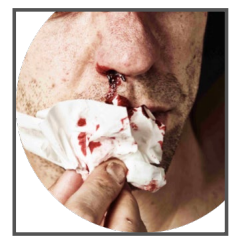

- Prior to COVID patients from Norfolk presenting with epistaxis that required nasal packing were always managed as inpatients.

- To reduce risk of contracting COVID new guidelines were created in March 2020 to enable packed epistaxis patients to be managed as outpatients where possible.

\section{AIM}

- To review how successful new guidelines were and whether they could be maintained safely in the future.

- Loop 1; Determine baseline of inpatient epistaxis management prior to COVID.

- Loop 2: Determine how many inpatient admissions were successfully avoided during COVID.

\section{METHOD}

Two loops; Loop 1: 6 months prior to the new guidelines (sept 19 to March 20) and loop 2: 6 months post the new guidelines (March 20 to Sept 20). The new guidelines were introduced $23^{\text {rd }}$ march 2020.

\section{RESULTS}

Primary Outcomes

\begin{tabular}{|l|l|l|}
\hline Primary Outcomes & Loop 1 & Loop 2 \\
\hline $\begin{array}{l}\text { Number attending } \\
\text { A\&E with Epistaxis }\end{array}$ & 414 & 309 \\
\hline $\begin{array}{l}\text { Number requiring } \\
\text { packing }\end{array}$ & $72(17.39 \%)$ & $59(19.09 \%)$ \\
\hline $\begin{array}{l}\text { Number admitted } \\
\text { with packs } \\
\text { (inpatient care) }\end{array}$ & $\begin{array}{l}72(100 \% \text { of those } \\
\text { packed) }\end{array}$ & $38(64.41 \%)$ \\
\hline $\begin{array}{l}\text { Number } \\
\text { discharged with } \\
\text { packs in situ }\end{array}$ & 0 & $21(35.60 \%)$ \\
\hline
\end{tabular}

\section{Secondary Outcomes}

- From the 21 (35.60\%) presentations managed as outpatients three re-presented;

- One with bleeding (not on correct pathway)

- Two patients (9.5\%);

- one with re-bleeding (PMH of prostate ca)

- one with pain from pack (nil PMH).

- Two re-bleeders were both packed with merocels.

- Outpatient clinics were;

- Following day in clinic $(61.11 \%)$

- Day $2(27.78 \%)$

- Day $3(11.11 \%)$.

- In terms of re-bleeding post pack removal the majority of these patients would not have met the 'pack and home' criteria (across both loops).

\section{CONCLUSION}

- The 'pack and home' criteria successfully identified patients who were suitable for outpatient management.

- The outpatient pathway saves money, reduces inpatient load and is likely to result in improved patient satisfaction.

\section{REFERENCES}

1. Pope L, Hobbs C. Epistaxis: an update on current management. Postgrad Med 2005; 81:309-314.

2. Kotecha B, Fowler S, Harkness P, Walmsley J, Brown P, Topham J. Management of epistaxis: a national survey. Annals of the Royal College of Surgeons of England 1996; 78:444-446.

3. Iqbal I, Jones G, Dawe N, Mamais C, Smith M, Williams R, Kuhn I, Carrie S. Intranasal packs and haemostatic agents for the management of adult epistaxis: systematic review. The Journal of Laryngology and Otology 2017; 131: 1065-1092.

4. NICE guidelines. Acute Epistaxis 2015 [Internet], London. Available at: https://cks.nice.org.uk/epistaxisnosebleeds\#!scenarioClarification:

5. Hajiioannou J, Bizaki A, Fragiadakis G, Bourolias C, Spanakis I, Chlouverakis G, Bizakis J. Optimal time for nasal packing removal after septoplasty. A comparative study. Rhinology 2007; 45:68-71.

6. Lubianca-Neto J, Sant'anna G, Mauri M, Arrarte J,

Norfolk and Norwich University Hospitals WHS 


\section{Paralysis from an Ear Infection: A Severe Case of Otitis External Leading to Acute Complete Cervical Cord Syndrome}

Dr Rachael Collins MBBS BSC (Hons) and Mr George Lafford MBBS

\section{BACKGROUND}

Necrotizing otitis externa (NOE) is a rare and potentially lethal progression of OE involving the temporal and adjacent bones ${ }^{1}$ and is predominately seen in elderly, diabetic or immunocompromised patients $\mathrm{s}^{2-4}$. There are numerous case reports where NOE has developed beyond osteomyelitis but these are almost always in diabetic or immunocompromised patients and without the neurological sequelae presented here.

\section{CASE Report}

- A generally fit 54-year-old gentleman presented with a 2-day history of worsening left sided ottorhea, headache, neck stiffness, vomiting and pyrexia on the background of a 7-week history of OE.

- Over the course of 48 hours his condition deteriorated dramatically as he developed confusion, imbalance and severe weakness in both his upper and lower limbs.

- He continued to deteriorate over the following week with new symptoms of dysarthria, dysphagia, weakness of voice and poor cough.

- A MDT approach involved ENT surgeons, neurologists, spinal surgeons, neurosurgeons, speech and language and physiotherapists.

\section{INVESTIGATIONS}

- Imaging revealed skull base osteomyelitis, parapharyngeal, retropharyngeal and paravertebral abscesses and sigmoid sinus thrombus (figures 1-3).

- Ear swab grew Streptococcus milleri.

- Flexible nasendoscopy was normal other than a nasal polyp extending from the left middle meatus.

\section{MANAGEMENT}

- He was treated with IV antibiotics (initially ceftriaxone, then piperacillin/Tazobactam), IV dexamethasone and treatment dose low molecular weight heparin.

- Operative intervention involved exploration of the prevertebral space, drainage of abscess and tracheostomy.

\section{OUTCOME}

A year on the patient has made a significant, although not complete, recovery. He is left with oesophageal dysmotility, hoarseness and continues to require the RIG tube for feeding. He lives independently and has regained full power in his limbs.

\section{SUMMARY}

This case is unique in demonstrating how OE can develop into a potentially life threatening condition. It emphasises the importance of early diagnosis and treatment of $\mathrm{OE}$, the recognition of 'red flag' symptoms and highlights the importance of a multi-disciplinary team (MDT) approach when managing complex complications.

\section{REFERENCES}

1. Hariga, l., et al., Necrotizing otitis externa: 19 cases' report. European Archives of Oto-

2. Rhino-Laryngology, 2010. 267(8): p. 1193-1198.

3. Hollis, S. and K. Evans, Management of malignant (necrotising) otitis externa. The Journal of Laryngology \& Otology, 2011. 125(12): p. 1212-1217.

Kamalden, T.M.I.T. and K. Misron, A 10-year review of malignant otitis externa: a new insight. European Archives of Kamalden, T.M.I.T. and K. Misron, A
Oto-Rhino-Laryngology, 2021.

5. Marina, S., et al., A retrospective review of 14 cases of malignant otitis externa. Journal of Otology, 2019. 14(2): p. 63Marina, S., et al., A retrospective review of 14 cases of malignant otitis externa. Journal of Otology, 2019. 14(2): p. 6366.

Carfrae, M.J. and B.W. Kesser, Malignant Otitis Externa. Otolaryngologic Clinics of North America, 2008. 41(3): p. 537

Alva, B., et al., Temporal bone osteomyelitis and temporoparietal abscess secondary to malignant otitis externa. The Journal of Laryngology \& Otology, 2009. 123(11): p. 1288-1291.

8. Charlton, A., N. Janjua, and D. Rejali, Cotton bud in external ear canal causing necrotising otitis externa and subdural abscess. BMJ Case Reports, 2019. 12(3): p.e227971.

9. Nawas, M.T., et al., Complicated necrotizing otitis externa. American Journal of Otolaryngology, 2013. 34(6): p. 706709.

10. Liu, X.-I., et al., Malignant otitis externa in a healthy non-diabetic patient. European Archives of Oto-RhinoLaryngology, 2016. 273(8): p. 2261-2265.

11. Chefi, M.A., et al., Osteomyelitis of the skull base and the cervical vertebrae. A case report and literature review. Otolaryngology Case Reports, 2020. 14: p. 100149.

12. Low, G., et al., C1/C2 osteomyelitis secondary to malignant otitis externa complicated by atlantoaxial subluxation-a case report and review of the literature. AME case reports, 2020. 4: p. 19-19.

13. Han, J.K. and J.E. Kerschner, Streptococcus milleri: An Organism for Head and Neck Infections and Abscess. Archives

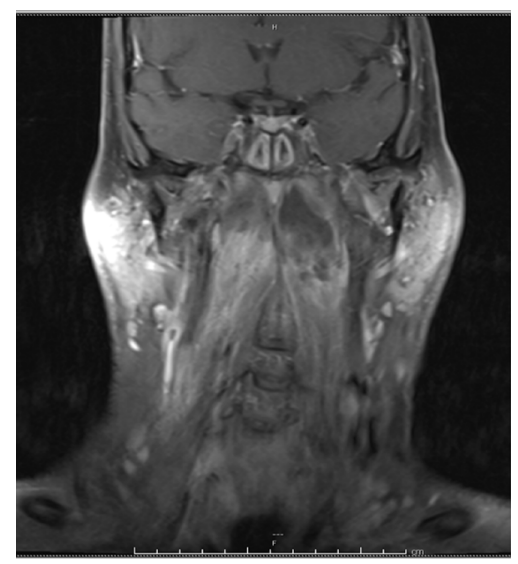

Fig. 1: coronal MRI demonstrating parapharyngeal abscess.

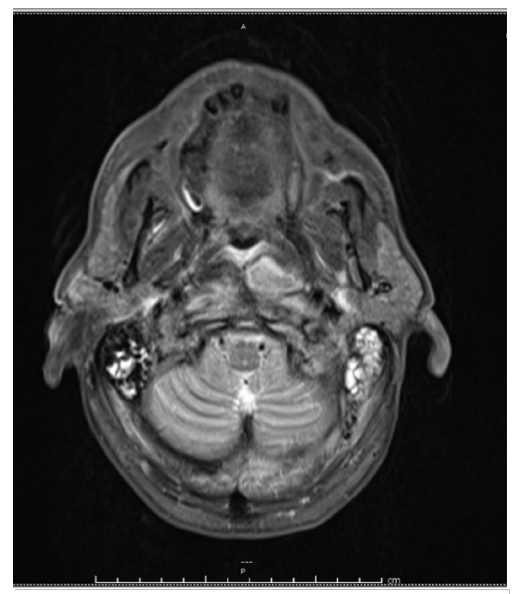

Fig. 2: axial MRI demonstrating retropharyngeal abscess.

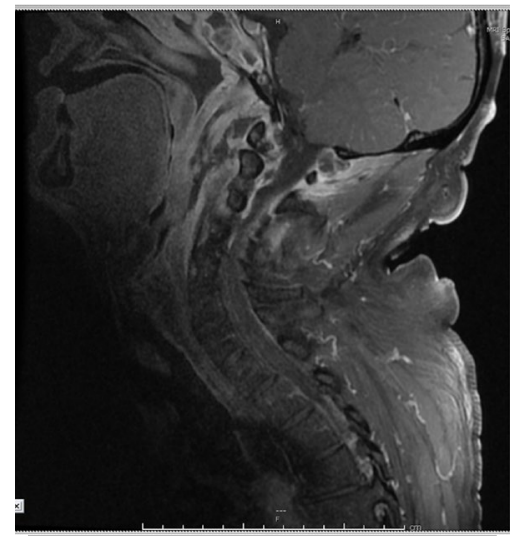

Fig. 3: Saggital MRI demonstrating inflammatory changes in cranial and C1/2 articulation, retropharyngeal abscess and para vertebral abscess.

Norfolk and Norwich University Hospitals W/HS 


\section{YIOS \\ Irish Otorhinolaryngology / Head \& Neck Surgery Society

Use of Tobramycin Impregnated Antibiotic Beads in Frontal Sinus Osteomyelitis

Emma Richards, Nighat Qamar, Paresh Pramod Naik and Shahzada Ahmed

\section{BACKGROUND}

Frontal bone osteomyelitis is a rare but devastating complication of frontal sinusitis. Treatment involves aggressive surgery and long-term antibiotic therapy. However, systemic antibiotics may struggle to penetrate any remaining infection in devascularised tissues. Locally implanted antibiotics, in contrast, provide a reliable, high concentration of therapy whilst minimising systemic side-effects. To date, tobramycin beads have largely been used in orthopaedics as an adjunct in the treatment of tibial osteomyelitis or prosthetic joint infection. To the best of our knowledge, we present the first report of tobramycin antibiotic bead use in frontal sinus osteomyelitis.

\section{Case Series}

A 59-year-old gentleman presented with a discharging left supraorbital fistula on a background of chronic frontal sinusitis. Computed tomography (CT) showed chronic frontal sinusitis with a markedly sclerotic margin and focal defect in the anterior orbital roof (figure 1). He underwent combined Draf III endonasal surgery with osteoplastic flap. Two weeks later he represented with necrotic skin and pus (figure 2). Further surgery via a bicoronal approach with excision of necrosed skin and sinus obliteration with pedicled pericranial tissue and tobramycin beads was performed. He was discharged with 6 weeks of antibiotics and successful management of the osteomyelitis was achieved.
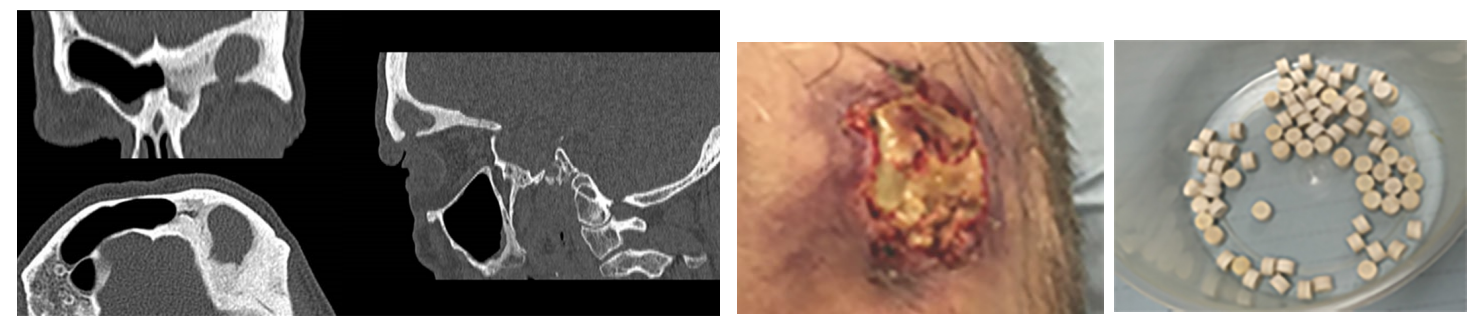

Our second case involved an immunosuppressed 58-year-old with sinocutaneous fistulae and erosive pansinusitis. At his local hospital he had been treated for invasive aspergillosis. Repeat CT showed multiple bony erosions especially involving the orbital floor. Further surgery revealed extensive crusting and a cerebrospinal fluid (CSF) leak through a pre-existing skullbase dehiscence. Following this surgery his symptoms improved and his sinocutaenous fistulas healed. Unfortunately, they both reopened a few months later at which point he was referred to our regional skull base department and underwent radical frontosphenoethmoidectomy and debridement of necrotic tissue. Following a number of septic episodes, he had revision surgery, which included closure of sinucutaneous fistulae at the medial canthus bilaterally and placement of tobramycin impregnated beads (figure 3) into the frontal cavity. Tissue samples grew S. aureus, pseudomonas, candida and vancomycin resistant enterococcus. His osteomyelitis improved following this intervention and he was transferred back to his local hospital. Unfortunately, he developed a separate underlying disease process and died four months later. His sinocutaneous fistulae at his medial canthus remained healed.

\section{Discussion}

The frontal bone is the second most common site of head and neck osteomyelitis. ${ }^{1}$ Due to the complex craniofacial skeleton and critical neural structures that cannot be easily debrided, osteomyelitis of the frontoethmoid region presents a particular management challenge ${ }^{2}$ and recurrence rates remain high. Complications include meningitis, brain abscess and cavernous sinus thrombosis. ${ }^{1}$ The local delivery of antibiotics in the treatment of osteomyelitis has been used safely and effectively by orthopaedic surgeons for decades. Given the already existing space within the frontal sinus which is then enlarged following surgical debridement, there is excellent cavity here for the placement of the impregnated beads to facilitate local delivery of antibiotics. Our cases show promising use of tobramycin beads in recalcitrant frontal osteomyelitis.

\section{REFERENCES}

1. Prasad KC, Prasad SC, Mouli N, Agarwal S. Osteomyelitis in the head and neck. Acta Otolaryngol 2007;127:194-205

2. Pincus D, Armstrong M, Thaller S. Osteomyelitis of the Craniofacial Skeleton. Semin Plast Surg 2009;23:073-9

3. Ostermann PAW, Seligson D, Henry SL. Local antibiotic therapy for severe open fractures. A review of 1085 consecutive cases. The Journal of Bone and Joint surgery 1995;77:93-97 
${ }^{2}$ Hematology department of Centro Hospitalar Universitário do Porto

\section{OBJectives}

To describe the importance of nasopharyngeal lymphomas as a differential diagnosis of nasopharyngeal tumors.

\section{Matherials AND Methods}

Clinical case report and literature review of nasopharyngeal lymphomas and pre-biopsy corticosteroids therapy.

\section{Clinical Case}

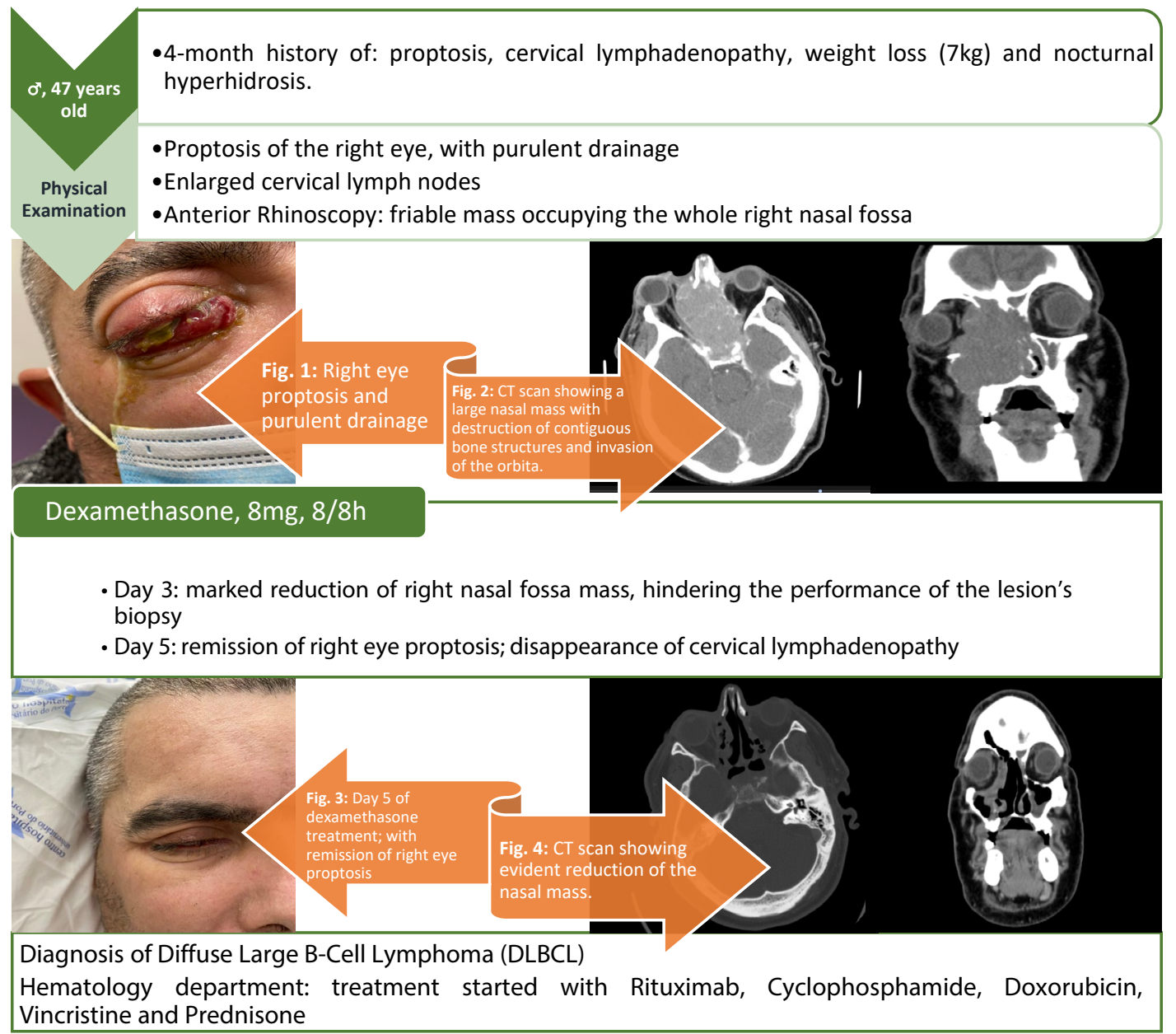

\section{DisCusSiON}

Lymphomas are the most common non-epithelial malignancy of the head and neck region, with the Waldeyer ring as the most common extranodal site of involvement. However, primary nasopharyngeal lymphomas remain a very rare tumor, with DLBCL as the most frequent pathologic diagnosis 1,2 . Corticosteroids are known to promote cytolysis of lymphoma cells, promoting cell destruction and sometimes clinical and radiological regression ${ }^{3}$. In spite of being associated with a delayed diagnosis in only a minority of patients ${ }^{3,4}$, this effect can hinder the performance of biopsies and alter histological findings. It is therefore important that clinicians consider this differential diagnosis when managing nasopharyngeal tumors, diminishing potentially adverse effects of pre-biopsy management and promoting a timely management of this tumors

\section{CONCLUSION}

Although rare, nasopharyngeal lymphomas should remain as a differential diagnosis for nasopharyngeal tumors, as prebiopsy management may negatively impact the performance of biopsies and their diagnostic accuracy.

\section{REFERENCES}

1. Hsueh CY, Yang CF, Gau JP, et al. Nasopharyngeal Lymphoma: A 22-Year Review of 35 Cases. J Clin Med. 2019;8(10):1604. Published 2019 Oct 3. doi:10.3390/jcm8101604

2. Weber AL, Rahemtullah A, Ferry JA. Hodgkin and non-Hodgkin lymphoma of the head and neck: clinical, pathologic, and imaging evaluation. Neuroimaging Clin N Am. 2003;13(3):371-392. doi:10.1016/s1052-5149(03)00039-x

3. Binnahil M, Au K, Lu JQ, Wheatley BM, Sankar T. The Influence of Corticosteroids on Diagnostic Accuracy of Biopsy for Primary Central Nervous System Lymphoma. Can J Neurol Sci. 2016;43(5):721-725. doi:10.1017/cjn.2016.255

4. Borenstein SH, Gerstle T, Malkin D, Thorner P, Filler RM. The effects of prebiopsy corticosteroid treatment on the diagnosis of mediastinal lymphoma. J Pediatr Surg. 2000;35(6):973-976. doi:10.1053/jpsu.2000.6945 
NA O'Keeffe, S Downes, SG Khoo

Department of Otolaryngology Head \& Neck Surgery

St. Vincent's University Hospital

\section{AIM}

To highlight the diverse multi-disciplinary input following major neck trauma in a Dublin trauma unit

\section{BACKGROUND}

We showcase the major trauma pathway in a designated Greater Dublin Region Trauma Unit pertaining to a case series of major neck injuries, involving a myriad of surgical specialties and ancillary health support staff, resulting in good outcomes for the patients involved. We chart the patients' progress from arrival at ED to final discharge home and detail extensive rehabilitative processes for good functional outcomes.

\section{CASE 1}

39-year-old male, self inflicted deep laceration to his neck and amputation of his penis with scrotal de-gloving during momentary psychosis following illicit drug use during covid pandemic at height of covid lockdown. His laryngeal injury was reconstructed followed by the first penile reimplantation in Ireland. His care involved ED, ENT, Vascular, Urology, Plastics, Psychiatry, ICU and extensive SLT rehabilitation.

\section{CASe 1}

25-year-old lady brought in by ambulance sustained a deep neck laceration resulting in contralateral vestibular artery and brachial plexus injuries following an attack with a glass shard by her partner. Her care involved the paramedics, ED, ENT, Vascular, plastics, ICU, physiotherapy and occupational therapy rehabilitation.

\section{MULTIDISCIPLINARY TEAM APPROACH}

Concise multidisciplinary surgical, medical and allied health care interactions are key to good functional outcomes. Our case series highlights the pivotal role played by ancillary health care staff including speech and language, physio, occupational health and dietitians

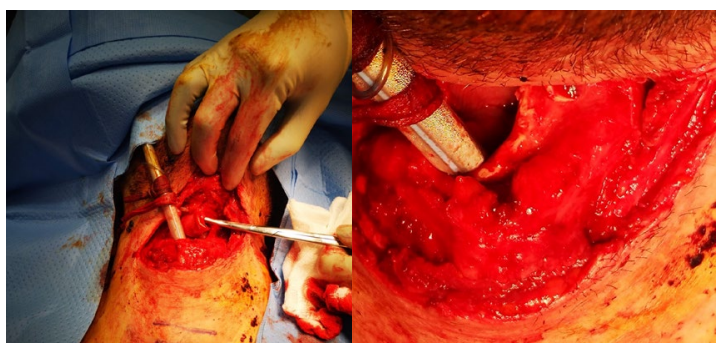

Fig. 1: Neck exploration with repair of transected epiglottis. Query damage to internal branch of superior laryngeal nerve

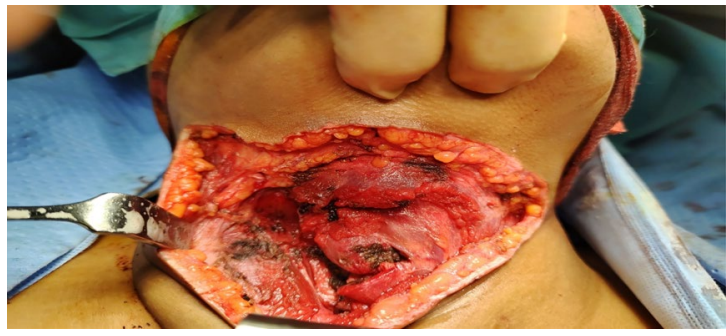

Fig. 2: $7 \mathrm{~cm}$ Left zone 2 injury - left neck penetrating across midline toward right common carotid artery

\section{DISCUSSION}

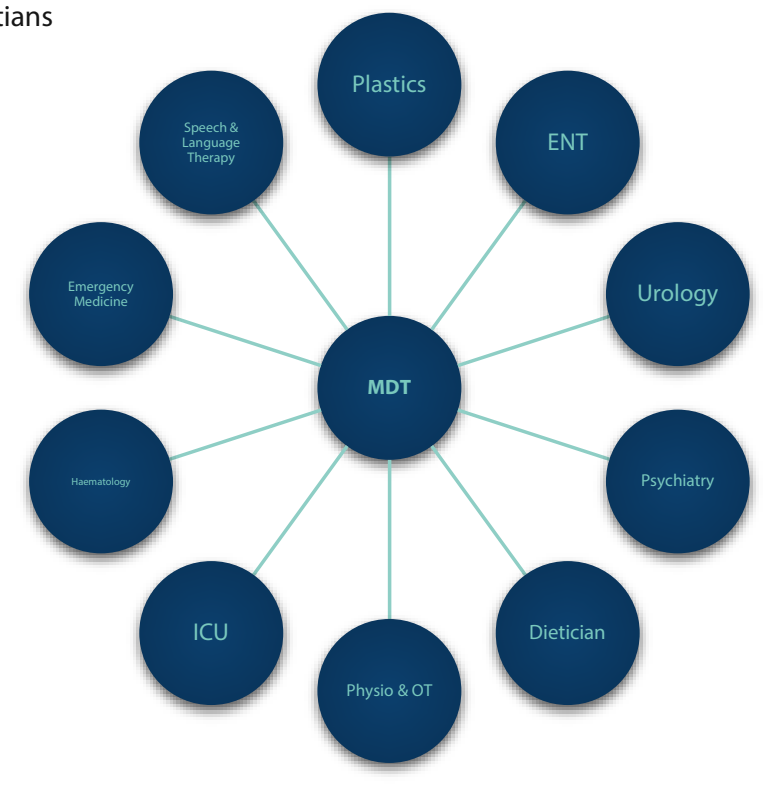

The case series above establishes a clear Emergency pathway for the management of multi-trauma patients involving the ENT team with airway management being the priority. All other involved surgical specialties were mobilized in advance of patient arrivals. Concise multi-disciplinary surgical and medical interaction is key to good patient outcomes. Rehabilitation ensures appropriate functional results. 


\section{BACKGROUND}

- Persistent cervical lymphadenopathy is one of the commonest referrals to ENT specialists

- While fine needle aspiration (FNA) is an reliable method of establishing a preliminary diagnosis, open surgical excision of lymph nodes may be needed in certain cases.

- Considering the vast majority of open surgical excisions are performed in cases suspicious for malignancy, time is a critical factor.

- Establishing a concise, expedited pathway from primary care referral to ENT clinic, and subsequent transfer to theatre is vital to providing a high standard of patient care.

- As highlighted in the Model of Care for Otolaryngology/ Head and Neck Surgery document, internationally recognised key performance indicators (KPI) exist for one-stop neck lump service pathways. ${ }^{1}$

- However, evidence-based guidance defining the optimal pathway for open lymph node biopsies is scarce.

\section{AIms}

- We present our experience of performing open lymph node biopsies over an 18-month period

\section{METHODS}

- We performed a single-centre retrospective review of all patients who underwent open lymph node biopsy between the $31^{\text {st }}$ March 2019 - 31st August 2021 in our institution.

- An electronic chart review was conducted. We collected sociodemographic, clinical and histopathological data.

- Data pertaining to the date of referral, clinic appointment and surgical excision of lymph nodes was retrieved from online tracking system and theatre logbooks.

Table 1 \& 2.

\begin{tabular}{|c|c|}
\hline Timeframe & 31st Mar'19-31st Aug '21 \\
\hline $\mathrm{N}$ & 38 \\
\hline Data Collection & $\begin{array}{ll}\text { - } & \text { Electronic Charts } \\
\text { - } & \text { Inpatient Management System } \\
\text { - } & \text { Theatre Logbook }\end{array}$ \\
\hline Patient Variables & $\begin{array}{l}\text { - } \text { Age \& Gender } \\
\text { - Lymph Node Location } \\
\text { - } \text { Date \& Source of Referral } \\
\text { - Preoperative Imaging } \\
\text { - Diagnosis } \\
\text { - Time to Theatre }\end{array}$ \\
\hline
\end{tabular}

\begin{tabular}{|l|l|}
\hline Diagnosis & Patients [n (\%)] \\
\hline Lymphoma & $25(65 \%)$ \\
\hline Reactive LAD & $3(8 \%)$ \\
\hline Squamous Cell Carcinoma & $3(8 \%)$ \\
\hline Atypical Mycobacterium & $3(8 \%)$ \\
\hline Tuberculosis & $1(3 \%$ \\
\hline Sarcoma & $2(5 \%)$ \\
\hline Necrotizing Lymphadenitis & $1(3 \%)$ \\
\hline
\end{tabular}

\section{RESULTS}

Table 3.

\begin{tabular}{|l|l|}
\hline Patient Characteristics & \\
\hline Age & 43.9yr (range, 2-89yr) \\
\hline Sex (M/F) & $21 / 17$ \\
\hline \multicolumn{2}{|r}{$\quad$ (Contd...) }
\end{tabular}

(Contd...)

\begin{tabular}{|l|l|}
\hline Lymph Node Location & \\
\hline Supraclavicular & $47 \%$ \\
\hline Posterior Triangle & $32 \%$ \\
\hline Other & $21 \%$ \\
\hline Preoperative Imaging & \\
\hline CT-Neck & $76 \%$ \\
\hline US & $5 \%$ \\
\hline PET-CT & $8 \%$ \\
\hline Nil & $11 \%$ \\
\hline Surgical Technique & \\
\hline Excisional & $84 \%$ \\
\hline Incisional & $16 \%$ \\
\hline Complication Rate & $0 \%$ \\
\hline Source of Referral & \\
\hline Hematology \& Oncology & $39 \%$ \\
\hline Primary Care & $26 \%$ \\
\hline Other & $35 \%$ \\
\hline Time from Clinic to Theatre & 6.5 days (range, 2-14 days) \\
\hline
\end{tabular}




\section{Discussion}

- Over an 18-month time period, 38 open lymph node biopsies were performed to diagnose a range of inflammatory, infectious and malignant pathologies in our institution.

- The high proportion of patients (78\%) diagnosed with malignant disease following biopsy highlights the importance in ensuring a rapid, and reliable pathway exists for this cohort of patients.

- The mean time from a patient's first presentation at ENT clinic to operating theatre for diagnostic biopsy was 6.5 days.

- Although $26 \%$ of referrals came directly from primary care, nearly three-quarters of patients were referred from other hospital specialties.

- This may suggest that delays in diagnosing patients may be caused by initial referral from primary care to other teams, such as haematology or oncology

- In Ireland, a great effort has been made via the development of GP education programs, rapid access neck lump clinics and direct referral proformas to reduce waiting times for patients with suspicious cervical lymphadenopathy.

\section{CONCLUSION}

- Maintaining a rapid, and reliable pathway for open lymph node biopsy is vital to providing high-quality cancer care.

- The results from this review demonstrate an efficient transfer time from first presentation to ENT clinic to operating theatre.

- Further research is needed to determine whether delays in obtaining cervical lymph node biopsy is occurring due to initial referral to other hospital specialties from primary care

\section{REFERENCES}

1. A Model of Care for Ireland - Otolaryngology/ Head and Neck Surgery. Royal College of Surgeons Ireland. 2018. 
Audit of Tonsillectomy Day Case and Readmission Rates in a Single Centre

L. Bateman CT2, O. Wakelam ST5, R. Duraipandi JCF, G. Mochloulis ENT Consultant Lister Hospital, Stevenage, UK
WHS

East and North Hertfordshire

NHS Trust

\section{ObJectives}

Getting It Right First Time (GIRFT) $2019^{1}$ set out targets for tonsil surgery day case rates and outlined HES statistics for readmission. This audit aims to ensure the elective tonsillectomy day case rates at this centre are in line with national standards; $70 \%$ and $80 \%$ for paediatric and adult elective tonsillectomy respectively (British Association Day Surgery).

\section{RESULTS}

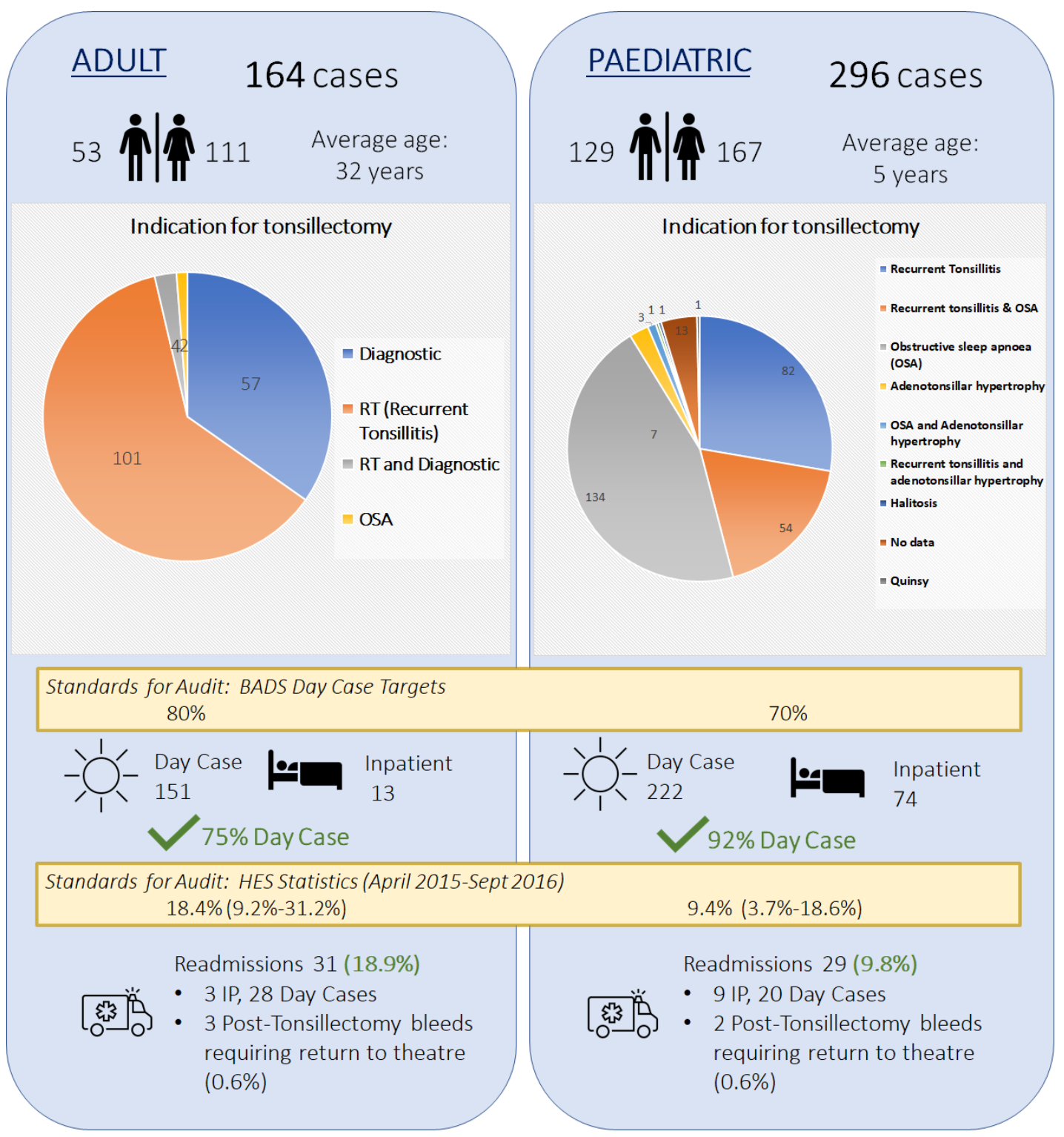

\section{CONCLUSION}

The day case rates for both paediatric and adult elective tonsillectomies have exceeded the BADS standards. Readmission rates for both paediatric and adult tonsillectomies are within the acceptable range, and so performing a large proportion of procedures as Day Case does not seem to aversely affect outcomes.

\section{REFERENCE}

1. Andrew Marshall, by, \& Marshall, A. (2019). Ear, Nose and Throat Surgery GIRFT Programme National Specialty Report

\section{METHODS}

Retrospective review of theatre records for all procedures including tonsil surgery in period 1-Mar-19 to 29-Feb-20. Tonsillectomies for recurrent tonsillitis, OSA and diagnostic procedures were included. Excluded were tonsillectomies done as part of emergency cases, biopsies and remnant or revision tonsillectomies. Online databases used to look at patient demographics, indication for surgery, whether performed as a day case or inpatient. Readmission rates and return to theatre were also recorded. 
Impact of the COVID-19 Pandemic on Thyroid Cancer Surgery in a Single Centre

L. Bateman $\mathrm{CT}^{1}{ }^{1}$, R. Bance Head and Neck Fellow ${ }^{2}$, G. Mochloulis ENT Consultant ${ }^{1}$

${ }^{1}$ Lister Hospital, Stevenage, ${ }^{2}$ University College Hospital, London

\section{OBJectives}

Differentiated thyroid cancer is recognised as a cancer with excellent outcomes once treated. Thyroid cancers in the UK are managed according to the BAETS 1 and $\mathrm{BAHNO}^{2}$ guidelines. Studies have indicated there is no increased oncological risk if thyroid cancer treatment is delayed between 4 and 12 weeks ${ }^{3}$. The COVID19 pandemic has impacted planned surgery, as operating theatres and staff were redeployed to help with managing the influx of patients at the height of the pandemic, and in order to minimise risk of contracting COVID19 in patients undergoing planned surgery ${ }^{4}$. Data from NHS England in November 2020 showed 2.3 million patients were awaiting surgical care, including cancer patients ${ }^{5}$. This preliminary evaluation aimed to identify any delay in thyroid surgery in our centre, and any impact on outcomes.

\section{METHOD}

A retrospective review of cases in two periods was completed: pre-pandemic (Feb 19 to Nov 19), and during the first wave of the pandemic (Feb 20 to Nov 20), to allow for comparison. Cases were identified from Head and Neck MDT lists. Referrals that resulted in Thy3a or Thy3f, and U3 or U4 grading on investigation were included. The numbers listed for surgery, the average time to surgery, and outcomes were recorded.

\section{RESULTS}

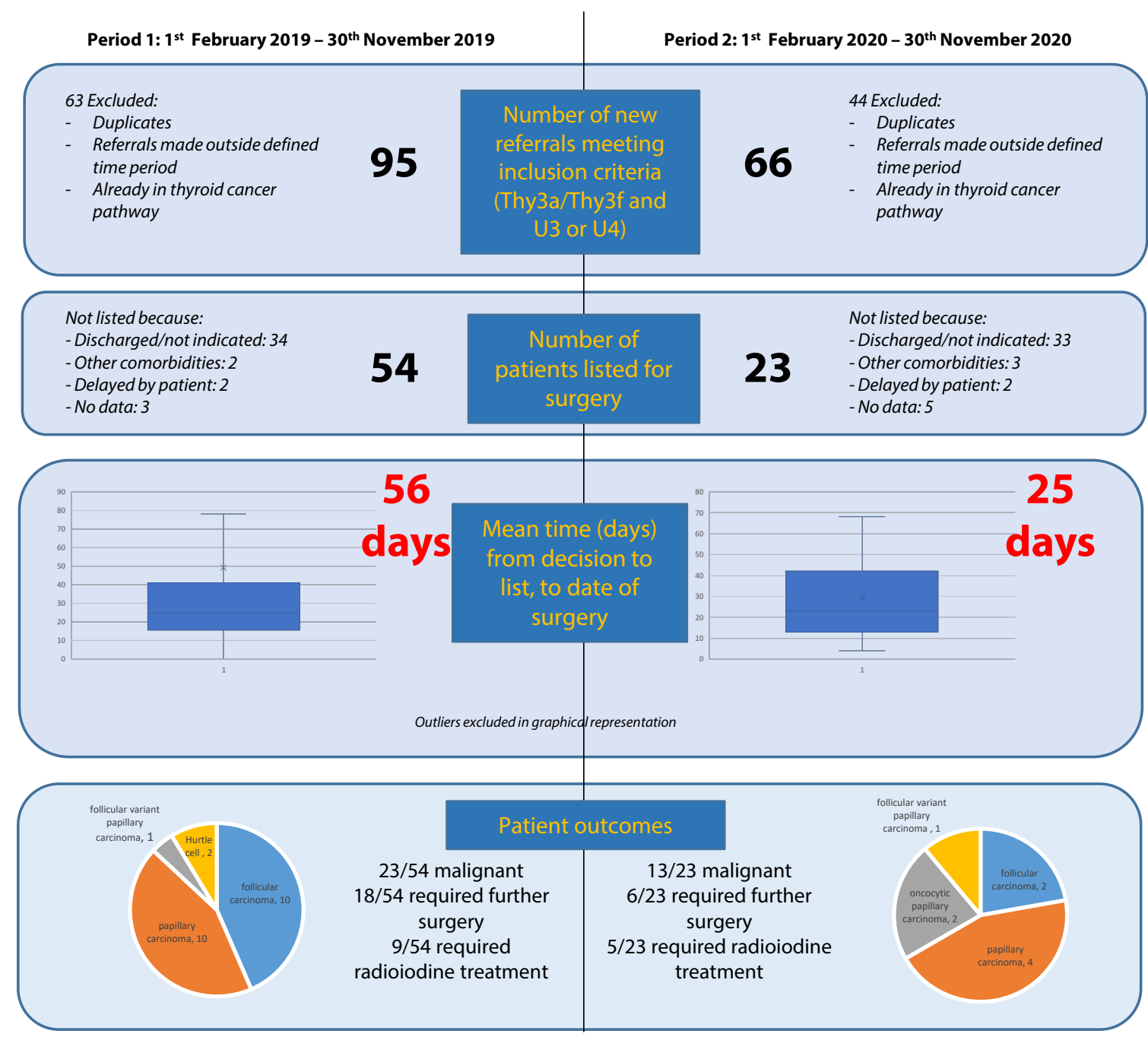

\section{CONCLUSIONS}

Interestingly, the time to surgical treatment of suspected thyroid cancers shortened in period 2, contrary to the reported delaying effect of the pandemic on elective surgery. Possible reasons for this include the cancellation of all non-cancer elective work, which although reduces overall available theatre time, may actually increase the accessible theatre time for cancer related procedures. Urgent elective cancer cases at this centre were moved to private sector hospitals during the pandemic, allowing for creation of non-COVID 'green' pathways for urgent patients. This preliminary work allows further assessment of the impact of the pandemic on treatment. In this case, changes in healthcare utilisation and delivery due to COVID have caused an inadvertent positive effect on treatment pathways and theatre access ${ }^{6}$. Future plans include analysis of the corresponding period in the second wave (February 2021 until November 2021), and an assessment of the patient experience of undergoing cancer treatment during the pandemic. 


\section{REFERENCES}

1. Perros, P. et al. Guidelines for the management of thyroid cancer. Clinical Endocrinology 81, 1-122 (2014).

2. Mitchell, A. L., Gandhi, A., Scott-Coombes, D. \& Perros, P. Management of thyroid cancer: United Kingdom National Multidisciplinary Guidelines. The Journal of laryngology and otology 130, S150-S160 (2016).

3. Shin, D. W. et al. Delay to curative surgery greater than 12 weeks is associated with increased mortality in patients with colorectal and breast cancer but not lung or thyroid cancer. Annals of Surgical Oncology 20, 2468-2476 (2013).

4. Carr, A., Smith, J. A., Camaradou, J. \& Prieto-Alhambra, D. Growing backlog of planned surgery due to covid-19. BMJ 372, n339 (2021).

5. Statistics » Cancer Waiting Times. https://www.england.nhs.uk/statistics/statistical-work-areas/cancer-waiting-times/.

6. Medical Association, A. Delays to Low-risk Thyroid Cancer Treatment During COVID-19-Refocusing From What Has Been Lost to What May Be Learned and Gained. (2020) doi:10.1001/jamaoto.2020.3878. 


\section{INTRODUCTION}

Covid-19 has caused major disruptions to the delivery of healthcare, and thus had a knock-on negative impact on training. This seemed particularly evident for ENT trainees, with some departments running at less than $10 \%$ capacity for operating when numbers of Covid cases peak.

There have also been longer-term concerns with regards to surgical training and the impact that increasing NHS pressures are having.

\section{OBJeCtive}

To assess and quantify the impact that Covid has had on the operative experience for ENT trainees in Northern Ireland. Given some concerns over surgical training pre-Covid, we also wanted to see how the operative experience of current trainees compared to that of consultants when they were in training.

\section{METHOD}

The 10 ENT trainees in Northern Ireland were asked for eLogbook consolidation reports for 3 separate 8-week periods to look at operative numbers pre-, during, and post-lockdown. These were compared to quantify how Covid has affected operative numbers.

Data was also collected from 7 consultants from their eLogbook, or data from their CCT numbers. The procedures were then categorised by the surgeons' involvement i.e. assisted, supervised (trainer scrubbed/unscrubbed), and performed. Observed procedures were discounted. The specific types of procedures were also looked at.

\section{RESULTS}

The average number of cases in each 8 -week period can be seen in fig 1 . This shows a marked reduction in operative numbers during lockdown (6 from 64).

Fig 2 shows the downward trend in the level of involvement from the consultants' time in training to the current trainees post-lockdown (93\% down to $75 \%$ of reported cases performed).

The total number of procedures performed by consultants at CCT has also changed. 2 consultants, who are $>5$ years post-CCT have $\sim 2600-2900$ cases. 5 consultants, $<5$ years post-CCT have $\sim 2300$ cases. Current senior registrars are estimated to attain similar or lower numbers.

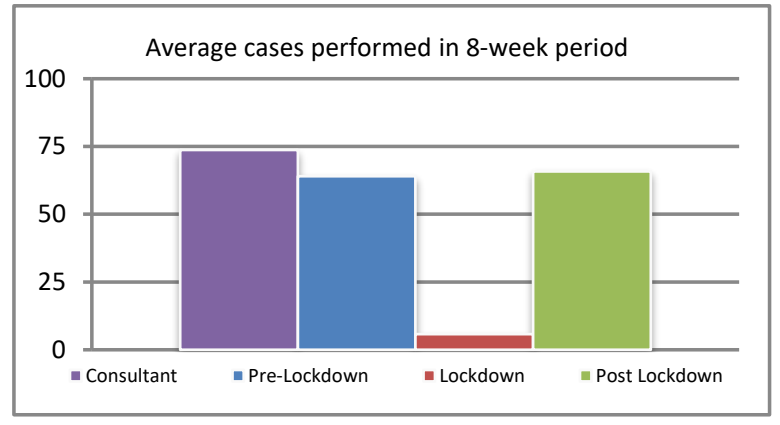

Fig. 1: Bar chart showing the average number of cases that consultants and trainees were involved in in an 8-week period

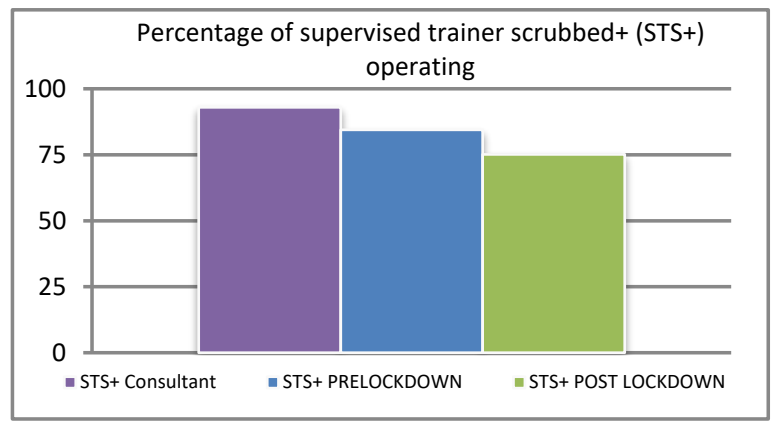

Fig. 2: Bar chart showing the percentage of procedures which the trainee performed (at least supervised)

\section{Discussion}

We have demonstrated how Covid-19 has had a huge impact on the operative experience of ENT trainees. Interestingly when looking at the specific operations being performed, trainees are getting much less experience in "routine" operations such as septorhinoplasty (SRP) and pinnaplasty over the last number of years. Our data showed that recent registrars are performing 9 septoplasties and 3 SRP in 18 months equivalent training time compared to 29 septoplasties and 18 SRP in 12 months a few years ago. This may be used as an indicator of the downward trend in routine ENT work, likely due to increasing pressures on the NHS.

\section{CONCLUSION}

Covid-19 lockdown negatively affected ENT trainee operative experience hugely, however factors such as reduced routine elective operating, and increased urgent and red flag work has led to a diluted training experience in certain procedures when compared to previous trainees.

'ENT department, Royal Victoria Hospital, Belfast Health and Social Care Trust, Northern Ireland 
Sudden Deterioration of Receptive Language - when Hearing doesn't Mean Listening!

Costa $\mathrm{S}^{1}$, Serdoura Alves $\mathrm{C}^{1}$, Feliciano $\mathrm{T}^{1}$, Coutinho $\mathrm{M}^{1}$, Almeida e Sousa $\mathrm{C}^{1}$

${ }^{1}$ Serviço de Otorrinolaringologia e Cirurgia da Cabeça e Pescoço, CHUP, Portugal

\section{INTRODUCTION}

Landau-Kleffner syndrome (LKS) is an age-related epileptic encephalopathy characterized by acquired aphasia and paroxysmal, sleep-activated EEG activity ${ }^{1-3}$.

\section{Objective}

To describe the clinical presentation and management of a child diagnosed with LKS.

\section{CASE Report}

Female, 5 years old, with a history of sporadic partial motor and generalized seizures. Presents with sudden verbal auditory agnosia followed by significant speech regression (Fig. 1).

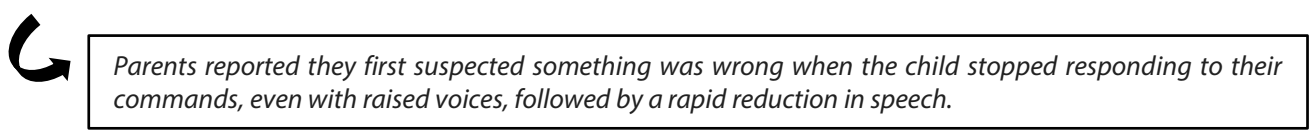

- Formal auditory tests and magnetic resonance imaging of the brain were normal.

- Electroencephalograph (EEG) showed bilateral centro-parietotemporal spikes during wakefulness and generalized, continuous spikes and waves during sleep (Fig. 2).
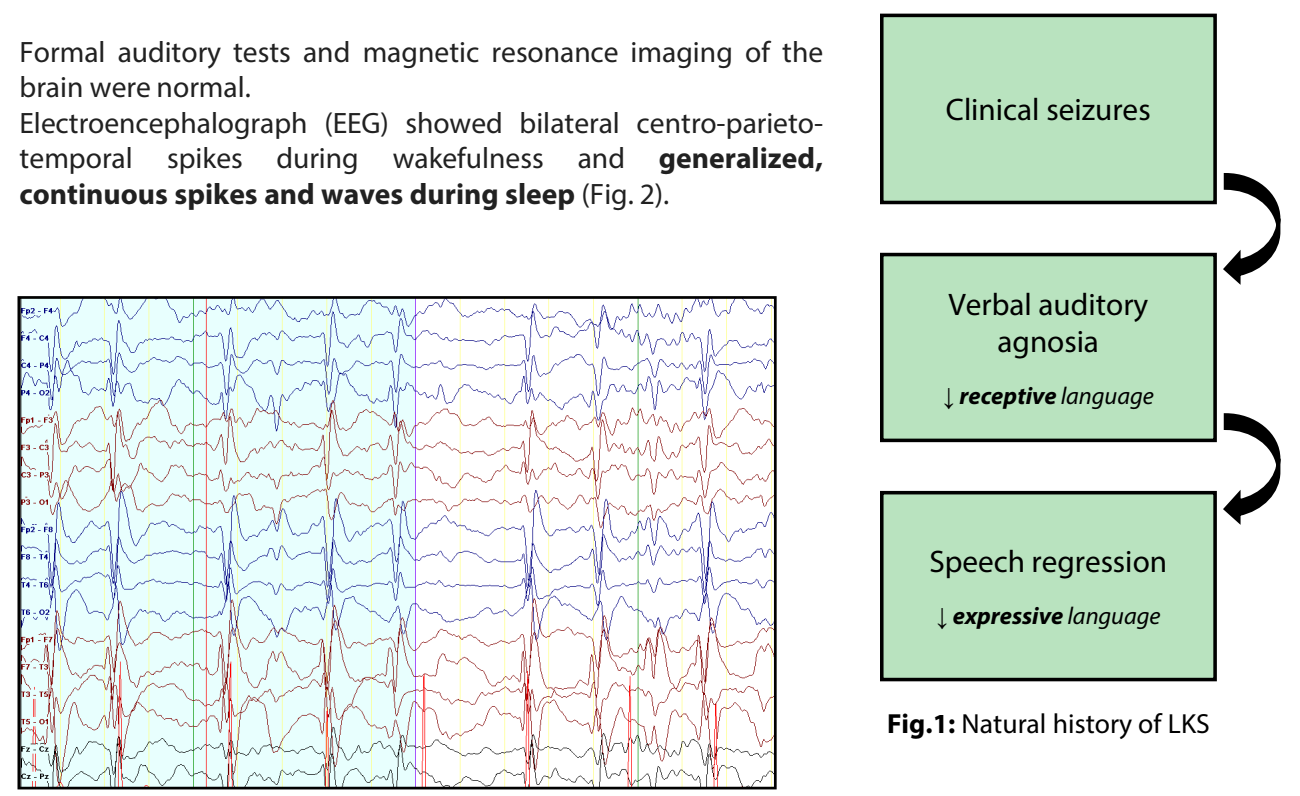

Fig.1: Natural history of LKS

Fig. 2: Characteristic sleep-EEG with continuous spikes and waves (blue - right; red - left)

Pharmacological intervention was successful in attaining clinical and electroencephalographic improvement.

Speech therapy has been helpful in addressing communication difficulties, but significant language impairment persists.

\section{Discussion AND CONCLUSION}

This rare syndrome is well recognized in paediatric neurology, but less know to paediatric otolaryngology, audiology professionals and speech therapists.

Clinical seizures are the first manifestation of LKS in about $2 / 3$ of the patients. However, about $1 / 3$ of the patients present with language deterioration without preceding clinical seizures ${ }^{1-3}$.

Therefore, children seen in paediatric otolaryngology consultation with previously normal cognitive development followed by language deterioration with normal auditory testing should elicit the suspicion of this syndrome, even when prior seizure history isn't present ${ }^{1-3}$.

\section{REFERENCES}

1. https://journals.sagepub.com/doi/full/10.1111/j.1469-5812.2005.00134.x-i1

2. https://www.tandfonline.com/doi/full/10.3109/17518423.2012.701241

3. https://jag.journalagent.com/ejm/pdfs/EJM_17_1_36_39.pdf 


\section{INTRODUCTION}

The external ear is a unique organ in that different anatomic locations favor different non-melanoma skin cancer ${ }^{1}$. Even though the external location of the anterior ear allows the surgeon to diagnose cutaneous disease with ease, it poses a challenge in reconstruction due to its complex topography and reduced skin laxity ${ }^{2}$. We report the largest consecutive case series using the trap door flap to reconstruct auricular defects.

\section{MetHODS}

A retrospective review of all trap door flaps done in a tertiary referral hospital from 2004 - 2021 was conducted. Relevant information such as patient's demographics, tumor characteristics, histopathological diagnosis, post-op complications, recurrence, cosmetic outcome and follow-up times were recorded using Microsoft Excel. Medical charts and "Evolve" computer medical notes were used to collect patient data.

\section{Surgical Technique}

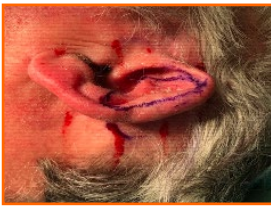

a) 62-year old male with Left Pinna residual SCC marked for a wider excision. Extends from scaphoid fossa to conchal bowl, and did not breach the posterior aspect of pinna.

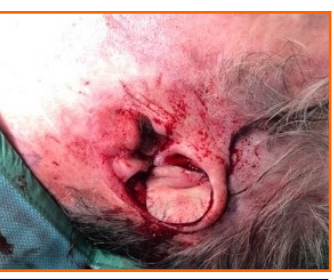

f) The flap is then rotated about the vascular axis to fil the defect. The anterior part is secured to medial aspect of defect using 4-0 vicryl rapide.

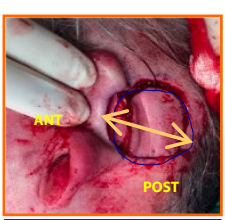

b) Flap designed on mastoid and postauricular surfaces according to defect The diameter was equal to diameter of excision.

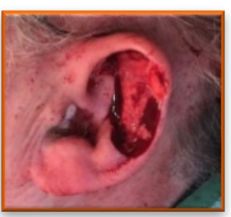

c) Lesion excised leaving a rim of cartilage and preserving the post-auricular skin

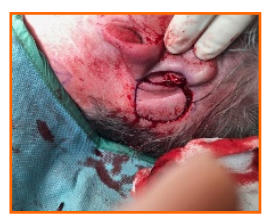

d) Post-auricular skin incised as marked.

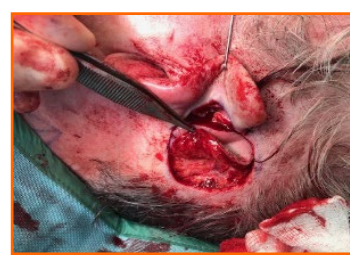

e) Flap raised anteriorly and posteriorly with the hinge or pivotal axis of this flap lying in the post-auricular groove. Flap dissected from surface of mastoid bone in a posterior to anterior fashion.

\section{RESULTS}

84 Cases - Characteristics:

- All operated on by a single surgeon, who coined the term "Trap Door Flap"

- Male $=76 ;$ Female $=8$

- Age ranged from $\mathbf{5 3 - 9 8}$ years

- Size of lesions ranged from 3-mm - 34-mm

- $\mathrm{GA}=\mathbf{1 8}, \mathrm{LA}=\mathbf{6 6}$

- The cutaneous lesions were excised from:

\begin{tabular}{|l|l|}
\hline Concha & $\mathbf{7 3}$ \\
\hline EAC & $\mathbf{5}$ \\
\hline Anti-helix & $\mathbf{4}$ \\
\hline Scaphoid Fossa & $\mathbf{2}$ \\
\hline
\end{tabular}

\begin{tabular}{|l|l|}
\hline SCC & 46 \\
\hline BCC & 27 \\
\hline Malignant Melanoma & 5 \\
\hline $\begin{array}{l}\text { Chondrodermatitis } \\
\text { Nodularis Helicis }\end{array}$ & 2 \\
\hline Dermal Cylindroma & 2 \\
\hline Basosquamous & 1 \\
\hline Atypical Fibroxanthoma & 1 \\
\hline
\end{tabular}

- Overall = No flap loss!

- One patient required reexcision of flap - margin involvement, later had extensive recurrence blocking EAC (pinnectomy and neck dissection)

- Rate of complications was $\mathbf{3 . 5} \%$

- Follow up: 3-months - 7years

- Satisfactory cosmetic results at both the recipient and donor sites. 


\section{Undergoing Panendoscopy.}

Ronan Fahy ${ }^{1}$, Thomas Crotty ${ }^{1}$, Anish Patil ${ }^{2}$, Javed Munir ${ }^{1}$

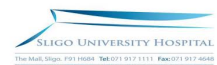

${ }^{1}$ ENT Department, Sligo University Hospital, Sligo, Ireland

${ }^{2}$ Anaesthetics Department, Royal Wolverhampton, England

\section{INTRODUCTION}

Panendoscopy is an important surgical procedure in patients presenting with dysphagia and in those with known head and neck cancer.

Panendoscopy provides direct visualization of the upper airway to aid in the diagnosis of head and neck diseases. Due to the high incidence of synchronous and metachronus malignances associated with squamous cell carcinoma ${ }^{1}$, panendoscopy is often required in the investigation of patients with head and neck cancer/

During the procedure, biopsies can be taken of any abnormalities found. To aid in the management of these patients, they often have pre-operative Computed Tomography (CT) imaging of their upper airway filmed prior to intubation for investigation of symptoms. Pre-op imaging can provide information to the performing surgeon about location of disease and the surrounding anatomy.

These pre-operative CT images provide information concerning the presence of disease and may provide information to predict intubation difficulty.

Intubation difficulty is based on a number of factors. Previously documented relevant factors include thyromental distance, mouth opening ability, Mallampati class and Cormack-Lehane grade².

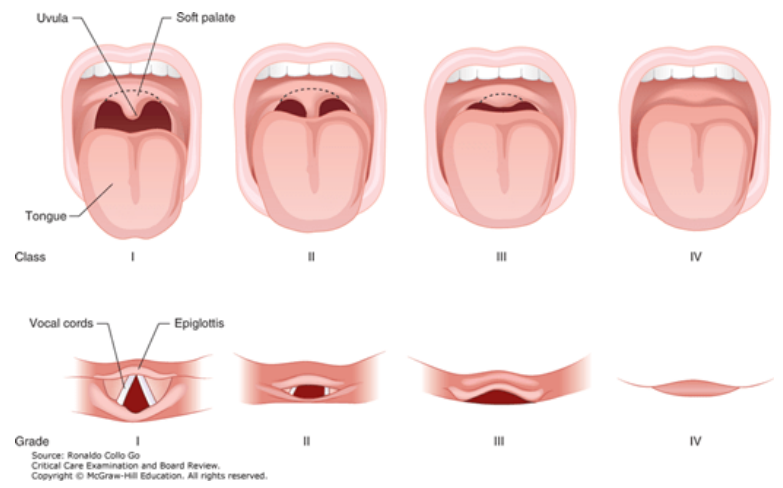

Our study aimed to investigate the role of tracheal diameter in impacting an anesthetist's ease of endotracheal intubation. Pre-operative CT imaging was used due to its ubiquity in this patient cohort

\section{METHODS}

The previous nine months of panendoscopies performed in both the elective and emergency theatre were examined. All patients included in the assessment had a panendoscopy, a pre-operative CT neck and a departmental anaestheia record of airway assessment and endotracheal intubation difficulty.

Retrospective appraisal of airway assessment findings was performed. Variables included endotracheal tube size, difficulty of intubation, Cormack-Lehane grade, Mallampati score, gender and age.

Tracheal diameter was measured at its origin from CT imaging. Anteroposterior (AP) and transverse diameter were measured.

Statistical analysis was performed with ANOVA test.

\section{Tracheal Diameter Measurement}

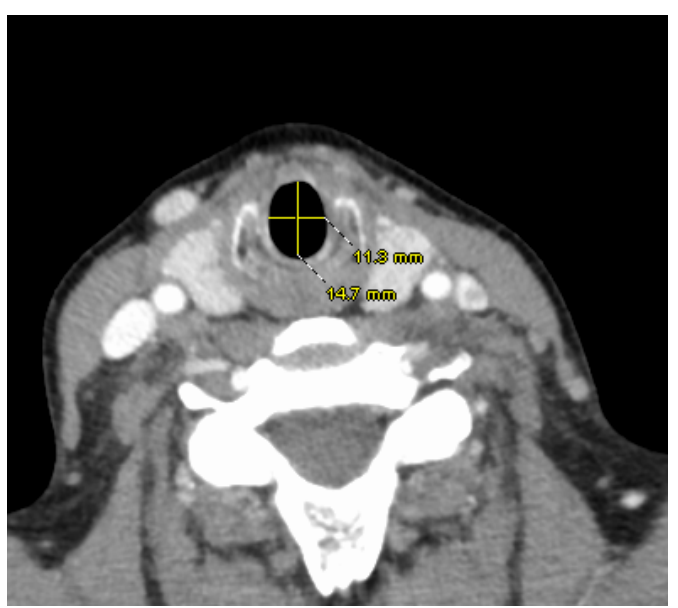

CT 1:

AP: $14.7 \mathrm{~mm}$

Transverse: $11.3 \mathrm{~mm}$

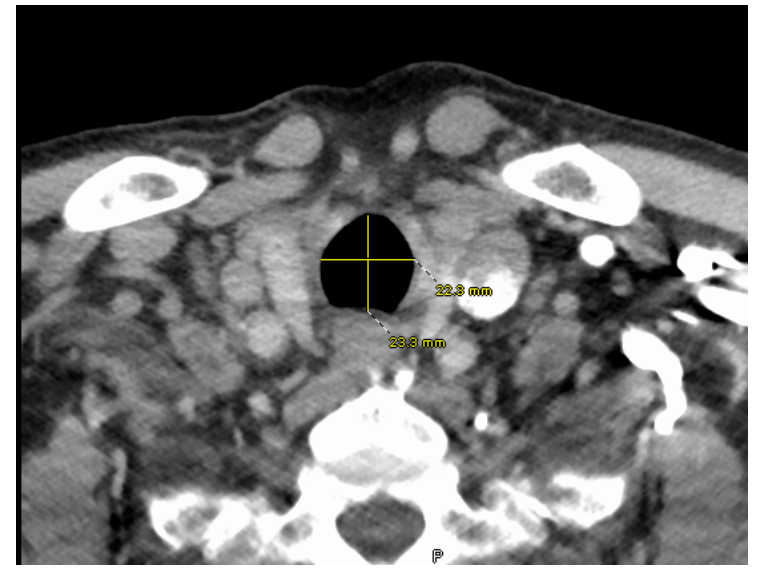

CT 2:

AP: $23.3 \mathrm{~mm}$

Transverse: $22.3 \mathrm{~mm}$ 


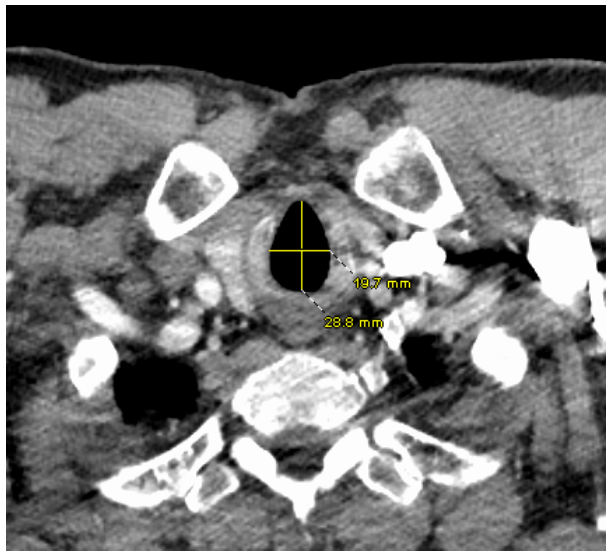

CT 3:

AP: $28.8 \mathrm{~mm}$

Transverse: $19.7 \mathrm{~mm}$

\section{RESULTS}

55 panendoscopies were performed over the 9-month period. Of those, 35 had pre-operative CT imaging of their upper airway. A cohort of 20 patients were selected for analysis.

20 tracheal diameters were measured and compared to the airway assessment variables collected. 13 patients were male and 7 were female. Mean age was 58.9.

\section{Gender}

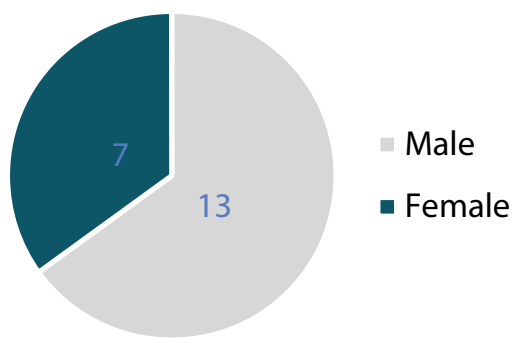

Mean tracheal AP diameter was $20.55 \mathrm{~mm}$, mean tracheal transverse diameter was $16.35 \mathrm{~mm}$

\begin{tabular}{|l|c|c|}
\hline \multicolumn{2}{|c|}{ Airway Assessment Variables } \\
\hline Variable & Mode score & $N$ \\
\hline Mallampati Class & II & 9 \\
\hline $\begin{array}{l}\text { Cormack and Lehane } \\
\text { score }\end{array}$ & 1 & 10 \\
\hline Endotracheal tube size & $6 \mathrm{~cm}$ & 13 \\
\hline
\end{tabular}

Intubation difficulty was assessed (easy $n=16$, moderate $n=2$, difficult $n=2$ ) and compared to tracheal diameter.

INTUBATION DIFFICULTY

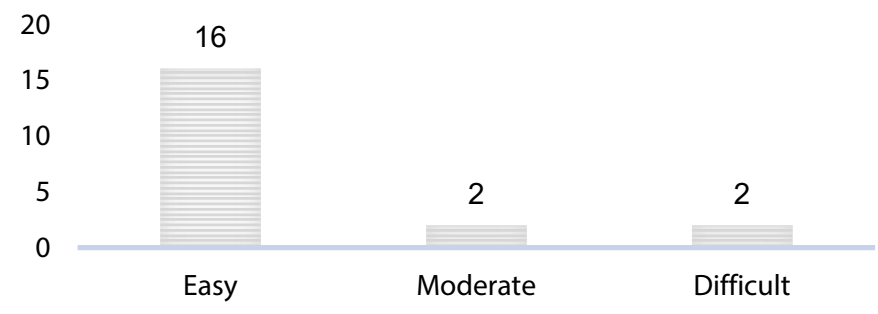

There was no statistically significant difference in AP tracheal diameter between the three groups $(p=0.22)$.

There was a statistically significant difference in transverse tracheal diameter $(p=0.02)$ with moderate and difficult intubations having an increased diameter.. 


\section{CONCLUSION}

Successful intubation is dependent on a number of variables. An increased transverse tracheal diameter indicated a more difficult intubation, albeit at a small population sample.

Patients undergoing panendoscopy often benefit from pre-operative CT imaging of their upper airway. These images may be useful in predicting which patients will have a difficult endotracheal intubation.

Further research is needed to investigate the measurement of tracheal diameter and its impact on endotracheal intubation difficulty.

\section{REFERENCES}

1. Mallampati S. Clinical sign to predict difficult tracheal intubation (hypothesis). Canadian Anaesthetists' Society Journal. 1983;30(3):316-317.

2. Schwartz L, Ozsahin M, Zhang G, Touboul E, De Vataire F, Andolenko P et al. Synchronous and metachronous head and neck carcinomas. Cancer. 1994;74(7):1933-1938. 


\section{ObJective}

The aim of this project is to determine the most efficient way to safely perform a medical validation of our waiting lists for routine tonsillectomy

\section{CONTEXT}

Surgical waiting lists in Northern Ireland have climbed significantly in the last decade, harmed further by the pandemic. With waiting times of over 4 years for routine surgery, we felt the need to validate all patients on these lists to better plan for the future. We also wanted to determine the most efficient way of doing this as it is often labour and time intensive for clinicians to contact patients out of scheduled appointments

\section{METHOD}

Two phases:

1. Patients contacted via 'cold call' by ENT to establish whether surgery still indicated.

2. Online questionnaire (eSurvey) examining need for tonsillectomy sent to second cohort

Those no longer needing surgery from both groups removed from waiting list

\section{RESULTS}
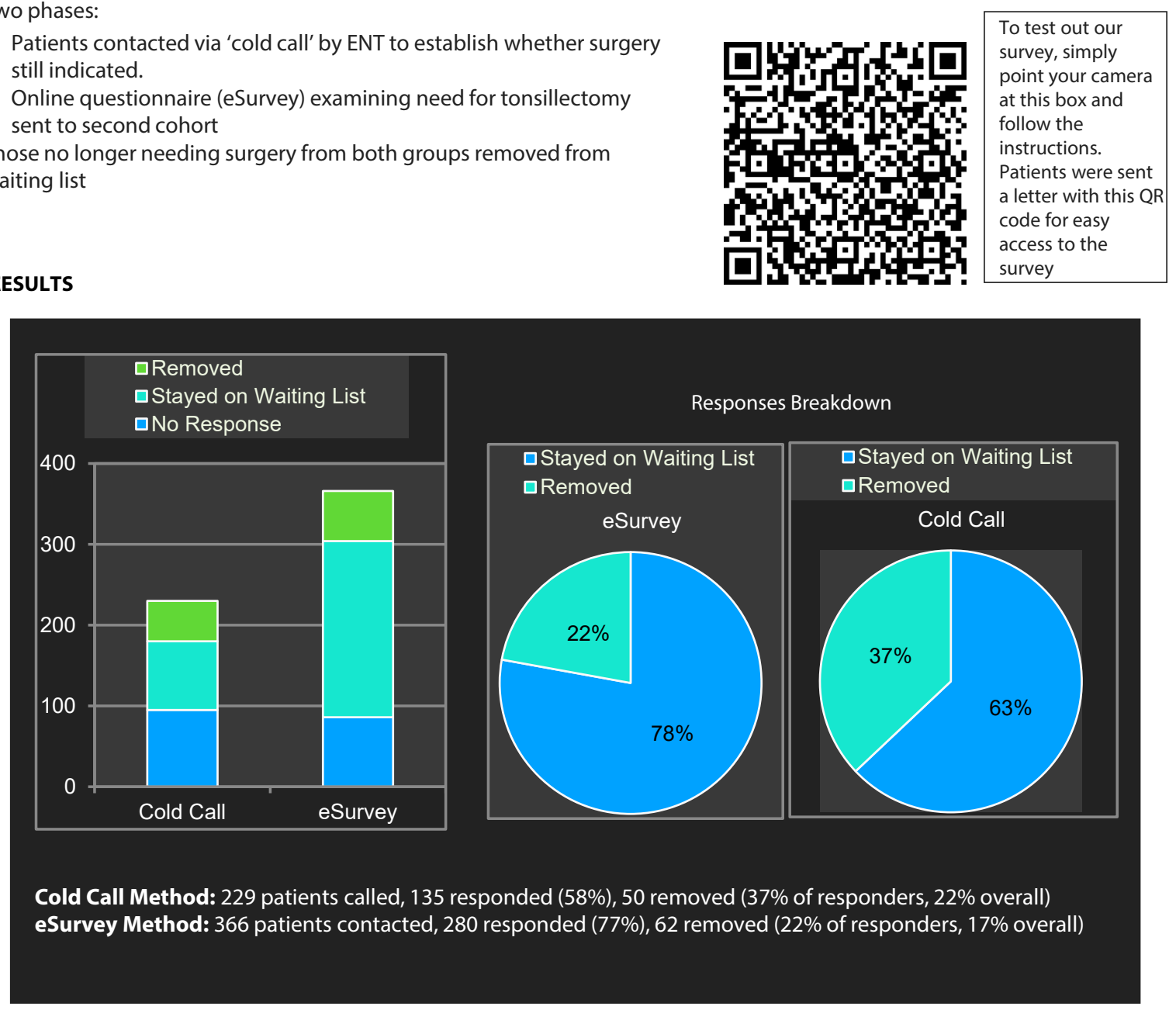

\section{CONCLUSION}

This initiative proved effective in cutting waiting lists, as well as demonstrate that whilst cold calling was more fruitful, the eSurvey was also useful and likely gave a more accurate attrition rate from the waiting list, given the increased numbers it reached.

Cold calling was extremely time-intensive and often frustrating. With the survey, we simply sent a letter to the patients inviting them to take part in their own time. We have demonstrated an efficient and effective, low cost way of medically validating waiting lists. 
HSC) Belfast Health and Social Care Trust

\section{Year Review of Incidental Thyroid Nodules Managed in ENT Outpatient Department}

Dr Chris Li, Mr David McCrory, Mr Barry Devlin

\section{Objective}

- Primary objective: To reduce over investigation of incidental thyroid nodules in keeping with current British Thyroid Association (BTA) guidelines.

- Incidental non-palpable nodules under $1 \mathrm{~cm}$ with no worrisome features (extra-capsular extension, tracheal invasion, associated lymphadenopathy) can be managed in primary care.

- Secondary objective: To assess total thyroid cancers arising from incidental nodules.

\section{METHOD}

Retrospective analysis of all ultrasound thyroid examinations requested, from the Belfast Trust ENT department from 1st January 2014 to 31 st December 2018, looking at the indication for each ultrasound request, matched with outpatient letters to identify incidental thyroid nodules. Radiological, cytological and histopathological data were analysed.

\section{RESULTS}

- 85 out of 614 (14\%) individual patients having ultrasound thyroid were for incidental nodules identified on imaging.

- 54 incidental nodules identified on CT, 9 on MRI, 10 on PET, 11 on ultrasound (US) and 1 on chest $x$-ray .

- 8 nodules (6 on CT, 2 US) were $<1 \mathrm{~cm}$ without adverse features.

- 7 nodules on CT / MRI and 4 nodules on US were between $1 \mathrm{~cm}$ and $1.49 \mathrm{~cm}$.

- 26 nodules on CT, 3 MRI, 1 PET and 2 US (32 nodules) were over $1.5 \mathrm{~cm}$.

- 34 nodule sizes were not specified in radiology report ( $74 \%>1.5 \mathrm{~cm}$ on follow-up ultrasound) .

- 7 cases required hemi-thyroidectomy, 3 requiring completion thyroidectomy.

- 3 thyroid cancers and 4 follicular adenomas.

\section{Cancers Identified $(\mathbf{n}=\mathbf{3})$}

- Incidental on MRI: 63 years old female, MRI for motor neurone disease, incidental multinodular goitre, no adverse features, size not specified, ultrasound advised. U4, Thy 1 on FNA. Cytology and radiology review and proceeded for hemithyroidectomy showing follicular variant of papillary thyroid carcinoma.

- Incidental on PET: 48 years old female, PET scan for myeloma work up. Incidental focal FDG uptake in left lobe of thyroid with SUV Max 5.3, suggest ultrasound for assessment. No $U$ classification, Thy 1 then Thy 4 on FNA,. Hemithyroidectomy showed follicular variant of papillary microcarcinoma.

- Incidental on ultrasound: 75 years old female left submandibular gland obstruction, incidental U4 thyroid nodule. Thy 2 then Thy4 on FNA. Hemithyroidectomy showed papillary carcinoma.

- All hemi-thyroidectomy went onto completion thyroidectomy.

\section{CONCLUSION}

- $3.5 \%$ of all nodules investigated were cancerous.

- 8 out of 85 (9.4\%) incidental thyroid nodules identified were $<1 \mathrm{~cm}$ with no adverse features.

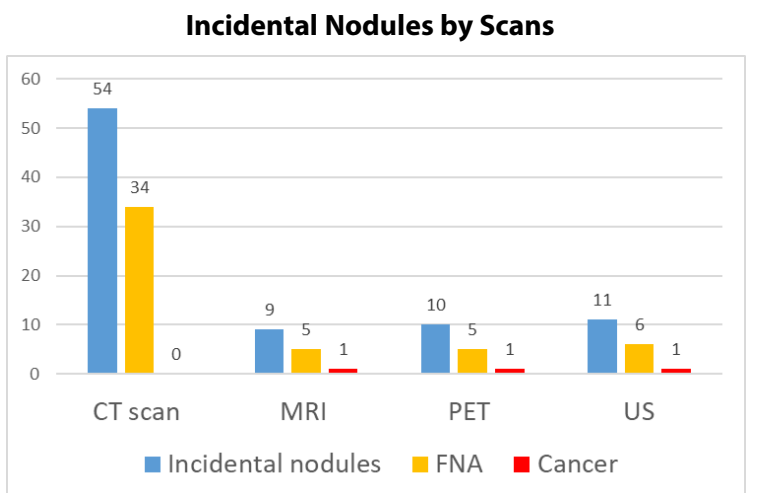

- This led to 13 ultrasound scans and 10 outpatient clinic appointments which could be avoided.

- We identified no cancers in incidental lesions under $1 \mathrm{~cm}$.

- Ideally, Radiologists could advise if no further investigation required on these nodules and avoid unnecessary investigation.

- For larger nodules $>1 \mathrm{~cm}$ Radiologists could directly book US +/- FNA and be seen in ENT OPC with result; therefore avoiding ENT outpatient appointment prior to US.

- $63.5 \%$ of incidental nodules identified were from CT scans.

- Interestingly, $0 \%$ of nodules on CT were cancerous.

- We suggest a minimum dataset for reporting incidental nodules identified on CT and MRI scans.

- Size of nodule, extra-capsular extension, tracheal invasion, calcification, associated lymphadenopathy.

- If ultrasound assessment is required or suitable for discharge.

- $10 \%$ of our PET scan incidental nodules were cancerous.

- We continue to advise FNA of all PET incidental nodules as per BTA guidelines.

\section{Discussion}

- American College of Radiology also suggest no intervention is required for nodules in patients aged over 35 with no risk factors and if the nodule is between $1 \mathrm{~cm}$ and $1.49 \mathrm{~cm}$ identified on CT / MRI.

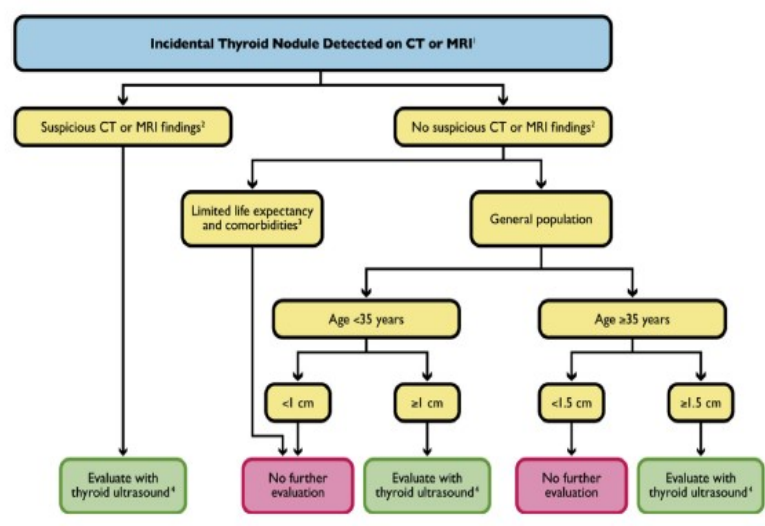


- Extrapolating from our dataset, if we adopted the American College of Radiology guidelines, a further 21 ultrasound slots and 22 outpatient clinic appointments could be potentially avoided.

- We would not have had any cancers in that cohort.

- At present we will continue adhering to BTA guidelines.

\section{REFERENCES}

1. Hoang, J., Langer, J., Middleton, W., Wu, C., Hammers, L., Cronan, J., Tessler, F., Grant, E. and Berland, L., 2015. Managing Incidental Thyroid Nodules Detected on Imaging: White Paper of the ACR Incidental Thyroid Findings Committee. Journal of the American College of Radiology, 12(2), pp.143-150.
2. Hoang, J., Langer, J., Middleton, W., Wu, C., Hammers, L, Cronan, J., Tessler, F., Grant, E. and Berland, L., 2015. Managing Incidental Thyroid Nodules Detected on Imaging: White Paper of the ACR Incidental Thyroid Findings Committee. Journal of the American College of Radiology, 12(2), pp.143-150. 


\section{Hungry Bone Syndrome (HBS) after Parathyroidectomy: How} Common is it and can it be Avoided?

J Smith, M Korda

Craigavon Area Hospital

\section{INTRODUCTION}

Hungry bone Syndrome can be a troublesome early complication of parathyroidectomy. We present a review of patients who suffered post-operative hypocalcaemia, possible risk factors and corrective actions for Hungry Bone syndrome

\section{METHODS}

We performed a retrospective chart review of all adult patients who underwent parathyroidectomy between 2012-2020 inclusive. We assessed patient demographics, imaging concordance, pre-/post-operative biochemical markers and histological outcomes.

\section{Hypocalcaemic Patient Analysis}

\section{DEMOGRAPHIC}

- Average age 54.3 yrs (range 29-73 yrs)

- 2 smokers, 2 ex-smokers, 2 non smokers

- Average length of stay 9.2 (range 2-33 days)

- 1 patient required readmission

\section{COMPLICATING FACTORS}

- 1 pt:MEN-4

- 1 pt: Hyperparathyroid Jaw Tumour syndrome

- $1 \mathrm{pt}$ : 2nd visit to theatre for neck exploration

\section{IMAGING}

- All had nuclear medicine scans

- 2 patients had concordant scans

- 2 patients had pre operative DEXA scans demonstrating osteopenia

\section{Pre operative biochemical markers}

\begin{tabular}{|c|c|c|c|c|c|c|c|}
\hline Patient & $\begin{array}{l}\text { Calcium } \\
\text { (mmol/L) }\end{array}$ & $\begin{array}{l}\text { Phosphate } \\
\text { (mmol/L) }\end{array}$ & $\begin{array}{l}\text { ALP } \\
\text { (U/L) }\end{array}$ & $\underset{(\mathrm{mmol} / \mathrm{L})}{\mathrm{Mg2}}$ & $\begin{array}{c}\text { Vit D } \\
\text { (nmol/L) }\end{array}$ & $\begin{array}{c}\text { PTH } \\
\text { (pg/mL) }\end{array}$ & $\begin{array}{c}\text { Creatinine } \\
\text { (umol/L) }\end{array}$ \\
\hline 1 & 2.46 & 0.9 & 38 & 0.73 & 38 & 75 & 90 \\
\hline 2 & 2.75 & 1 & 95 & N/A & 61 & 104 & 61 \\
\hline 3 & 3.27 & 0.62 & 414 & 0.84 & 23 & 1726 & 37 \\
\hline 4 & 2.38 & 0.87 & 116 & 0.54 & 63 & 85 & 89 \\
\hline 5 & 2.76 & 0.94 & 80 & 0.84 & 32 & 87 & 74 \\
\hline 6 & 2.56 & 1 & 202 & 0.89 & 35 & 92 & 57 \\
\hline
\end{tabular}

Post operative biochemical markers

\begin{tabular}{|c|c|c|c|c|}
\hline Patient & $\begin{array}{c}\text { Lowest Calcium } \\
(\mathbf{m m o l} / \mathbf{L})\end{array}$ & $\begin{array}{c}\text { Mg2+ } \\
(\mathbf{m m o l} / \mathbf{L})\end{array}$ & $\begin{array}{c}\text { Phosphate } \\
(\mathbf{m m o l} / \mathbf{L})\end{array}$ & $\begin{array}{c}\text { PTH } \\
\text { (pg/mL) }\end{array}$ \\
\hline 1 & 1.96 & 0.73 & 0.91 & 11 \\
\hline 2 & 1.90 & 0.72 & 1.05 & 5 \\
\hline 3 & 1.87 & 0.56 & 0.47 & 70 \\
\hline 4 & 1.91 & 0.54 & 1.29 & 12 \\
\hline 5 & 1.57 & 0.55 & 1.2 & 6 \\
\hline 6 & 1.86 & 0.72 & 1.04 & 5 \\
\hline
\end{tabular}

\section{HistologY}

- All patients had adenoma confirmed histologically

- One patient had ectopic tissue in the upper mediastinum 


\section{HUNGRY BONE SYNDROME (HBS)}

1 patient fulfils the expected literature definition of HBS by demonstrating immediate post operative hypocalcaemia, hypophosphataemia and hypomagnesaemia (red above)

\section{HBS POTENTIAL RISK FACTORS}

- Preoperative biochemistry

- Low serum Magnesium

- High serum PTH

- High serum ALP

- Patient factors

- Associated syndrome

\section{Discussion}

Wang et al (2020) discussed common risk factors for HBS in secondary hyperparathyroidism. They noted pre-operatively high PTH, high ALP, and low/normal calcium to be the 4 most reliable predictors of high risk patients for HBS.

Each of our 6 patients fulfilled at least one of these criteria (noted in green on the chart opposite), and therefore we believe that our data supports the notion that similar risk factors apply in the wider setting of hyperparathyroidism in general.

Identification of patients using these factors may be useful in perioperative planning. In future cases, it may be beneficial to load pre-operatively with calcium, and equally so, our data would suggest they are not offered day case surgery routinely.

\section{REFERENCES}

Wang M, Chen B, Zou X, Wei T, Gong R, Zhu J, Li Z. A Nomogram to Predict Hungry Bone Syndrome After Parathyroidectomy in Patients With Secondary Hyperparathyroidism. J Surg Res. 2020 Nov;255:33-41. doi: 10.1016/j.jss.2020.05.036. Epub 2020 Jun 13. PMID: 32540578. 


\section{Rare Case Presentation of Diffuse Large B-Cell Lymphoma With Trigeminal Neuralgia and Subsequent Cutaneous Deposits on Nasal Ala}

Dr M McFadden (Core Surgical Trainee), Mr D McCrory (Specialty Registrar), Ms C P Smith (Consultant ENT Surgeon)

\section{Cinical Presentation}

- A 59-year-old Male presented with a 3 month history of progressive neuropathic pain and paraesthesia in the distribution of V2 and V3 branches of the right Trigeminal nerve

- Had trialled Amitriptyline and Gabapentin in the community to minimal effect

- Examination revealed altered sensation right $\mathrm{V} 1, \mathrm{~V} 2$ and V3 only

\section{INVESTIGATIONS}

- Red Flag CT sinuses and MRI Head requested

- MRI (Fig 1) revealed a pathological process involving the right trigeminal nerve with evidence of diffuse perineural spread, involving its V2 and V3 branches, with intracranial involvement into the right masticator space, pterygopalatine fossa and right infratemporal fossa, inferior orbit and infraorbital nerve

\section{MANAGEMENT}

- Patient was discussed at the neurosurgical MDM. Appearances highly suggestive of malignancy.

- Planned for endoscopic biopsy (Fig 2)

- In the interim between imaging and review at ENT OPC to discuss surgery, the patient developed new cutaneous lesions on the right nasal ala (Fig 3)

- Dermatology kindly facilitated a punch biopsy, avoiding the need for GA

- Histology confirmed diffuse high grade large B-cell lymphoma

- Referred to Haematology team and responding well to treatment with R-CHOEP chemotherapy

Diffuse Large B Cell Lymphoma (DLBCL)

- Most common subtype of non-hodgkins lymphoma (25\%)

- $\mathrm{M}>\mathrm{F}, 55 \%$ cases occur in males

- Typical presentation with rapidly enlarging symptomatic lymph nodes, extra nodal involvement common in advanced disease. $30 \%$ will have B symptoms.

- Primary nervous system DLBCL can present with cranial neuropathies with case reports demonstrating DLBCL mimicking drug resistant trigeminal neuralgia

- A small number of case studies comment on facial cutaneous manifestations of lymphoma with one Polish study commenting on an erythematous eruption on the nasolabial fold that was initially treated as erysipelas
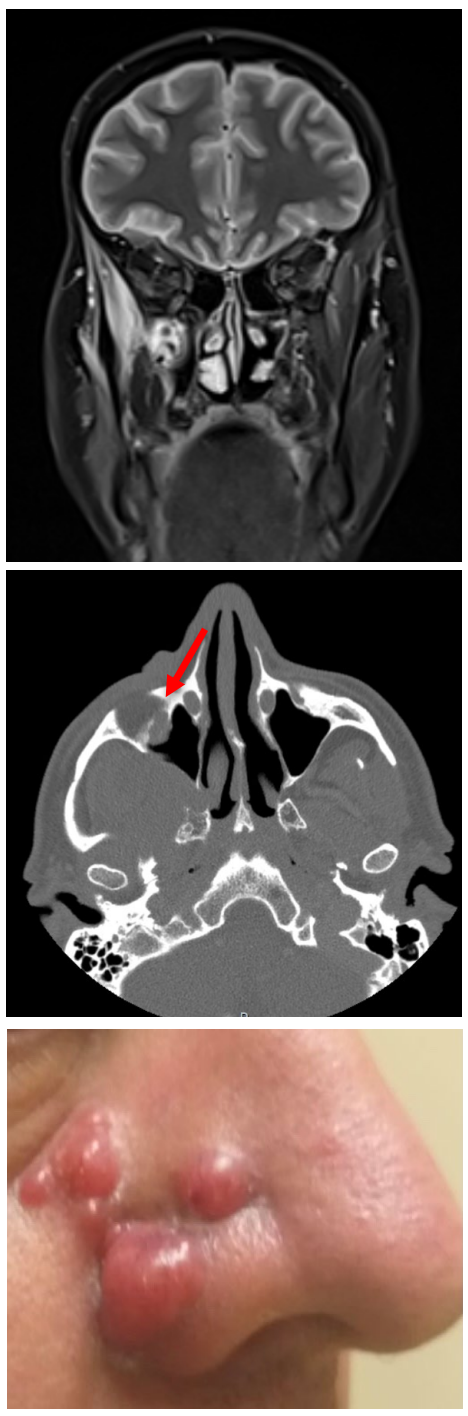

Fig. 3: Cutaneous lesions right nasa ala
Fig. 2: $\mathrm{CT}$ sinuses with contrast axial view showing right infraorbital lesion and access via prelacrimal approach (red arrow)

\section{CONCLUSION}

1. An unusual presentation of B-cell lymphoma

2. Consider Red Flag MRI in persistent trigeminal neuralgia to exclude sinister pathology

3. Cutaneous Punch Biopsy avoided intranasal biopsy and so reduced time to diagnosis and treatment

4. Awareness that B cell lymphoma may present with skin changes

\section{RefERENCES}

1. Teresiak-Mikołajczak E, Szymańska M, Czarnecka-Operacz M. A case of diffuse large B-cell lymphoma misdiagnosed as an erysipelas of the face. Postepy Dermatol Alergol. 2013 Aug;30(4):268-70. doi: 10.5114/pdia.2013.37040. Epub 2013 Aug 27. PMID: 24278087 ; PMCID: PMC3834703.

2. WHO Classification of Tumours of Haematopoietic and Lymphoid Tissues, revised 4th edition, Swerdlow SH, Campo E, Harris NL, et al. (Eds), International Agency for Research on Cancer (IARC), Lyon 2017

3. Inatomi Y, Inoue T, Nagata S, Matsuno H, Itoh Y. Trigeminal neuralgia caused by the metastasis of malignant lymphoma to the trigeminal nerve: a case report. No Shinkei Geka. 1998 May;26(5):401-5. PMID: 9621352 


\section{INTRODUCTION}

Squamous cell carcinoma of the larynx is a common presentation of head and neck malignancy. Early lesions presenting as T1 frequently affect the glottis and present as hoarseness. The management of these early lesions is typically by transoral laser microsurgery (TLM) or radiotherapy (RT). The recurrence of T1 lesions between estimated to be between $5-13 \%$. The majority, around $90 \%$, are observed within three years of treatment and $50 \%$ occur within the first year. There has been no difference reported between TLM and RT in terms of disease recurrence.

\section{Objective}

This study aims to evaluate the recurrence of $\mathrm{T} 1$ larynx disease in Northern Ireland as well as assessing whether there is any significant difference in the recurrence according to the treatment modality, TLM or RT.

\section{MetHODS}

A data request for patients presenting with T1 lesions from 2017-2019 was made from the Northern Ireland Cancer Registry. 87 patients were included in a retrospective data collection of date of pathological diagnosis, TNM staging, treatment modality, recurrence and length of follow up. The data was then analysed by generating Kaplan-Meier disease-free survival curves for T1 disease in SPSS, where the event was a recurrence of disease and factor was treatment modality. Recurrence was defined as a pathological diagnosis following at least one flexible nasendoscopy showing no suspicion for malignancy after treatment. The difference between these curves was then assessed.

\section{RESULTS}

A total of 87 patients were included in the analysis. 33 patients received TLM of which there were 9 recurrences. 54 patients received RT of which there was 1 recurrence. Overall the recurrence was $11 \%$. All of the recurrences occurred within 3 years. Kaplan Meier analysis demonstrated a statistically significant difference between recurrence of disease treated with RT compared to TLM, $\mathrm{p}<0.001$.

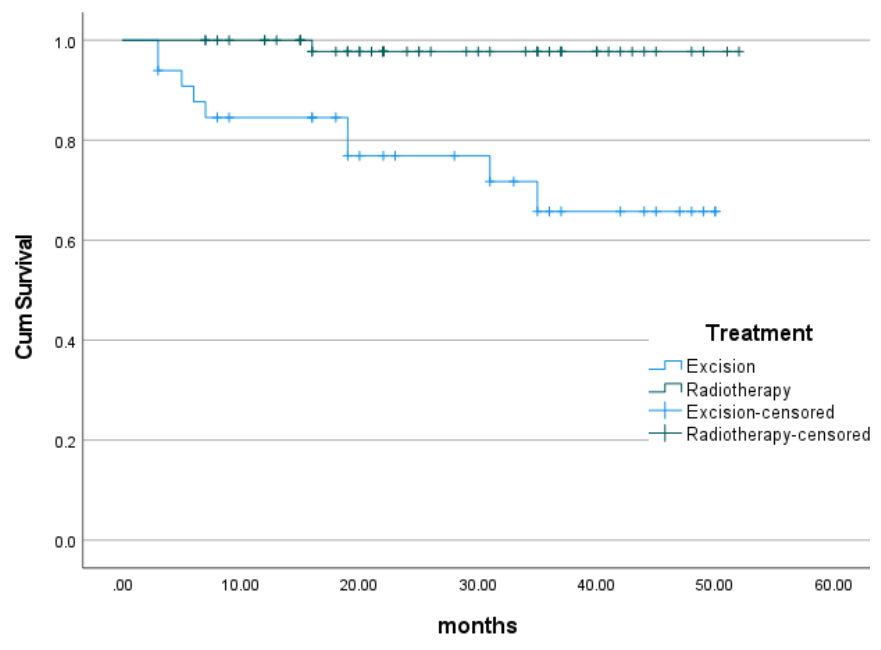

\section{Discussion}

Our data shows the rate of recurrence of T1 lesions treated with either TLM or RT is $11 \%$. All the recurrences occurred within three years. Both of these findings are consistent with the literature. Our data also show an apparent increased level of recurrence when T1 lesions which are treated with TLM compared to RT. This is not consistent with the literature. However this finding needs to be treated with caution for several reasons. Our dataset in this study is small. We have no set interval of follow up leading to a high censorship rate in the analysis. Despite this, the high level of significance and the important clinical implications of the difference means that further data control of confounding factor needs analysed, and longer-term data with increased power will be sought. 


\section{What's the Point in the ENT SHO? \\ Examining out-of-hours Workload to Reduce in-hours Cancellations}

By K. Dodds, A. Zuccarelli, D. Dick, M. Valko

\section{OBJectives}

In one district general hospital, excessive out-of-hours referrals to the ENT doctor on-call led to frequent, last-minute cancellations of in-hours services the next day secondary to fatigue. The aim of this study was to assess what interventions were required from the first on-call ENT doctor In the management of basic ENT presentations. By identifying and addressing areas for improvement, patient care could be made more efficient and the volume of unnecessary referrals to the ENT doctor on-call could be reduced. As a result the provision of in-hours ENT services could be improved.

\section{METHOD}

A retrospective chart review was conducted of unplanned ENT admissions with epistaxis, tonsillitis and quinsy over 8 weeks. Data was collected on the initial management instigated by the emergency department (ED), and any additional management by the ENT doctor on-call.

\section{RESULTS}

47 patients included

21 Epistaxis; 26 Tonsillitis/Quinsy

$77 \%$ patients were referred and seen out of hours

Median time to be seen was 38 minutes

(range 0 - 80 minutes; $\mathrm{n}=25$ ).

\section{Epistaxis (Fig. 1)}

- Although $95 \%$ had routine bloods sent, only $38 \%$ were group and held $(\mathrm{G} \& \mathrm{H})$ in ED

- ED documentation of nose examination in $51 \%$

- Haemostasis was achieved by ED in $71 \%$ prior to ENT assessment

- ENT input comprised of the insertion of packs or inflation of already present packs in $38 \%$, and cautery in $5 \%$

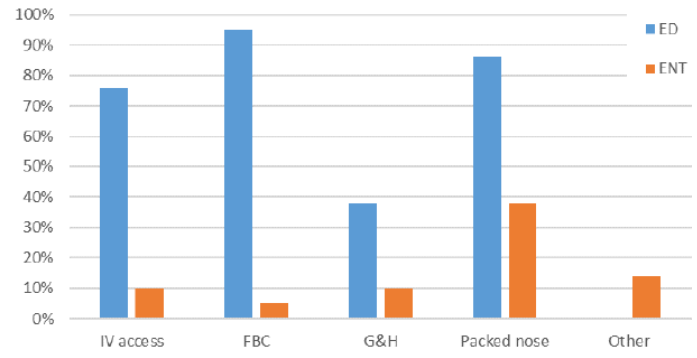

Fig. 1: Percentage of patients for whom the above steps were taken in the management of epistaxis
Tonsillitis \& Quinsy (Fig. 2)

- Although over $95 \%$ had their oropharynx examined by $E D$, only $31 \%$ had their neck examined. ENT neck examination rate was also poor at $35 \%$. However, no deep neck space infections went undiagnosed.

- Following ENT review, the final diagnosis was changed in only $15 \%$ (usually from quinsy to tonsillitis)

- Only $31 \%$ had been prescribed the basic combination of analgesia, antibiotics and steroids by ED

- $65 \%$ of patients had quinsies, of whom $41 \%$ were drained by ENT out-of-hours

\section{Discussion}

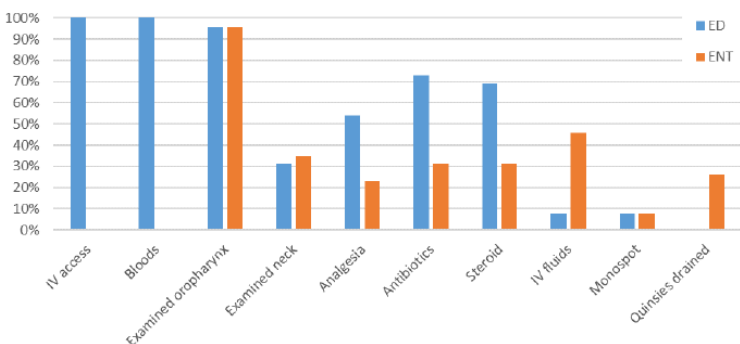

Fig. 2: Percentage of patients for whom the above steps were taken in the management of tonsillitis and quinsy

\section{Epistaxis}

According to Passali et al. (2020), the initiation of simple first aid measures by primary care or ED can be effective in achieving haemostasis in $65 \%$ to $70 \%$, which is consistent with our results. Only the recurrent or severe nosebleeds require ENT referral. Unfortunately, of those bleeds warranting ENT referral, only $76 \%$ had IV access and $38 \%$ were group and held. This led to an excess of work to be done overnight by the ENT team on call. In this study, $43 \%$ required ENT input overnight to stem bleeding. This percentage may be reduced by providing training in nasal examination and cauterisation to ED staff.

\section{Tonsillitis \& Quinsy}

In this study, the ED and ENT doctors agreed on a diagnosis of tonsillitis or quinsy in $85 \%$ of cases. Both parties performed oropharyngeal examination in over $95 \%$; however, both frequently neglected neck examination which is vital in the diagnosis of deep space neck infections. Only $31 \%$ of patients were prescribed what we considered a "basic package" of analgesia, antibiotics and steroids. Given the indications for hospital admission in acute tonsillitis include dysphagia, we would argue that IV fluids should be considered part of this basic package. Only $8 \%$ were prescribed IV fluids by ED. Overall, ENT initiated part or all of basic management in $77 \%$ of cases.

\section{CONCLUSION}

The initial management of ENT presentations by ED often lacked the basic interventions that do not require an ENT specialist. A more consistent approach by ED could expedite and therefore improve patient care as well as reduce the need for ENT review out-of-hours. In turn, this could reduce in-hours ENT clinic cancellations. The introduction of admission packs, antimicrobial guidelines and training for ED staff may help in this regard.

\section{REFERENCES}

Passali, D., Damiani, V., Passali, F.M. et al. (2020) An International Survey on the Pragmatic Management of Epistaxis. Acta Biomed. 2020; 91 (Suppl 1): 5-10 


UHW LE
$\begin{aligned} & \text { Ospidéal Ollscoile } \\ & \text { Phort Láirge } \\ & \text { University Hospital } \\ & \text { Waterford }\end{aligned}$

\section{INTRODUCTION}

Silent sinus syndrome(SSS) is a rare clinical entity characterised by enophthalmos and hypo-globus secondary to chronic maxillary sinus atelectasis. The term SSS was first coined in 1994 by Soparkar et al, but originally described by Montgomery in 1964. ${ }^{1,2}$ We would like to present our institutional experience in the investigation and management of patients with SSS, along with the pathological framework on which it is based.

\section{BACKGROUND}

It is postulated that chronic occlusion of the ostiomeatal complex leads to gradual resorption of air and the creation of negative pressure within the maxillary sinus. This results in gradual inward displacement of the maxillary walls. Osteoclastic resorption of the orbital floor leads to bone thinning with collapse, manifesting clinically as enophthalmos and sometimes diplopia. Posterior bowing of the anterior wall leads to flattening of the malar eminence, contributing to facial asymmetry.

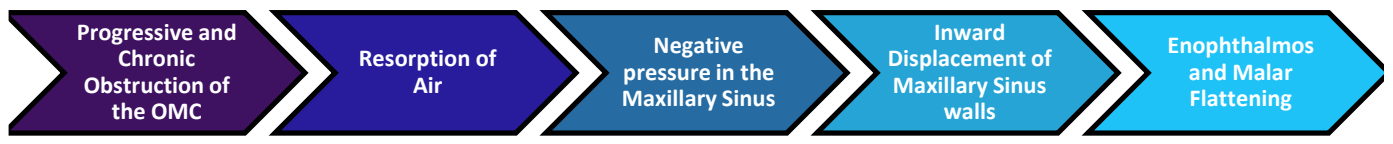

\section{RESULTS}

- In the last 4 years we have had 4 cases of SSS in our department. There was an equal male to female ratio with age range from $25-34$ years

- Presentations varied, two patients presented with symptoms of chronic rhinosinusitis, one patient noted facial asymmetry with nasal congestion and one patient was completely asymptomatic and picked up incidentally

- All patients underwent investigation with flexible nasendoscopy and CT sinuses

- All patients were managed surgically with functional endoscopic sinus surgery, involving middle meatal antrostomy. There were no complications and no further progression in disease post-operatively
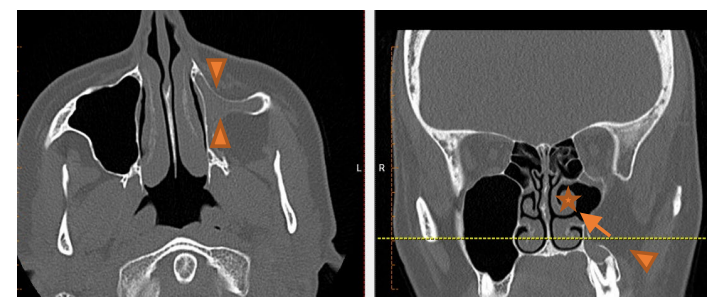

Axial and coronal view of CT paranasal sinuses showing reduced left maxillary sinus volume with opacification, lateralisation of the left uncinate process occluding the infundibulum (arrow), widening of the left middle meatus (star) and inward bowing maxillary sinus walls (arrowheads)

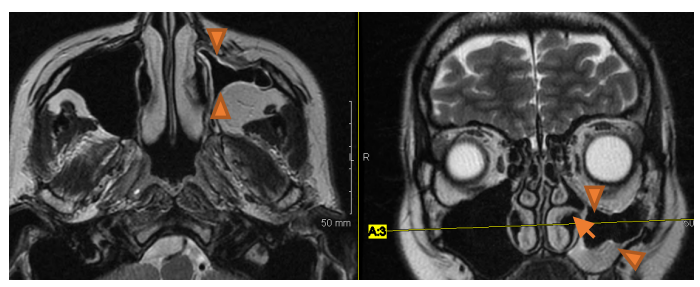

Axial and coronal view of MRI paranasal sinuses showing reduced left maxillary sinus volume with, lateralisation of the left uncinate process occluding the infundibulum (arrow) and inward bowing of the maxillary sinus walls including inferior displacement of the orbital floor (arrowheads)

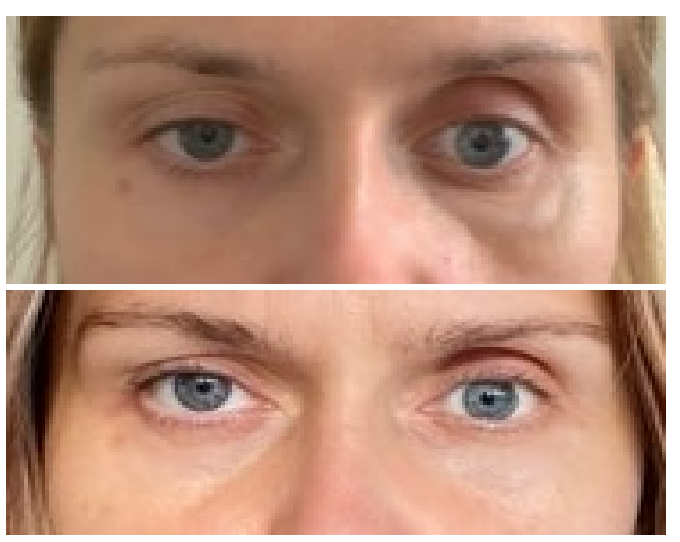

Photographs used with consent. Above: Before endoscopic sinus surgery. Below: 6 months after surgery

\section{Discussion}

- The literature suggests that a prolonged history of painless eye or facial asymmetry, with or without diplopia is the typical presentation of SSS ${ }^{1-5}$. From our experience, $3 / 4$ patients did not have any symptoms of facial dissymmetry or ophthalmic pathology and $1 / 2$ did not have significant sinusitis to warrant further investigation. This highlights the importance of considering SSS as a differential and including assessment of the orbits and facial symmetry during examination

- CT sinuses is the investigation of choice, characterising the pathological features of SSS namely; maxillary sinus opacification with reduced volume. MRI imaging will display similar findings but is not necessary for diagnosis $^{3-5}$

- Optimal management is with a multidisciplinary approach with a goal of restoring sinus aeration. FESS with a maxillary antrostomy and uncinectomy is the cornerstone of treatment with or without orbital floor reconstruction ${ }^{1,4,5}$

\section{CONCLUSION}

Silent sinus syndrome is a rare clinical condition with potentially sight threatening consequences. Patients can present with a myriad of symptoms or may be asymptomatic. It is important that the clinician regards silent sinus syndrome as part of their differential when assessing patients in the outpatient's department. 


\section{REFERENCES}

1. Soparkar, C., Patrinely, J., Cuaycong, M., Dailey, R., Kersten, R., \& Rubin, P. et al. (1994). The Silent Sinus Syndrome. Ophthalmology, 101(4), 772-778. doi: 10.1016/s0161-6420(94)31267-x

2. WW M. MUCOCELE OF THE MAXILLARY SINUS CAUSING ENOPHTHALMOS. Eye Ear Nose Throat Mon. 1964;43:41-4.

3. Rose, G., Sandy, C., Hallberg, L., \& Moseley, I. (2003). Clinical and radiologic characteristics of the imploding antrum, or "silent
4. sinus," syndrome. Ophthalmology, 110(4), 811-818. doi: 10.1016/s0161-6420(02)01993-0

5. Illner, A., Davidson, H., Harnsberger, H., \& Hoffman, J. (2002). The Silent Sinus Syndrome. American Journal Of Roentgenology, 178(2), 503-506. doi: 10.2214/ajr.178.2.1780503

6. Numa, W., Desai, U., Gold, D., Heher, K., \& Annino, D. (2005). Silent Sinus Syndrome: A Case Presentation and Comprehensive Review of All 84 Reported Cases. Annals Of Otology, Rhinology \& Laryngology, 114(9), 688-694. doi: 10.1177/000348940511400906 
The Extended, Endoscopic, Endonasal Approach for Resection of

Adult Craniopharyngioma is Safe and Well-tolerated with

Acceptable Rates of CSF Rhinorrhoea, Endocrinological and

Ophthalmological Complications.

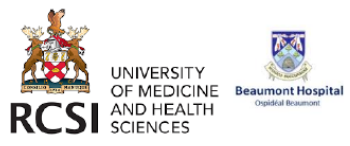

Fionn Slattery ${ }^{1,2}$, Mohsen Javadpour ${ }^{1,2,3}$

${ }^{1}$ National Neurosurgical Centre, Beaumont Hospital, Dublin 9

${ }^{2}$ Royal College of Surgeons in Ireland, 123 St. Stephen's Green, Dublin 2

${ }^{3}$ Trinity College Dublin, University of Dublin, Dublin 2

\section{Outcomes of the Extended, Endonasal Approach for Adult Craniopharyngioma}

\section{INTRODUCTION}

Craniopharyngioma is a rare, embryonic, epithelial malformation of cells derived from Rathke's pouch or from metaplasia of the pituitary stalk. ${ }^{1}$ The mainstay of management of adult craniopharyngioma is controversial. Achieving as close to gross total resection is of paramount importance. Clasically, the trans-cranial approach was used however, more recently the endoscopic, endonasal approach has gained popularity.

Owing to the comparative rarity of adult craniopharyngioma, little data exists on operative, endocrinological or ophthalmological outcomes of the endoscopic, endonasal approach

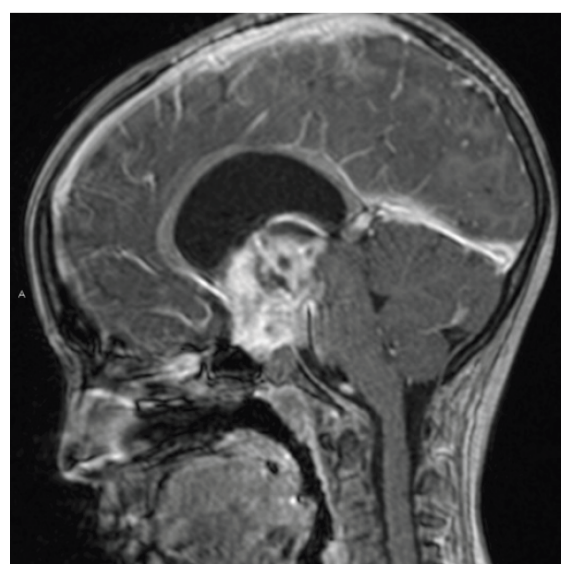

Fig. 1: Sagittal T1+Gad MRI showing a solid/cystic mass in the suprasellar region

\section{OBJeCtIVe} consistent with Craniopharyngioma

Our 10-year retrospective review was performed in order to elucidate the ophthalmological, endocrinological, radiological and operative outcomes in adult onset craniopharyngioma.

\section{Methodology}

A 10-year retrospective review of all adult patients who underwent the extended, endoscopic, endonasal approach for adult craniopharyngioma. Ophthalmological and endocrinological outcomes were recorded along with postoperative complications.

Specifically the occurrence of CSF rhinorrhoea, neurological deficits, shunt dependency, meningitis or infection, need for CSF diversion and mortality were recorded.

Additionally, data were collected whether or not a gross total resection was achieved, along with radiologist interpretation of the postoperative imaging.

\section{RESULTS}

20 adult patients underwent endoscopic, endonasal surgery for craniopharyngioma between 2011 - 2021.

See QR code for full, formatted data

- Ophthalmological: 50\% experienced improvement in VA, 70\% had an improvement in VF

- Endocrinological: 45\% were panhypopituitary postoperatively, 70\% developed permanent Diabetes Insipidus

- CSF Rhinorrhoea: $20 \%$ developed a CSF leak with $50 \%$ of these developing a meningitis

- Other: There was no mortality, neurological deficit or stroke postoperatively

\section{CONCLUSION}

- The endoscopic, endonasal approach is effective at decompressing optic apparatus and improving visual outcomes.

- Our cohort had rates of anterior pituitary endocrine dysfunction that is in keeping with the currently published body of literature following endoscopic, endonasal pituitary surgery. ${ }^{2}$

- Our rate of CSF leak is in keeping with the figure quoted in the literature, which is approximately $18 \%{ }^{3,4,5}$. All of these were repaired endoscopically.

- Occurrence rate of CSF leak is decreasing as new techniques are utilised for skull-base closure such as the Haddad flap and multilayered closure. 
VA

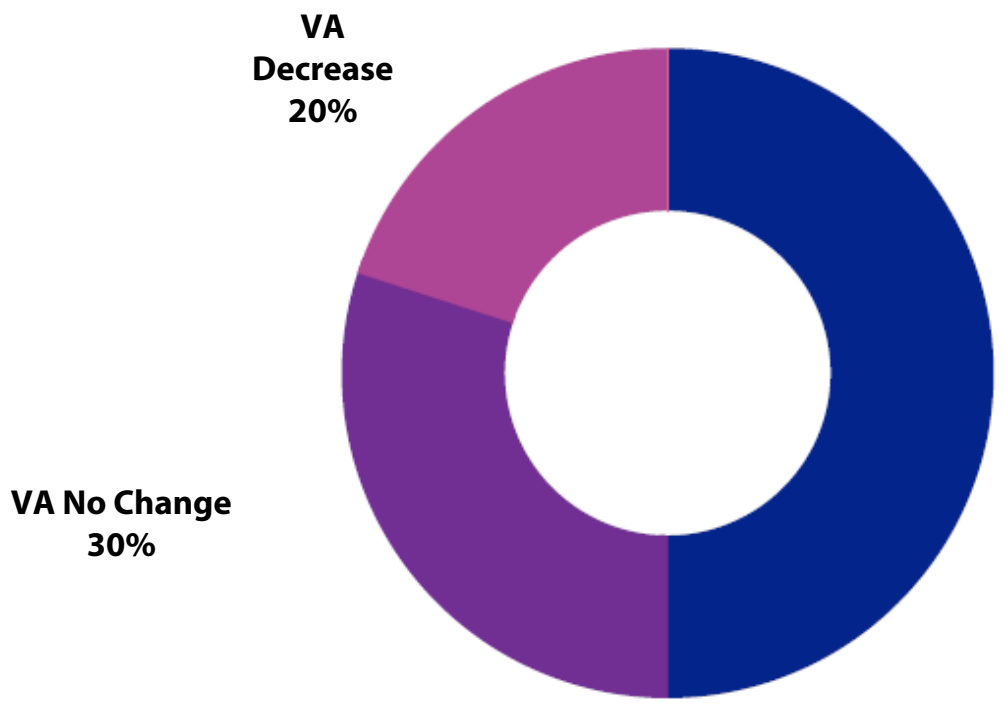

VA Increase

$50 \%$

Fig. 2: Visual Acuity (VA) Outcomes

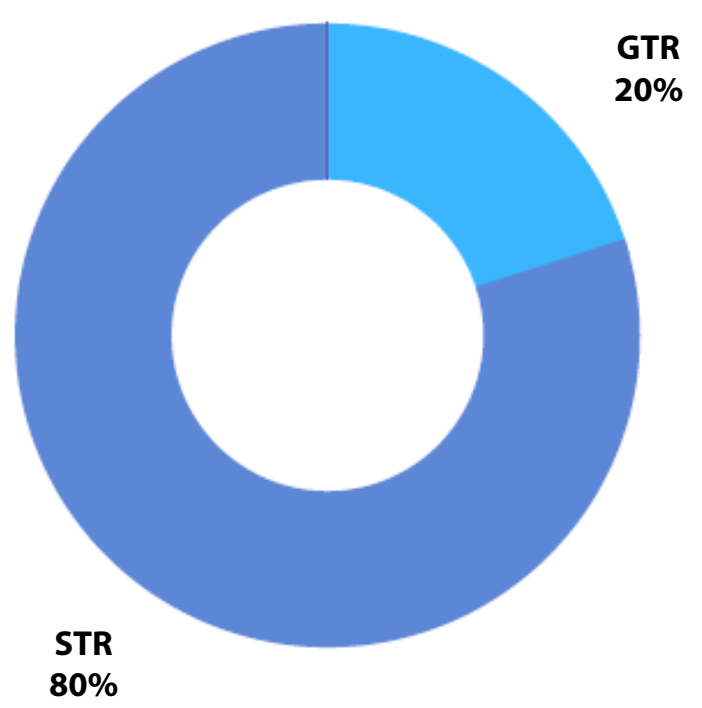

Fig. 3: Extent of Resection (STR = Subtotal Resection, GTR = Gross Total Resection)

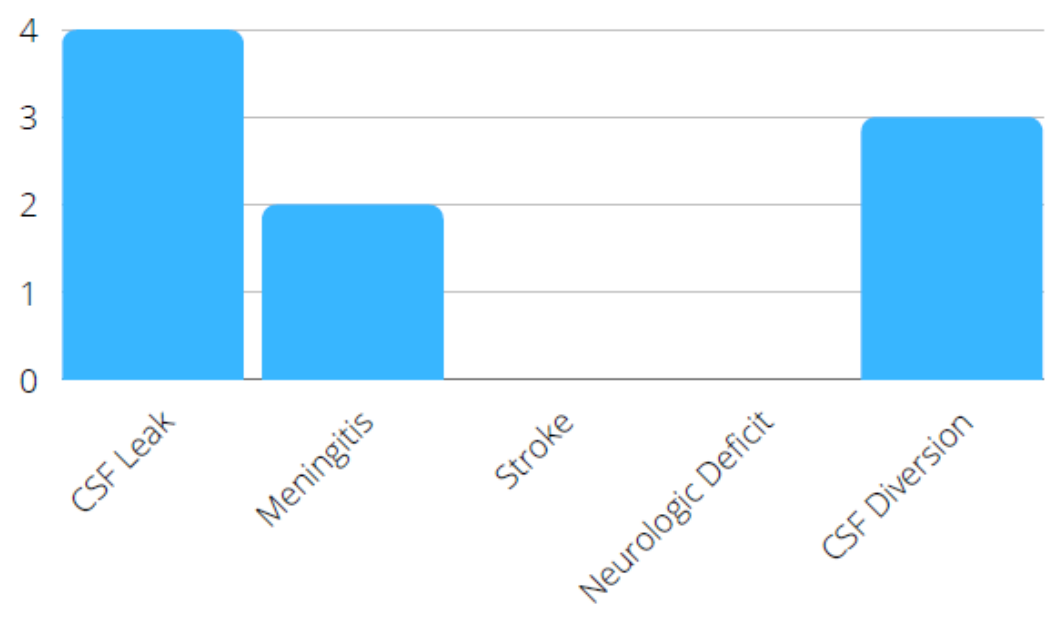

Fig. 4: Postoperative Complications 


\section{FUTURE DiRECTIONS}

We are currently working to compare our endoscopic, endonasal data directly with trans-cranial data over the past 20 years with respect to:

- Endocrinological

- Ophthalmological

- CSF rhinorrhoea

- Rates of recurrence

- Other postoperative complications

\section{REFERENCES}

1. Dandurand C, Sepehry AA, Asadi Lari MH, Akagami R, Gooderham P. Adult Craniopharyngioma: Case Series, Systematic Review, and Meta-Analysis. Neurosurgery. 2018;83(4):631-41.

2. Campbell PG, McGettigan B, Luginbuhl A, Yadla S, Rosen M, Evans JJ. Endocrinological and ophthalmological consequences of an initial endonasal endoscopic approach for resection of craniopharyngiomas. Neurosurg Focus [Internet]. 2010 Apr;28(4):E8.

3. Fomichev D, Kalinin P, Kutin M, Sharipov O. Extended Transsphenoidal Endoscopic Endonasal Surgery of Suprasellar Craniopharyngiomas. World Neurosurg [Internet]. 2016;94:181-7.

4. Koutourousiou M, Gardner PA, Fernandez-Miranda JC, Tyler-Kabara EC, Wang EW, Snyderman CH. Endoscopic endonasal surgery for craniopharyngiomas: surgical outcome in 64 patients. J Neurosurg [Internet]. 2013 Nov;119(5):1194-207.

5. Gardner PA, Kassam AB, Snyderman CH, Carrau RL, Mintz AH, Grahovac S, et al. Outcomes following endoscopic, expanded endonasal resection of suprasellar craniopharyngiomas: a case series. J Neurosurg [Internet]. 2008 Jul;109(1):6-16. 


\section{A Novel 6 Case Series of Biphenotypic Sinonasal Sarcoma}

Katerina Green ${ }^{1}$, Eric Farrell ${ }^{2}$, Adrien Gendre ${ }^{2}$, Justin Hintze ${ }^{2}$, Helen Barrett ${ }^{2}$, James Paul O’Neill ${ }^{2}$, Peter Lacy², Neville Shine ${ }^{2}$ ${ }^{1}$ The Royal College of Surgeons in Ireland, ${ }^{2}$ Beaumont Hospital

\section{INTRODUCTION}

Biphenotypic sinonasal sarcoma (BSNS) was first described by Lewis et al. in 2012. Previously known as low-grade sinonasal sarcoma with neural and myogenic features, this histopathological diagnosis is both rare and novel and prompting a call for research. BSNS is described as a slow progressing tumor that typically originates in the ethmoid sinuses or nasal cavity and presents with non-specific, mass related symptoms. BSNS was previously, and still often is misdiagnosed as a variety of alternative low-grade mesenchymal tumors such as fibrosarcomas, malignant peripheral nerve sheath tumors, among others. This is likely attributable to immunohistochemical positivity for S100 and SMA. Presented in this study are 6 novel cases of BSNS diagnoses from Dublin, Ireland. This study aims to summarise and compare these cases to trends in the existing literature.

\section{MethodS AND MATERIALS}

Permission was sought and granted from the hospital board. Cases of BSNS were identified in a retrospective fashion using a pathology database. The cases were diagnosed over a period of 6 years (2015 to 2021) with an average follow-up period of 28.8 months. All cases diagnosed as BSNS were included. Patient paper charts as well as online imaging and lab records were reviewed. All radiology and pathology reports were reported by consultants. Demographic details, pathology reports, staining pattern and radiological features were recorded. A literature review of "biphenotypic sinonasal sarcoma" and "low-grade sinonasal sarcoma with neural and myogenic features" was conducted using Pub-Med to inform a comparison database.

\section{RESULTS}

Table 1: Patient and Tumor Characteristics, - = missing data

\begin{tabular}{|l|l|l|l|l|l|l|}
\hline Case \# & $\begin{array}{l}\text { Age at } \\
\text { Present } \\
\text { ation }\end{array}$ & $\begin{array}{l}\text { Male/ } \\
\text { Female }\end{array}$ & Presenting Complaint & Location & $\begin{array}{l}\text { Extrasinonasal } \\
\text { Extension }\end{array}$ & $\begin{array}{l}\text { Initial } \\
\text { Histopathological } \\
\text { Differential Diagnosis }\end{array}$ \\
\hline 1 & 48 & F & $\begin{array}{l}\text { Obstruction, } \\
\text { occipital pain, } \\
\text { headaches, epistaxis }\end{array}$ & $\begin{array}{l}\text { Left nasal } \\
\text { cavity }\end{array}$ & No & $\begin{array}{l}\text { Squamous cell } \\
\text { carcinoma, inverting } \\
\text { papilloma }\end{array}$ \\
\hline 2 & 64 & F & $\begin{array}{l}\text { Epistaxis, right sided } \\
\text { nasal polyposis }\end{array}$ & $\begin{array}{l}\text { Posterior } \\
\text { ethmoid }\end{array}$ & No & $\begin{array}{l}\text { Sarcoma or } \\
\text { schwannoma, BSNS }\end{array}$ \\
\hline 3 & 40 & M & $\begin{array}{l}\text { Single generalized } \\
\text { tonic clonic seizure }\end{array}$ & $\begin{array}{l}\text { Anterior } \\
\text { ethmoid }\end{array}$ & $\begin{array}{l}\text { Yes, involving } \\
\text { frontal lobe } \\
\text { (image 1) }\end{array}$ & $\begin{array}{l}\text { Esthesioneuro- } \\
\text { blastoma }\end{array}$ \\
\hline 4 & 50 & M & $\begin{array}{l}\text { Global headache, } \\
\text { epistaxis, foul } \\
\text { odour/discharge }\end{array}$ & $\begin{array}{l}\text { Anterior } \\
\text { ethmoid }\end{array}$ & Yes, skull base & $\begin{array}{l}\text { Schwannoma, } \\
\text { olfactory } \\
\text { neuroblastoma }\end{array}$ \\
\hline 5 & - & F & - & $\begin{array}{l}\text { Ethmoid sinus } \\
\text { and middle } \\
\text { turbinate }\end{array}$ & No & - \\
\hline 6 & - & M & $\begin{array}{l}\text { Nasal congestion, } \\
\text { nasal polyposis }\end{array}$ & $\begin{array}{l}\text { Anterior } \\
\text { turbinate }\end{array}$ & No & - \\
\hline
\end{tabular}

\section{Discussion}

- The demographic distribution this series of 6 patients was 1:1 male:female, however, the literature reports a female predominance

- The reported mean age of diagnosis is within the $5^{\text {th }}$ decade of life, in our series the mean age at diagnosis was 50.5 years

- In this series, the ethmoid sinuses were the most affected subsites of the sinonasal tract which is in keeping with the trends seen in larger series

- The matrix of presenting complaints amongst our cohort included common sinonasal complaints associated with benign conditions, however, there were a considerable number of red flags amongst this population that should alert the clinician towards a more sinister cause

- Although generally indolent, one of our cases of BSNS demonstrated the tumor's ability to invade beyond the sinonasal tract and dura causing considerable morbidity; a feature not previously described

- BSNS consistently stains positive for S100 and SMA and negative for SOX10, this remained true in this cohort of patients, barring the positivity for SOX10 in Case 4 which requires further investigation, as there are no cases of SOX10 positive BSNS in existing literature

- The presence of PAX3 mutations has been found to be highly sensitive and specific for BSNS, in our series, Case 3 demonstrated diffuse nuclear positivity for PAX3, PAX3 report was not included in other cases

Table 2: Histologic staining of specimens diagnosed as BSNS, $Y=$ Yes, positive *Case 3 showed diffuse nuclear positivity for PAX3

\begin{tabular}{|l|l|l|l|}
\hline Case \# & $\begin{array}{l}\text { S100 } \\
+\end{array}$ & $\begin{array}{l}\text { SMA } \\
+\end{array}$ & $\begin{array}{l}\text { SOX10 } \\
+\end{array}$ \\
\hline 1 & $\mathrm{Y}$ & $\mathrm{Y}$ & - \\
\hline 2 & $\mathrm{Y}$ & $\mathrm{Y}$ & - \\
\hline $3^{*}$ & $\mathrm{Y}$ & $\mathrm{Y}$ & - \\
\hline 4 & $\mathrm{Y}$ & $\mathrm{Y}$ & $\mathrm{Y}$ \\
\hline
\end{tabular}

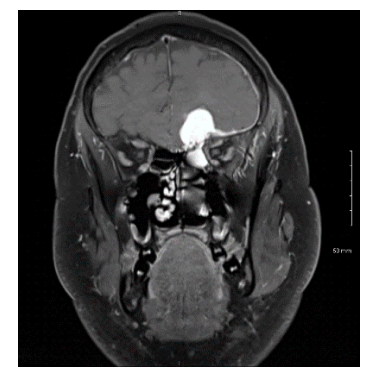

Fig. 1: Extrasinonasal, intracranial extension of BSNS in Case 3

- All cases are being followed with clinical, endoscopic and radiological examinations as these lesions have a propensity to recur in $30 \%$ of cases with majority recurring within 5 years. Our mean follow up date is 28.8 months, ranging from 1-6 years and to date we have not observed a recurrence

- This paper demonstrates consistency in our findings with reported diagnostic and histopathologic cases. While this entity is generally believed to be indolent, our cases demonstrate manifestations with significant morbidity

- Close cooperation between multiple disciplines and thorough excision with adjuvant therapies will likely form the mainstay of this pathology

The demographic distribution of our series of 6 patients was 1:1 male to female, the literature reports a female to male predominance however. This may come to pass with a larger series. The reported mean age of diagnosis is thought to be around the 5th decade of life, in our series the mean age at diagnosis was...

The ethmoid sinuses were the most commonly affected subsites of the sinonasal tract in our series, this is in keeping with other trends seen in larger series. 
The matrix of presenting complaints amongst our cohort included the more common sinonasal complaints associated with benign conditions such as nasal congestion and nasal blockage. However, there were a considerable number of red flags amongst our population that should alert the clinician to a more sinister cause.

Although BSNS is generally thought to be indolent, one of our cases demonstrates the ability for this tumour to invade beyond the confines of the sinonasal tract and cause considerable morbidity. This is a feature of the condition not previously described.

BSNS overwhelmingly stains positive for S100, SMA and negative for SOX10. This was true for our cohort of patients. The presence of PAX3 mutations has also been found to be highly sensitive and specific for BSNS, however in our series.... (what happened with these in our series?)

All of our cases are being followed up with clinical/endoscopic and radiological examinations. These lesions have a propensity to recur in $30 \%$ of cases with the majority recurring in 5 years. Our mean follow up to date is 28.8 months with a range of 1-6 years. To date we have not had a recurrence.

This paper demonstrates consistency in our findings across diagnostic and histopathologic cases. While this entity is generally thought to be indolent, as shown from our cases, it can manifest with significant morbidity. Close cooperation between multiple disciplines and thorough surgical excision with adjuvant therapies will likely form the mainstay of this condition.

\section{REFERENCES}

1. Lewis JT, Oliveira AM, Nascimento AG, et al. Low-grade sinonasal sarcoma with neural and myogenic features: a clinicopathologic analysis of 28 cases. Am J Surg Pathol. 2012;36:517-25.

2. Kakkar A, Rajeshwari M, Sakthivel P, et al. Biphenotypic sinonasal sarcoma: a series of six cases with evaluation of role of beta-catenin immunohistochemistry in differential diagnosis. Ann Diagn Pathol. 2018;33:6-10.

3. Kominsky E, Boyke AE, Madani D, Kamat A, Schiff BA, Agarwal V. Biphenotypic Sinonasal Sarcoma: A Case Report and Review of Literature. Ear, Nose \& Throat Journal. April 2021. doi:10.1177/0145561321999196

4. Gross, J., Fritchie, K. Soft Tissue Special Issue: Biphenotypic Sinonasal Sarcoma: A Review with Emphasis on Differential Diagnosis. Head and Neck Pathol 14, 33-42 (2020). https://doiorg.proxy.library.rcsi.ie/10.1007/s12105-019-01092-4

5. Lisa M. Rooper, Shih-Chiang Huang, Cristina R. Antonescu, William H. Westra, Justin A. Bishop, Biphenotypic sinonasal sarcoma: an expanded immunoprofile including consistent nuclear $\beta$-catenin positivity and absence of SOX10 expression, Human Pathology, Volume 55, 2016, https://doi.org/10.1016/j.humpath.2016.04.009. 


\section{INTRODUCTION}

There is currently a limited evidence base for recommending treatments for non-allergic rhinitis (NAR). Capsaicin is the bioactive component of chili peppers, which are plants of the genus, Capsicum. Capsaicin is a capsaicinoid and a selective agonist of transient receptor potential vanilloid 1 (TRPV1), which is a peripheral nociceptor expressed in the nasal mucosa. The ability of capsaicin to desensitise TRPV1 has led to investigation of its therapeutic use in NAR (Fokkens et al., 2016).

AIM

The primary aim of this review was to determine if capsaicin is an effective treatment for NAR, considering its effect on symptoms and various objective outcomes.

\section{METHODS}

\section{Search Methods for Identification of Studies}

Systematic searches were performed on electronic databases. Specific search strategies were developed for each database.

\section{ELIGIBILITY CRITERIA}

Types of studies: randomised controlled trials (RCTs); quasirandomised controlled trials; non-randomised controlled trials (NRCTs) and uncontrolled studies.

\section{TYPES OF PARTICIPANTS}

Inclusion criteria: adults (over 16 years of age) with any type of non-allergic rhinitis.

Exclusion criteria: adolescents (under 16 years of age); patients with allergic, infectious or autoimmune rhinitis; patients with rhinitis due to anatomic abnormalities and patients with acute or chronic rhinosinusitis.

Types of intervention: topical intranasal capsaicin. Where applicable, the following comparators were considered: no treatment; placebo; other topical or systemic treatments; a combination of two or more topical or systemic treatments; different capsaicin regimens.

\section{Types of Outcome Measures}

Primary outcomes: overall nasal symptom scores; individual nasal symptom scores; therapeutic response evaluation (TRE) scores; objective measurements and adverse events.

Secondary outcomes: analyses of nasal mucosal biopsies and nasal secretions.

\section{Data Collection and Analysis}

Reports obtained from searches of databases were merged using EndNote 20 Reference Manager. Duplicate records were removed. The titles and abstracts of the remaining reports were screened. Reports which did not meet the inclusion criteria were excluded. The remaining reports were screened for eligibility by two independent reviewers. Data was extracted using a prespecified data collection form. WebPlotDigitizer was used to extract data from figures. We assessed the quality of the evidence using the Grading of Recommendations Assessment, Development and Evaluation (GRADE) guidelines (Schünemann et al., 2013).

\section{MEAsures of TReatment Effect}

When capsaicin was compared to another intervention, we calculated measures of treatment effect for overall nasal symptoms. For continuous outcomes, we calculated the mean difference (MD). For dichotomous outcomes, we calculated the risk ratio (RR). We also reported $95 \%$ confidence intervals $(\mathrm{Cl})$. We were only able to calculate measures of effect in three studies.

\section{DATA SYNTHESIS}

Our main objective was to provide a narrative synthesis of the findings of the included studies, supported by statistical analysis of results. We calculated the concentration of capsaicin in $\mathrm{mmol} / \mathrm{l}$ for ease of comparison across studies.

\begin{tabular}{|c|c|c|c|}
\hline Study & Study design & Treatment arm(s) & $\begin{array}{l}\text { Quality of } \\
\text { Evidence* }\end{array}$ \\
\hline \begin{tabular}{|lr} 
Lacroix \\
et al. \\
$(1991)$
\end{tabular} & $\begin{array}{l}\text { Uncontrolled } \\
\text { study }\end{array}$ & $\begin{array}{l}\text { All patients were treated with } \mathbf{3 . 3} \\
\mathbf{~ m m o l} / \mathbf{L} \text { capsaicin intranasal spray. } \\
\text { Capsaicin was applied once a week } \\
\text { for } 5 \text { weeks. }\end{array}$ & Very low \\
\hline $\begin{array}{l}\text { Marabi } \\
\text { ni et al. } \\
(1991)\end{array}$ & $\begin{array}{l}\text { Uncontrolled } \\
\text { study }\end{array}$ & $\begin{array}{l}\text { All patients were treated with } \mathbf{0 . 4 9} \\
\mathbf{m m o l} / \mathbf{L} \text { capsaicin intranasal spray. } \\
2 \text { sprays of capsaicin per nostril } 3 \\
\text { times a day, at } 1 \text { hour intervals, for } 3 \\
\text { consecutive days. }\end{array}$ & Very low \\
\hline $\begin{array}{l}\text { Stjärne } \\
\text { et al. } \\
(1991)\end{array}$ & $\begin{array}{l}\text { Uncontrolled } \\
\text { study }\end{array}$ & $\begin{array}{l}\text { All patients were treated with } \mathbf{0 . 0 3} \\
\mathbf{m m o l} / \mathbf{L} \text { capsaicin. Capsaicin was } \\
\text { applied once a day for } 3 \text { consecutive } \\
\text { days; cotton wool soaked with } \\
\text { solution was applied to each nostril. }\end{array}$ & Very low \\
\hline $\begin{array}{l}\text { Filiaci } \\
\text { et al. } \\
(1994)\end{array}$ & $\begin{array}{l}\text { Uncontrolled } \\
\text { study }\end{array}$ & $\begin{array}{l}\text { All patients were treated with } \mathbf{0 . 0 3} \\
\mathbf{m m o l} / \mathrm{L} \text { capsaicin. Capsaicin was } \\
\text { applied once a week for } 5 \text { weeks } \\
\text { (mechanism of delivery not } \\
\text { specified). }\end{array}$ & Very low \\
\hline \begin{tabular}{|l|} 
Blom \\
et al. \\
$(1997)$
\end{tabular} & $\begin{array}{l}\text { Double-blind } \\
\text { randomised } \\
\text { placebo- } \\
\text { controlled trial }\end{array}$ & $\begin{array}{l}\text { 0.1 } \mathbf{~ m m o l} / \mathrm{L} \text { capsaicin intranasal } \\
\text { spray or placebo was applied every } 2 \\
\text { or } 3 \text { days for } 2 \text { weeks ( } 7 \text { treatments in } \\
\text { total). }\end{array}$ & Moderate \\
\hline \begin{tabular}{|l|} 
Havas \\
and \\
Taplin \\
(2002)
\end{tabular} & $\begin{array}{l}\text { Quasi- } \\
\text { randomised } \\
\text { controlled trial }\end{array}$ & $\begin{array}{l}\text { Group one - } 2 \text { sprays of budesonide } \\
\text { in each nostril twice daily for } 2 \\
\text { weeks, after initial treatment at clinic. } \\
\text { Group two }-2 \text { sprays of capsaicin in } \\
\text { each nostril once a week for } 4 \text { weeks } \\
\text { using } \mathbf{0 . 0 1} \mathbf{~ m m o l / L ~ c a p s a i c i n , ~ a f t e r ~} \\
\text { initial treatment at clinic with } \mathbf{0 . 0 3} \\
\text { mmol/L capsaicin. }\end{array}$ & Moderate \\
\hline \begin{tabular}{|l|} 
Van \\
Rijswij \\
k et al. \\
$(2003)$
\end{tabular} & $\begin{array}{l}\text { Double-blind } \\
\text { randomised } \\
\text { placebo- } \\
\text { controlled trial }\end{array}$ & $\begin{array}{l}\text { Group A - patients were treated with } \\
\mathbf{0 . 1} \text { mmol/L capsaicin intranasal } \\
\text { spray } 5 \text { times on one day at } 1 \text { hour } \\
\text { intervals; after } 2 \text { weeks, patients } \\
\text { received a total of } 5 \text { placebo } \\
\text { treatments once every second or } \\
\text { third day, over } 10 \text { days. } \\
\text { Group B - patients were treated with } \\
\text { placebo } 5 \text { times on one day at } 1 \text { hour } \\
\text { intervals; after } 2 \text { weeks, patients } \\
\text { received a total of } 5 \text { treatments with } \\
\mathbf{0 . 1} \text { mmol/L capsaicin once every } \\
\text { second or third day, over } 10 \text { days. }\end{array}$ & High \\
\hline \begin{tabular}{|l|} 
Ciabatt \\
i and \\
D'Asca \\
nio \\
$(2009)$
\end{tabular} & $\begin{array}{l}\text { Quasi- } \\
\text { randomised } \\
\text { placebo- } \\
\text { controlled trial }\end{array}$ & $\begin{array}{l}\text { Group A - } \mathbf{0 . 0 4 7} \mathbf{~ m m o l} / \mathbf{L} \text { capsaicin; } \\
\text { group B }-\mathbf{0 . 0 9 4} \mathbf{~ m m o l} / \mathbf{L} \text { capsaicin; } \\
\text { group C }-\mathbf{0 . 1 9} \mathbf{~ m m o l} / \mathrm{L} \text { capsaicin; } \\
\text { group D - placebo. } \\
1 \text { spray of capsaicin or placebo per } \\
\text { nostril, } 3 \text { times a day, at } 30 \text { minute } \\
\text { intervals, for } 3 \text { consecutive days. }\end{array}$ & Moderate \\
\hline \begin{tabular}{|l|} 
Van \\
Gerven \\
et al. \\
$(2013)$ \\
\end{tabular} & $\begin{array}{l}\text { Uncontrolled } \\
\text { study }\end{array}$ & $\begin{array}{l}2 \text { applications of } \mathbf{0 . 1} \mathbf{~} \mathbf{~ m o l} / \mathbf{L} \\
\text { capsaicin intranasal spray per nostril, } \\
5 \text { times on a single day at } 1 \text { hour } \\
\text { intervals. }\end{array}$ & Low \\
\hline \begin{tabular}{|l|} 
Van \\
Gerven \\
et al. \\
$(2017)$ \\
\end{tabular} & $\begin{array}{l}\text { Double-blind } \\
\text { randomised } \\
\text { placebo- } \\
\text { controlled trial }\end{array}$ & $\begin{array}{l}2 \text { applications of } \mathbf{0 . 1} \mathbf{~} \mathbf{m m o l} / \mathbf{L} \\
\text { capsaicin intranasal spray or placebo } \\
\text { per nostril, } 5 \text { times on a single day, at } \\
1 \text { hour intervals. }\end{array}$ & High \\
\hline \begin{tabular}{|l|} 
Van \\
Gerven \\
et al. \\
$(2021)$
\end{tabular} & $\begin{array}{l}\text { Double-blind } \\
\text { randomised } \\
\text { placebo- } \\
\text { controlled trial }\end{array}$ & $\begin{array}{l}\text { Placebo [1] / placebo [2]; placebo [1] } \\
/ \quad \mathbf{0 . 0 0 1} \mathbf{~ m m o l / L ~ c a p s a i c i n ~ [ 2 ] ; ~} \\
\text { placebo [1]/ } \mathbf{0 . 0 1} \mathbf{~ m m o l / L ~ c a p s a i c i n} \\
{[2] ; \mathbf{0 . 1} \mathbf{~ m m o l / L ~ c a p s a i c i n ~ [ 1 ] ~} /} \\
\text { placebo [2] } \\
5 \text { applications of capsaicin or } \\
\text { placebo intranasal spray at first } \\
\text { hospital visit at } 1 \text { hour intervals [1], } \\
\text { followed by daily application of } \\
\text { capsaicin or placebo (2 sprays per } \\
\text { nostril) for } 4 \text { weeks [2]. }\end{array}$ & Moderate \\
\hline \begin{tabular}{|l|} 
Zebda \\
et al. \\
$(2021)$
\end{tabular} & $\begin{array}{l}\text { Double-blind } \\
\text { randomised } \\
\text { placebo- } \\
\text { controlled trial }\end{array}$ & $\begin{array}{l}5 \text { consecutive applications of } \mathbf{0 . 1} \\
\mathbf{m m o l} / \mathrm{L} \text { capsaicin intranasal spray at } \\
1 \text { hour intervals on a single day. }\end{array}$ & Moderate \\
\hline
\end{tabular}




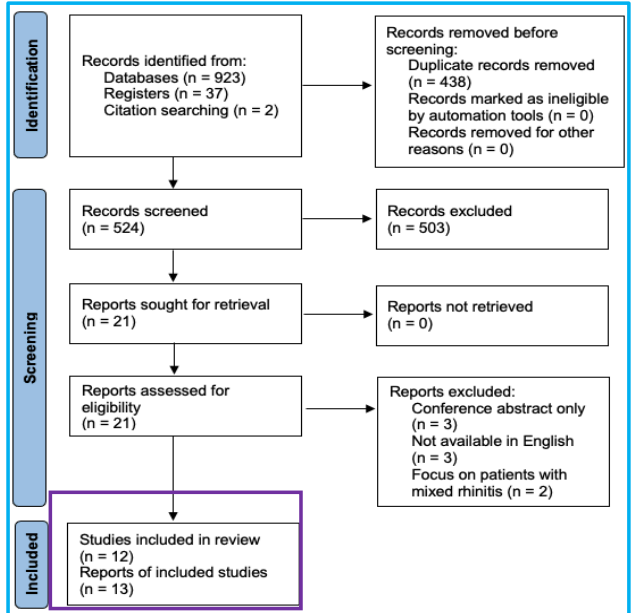

Fig. 1: Flow chart of the included studies ( $n=$ number of studies) (Page et al., 2021).

\begin{tabular}{|c|c|}
\hline Study & St \\
\hline $\begin{array}{l}\text { Lacroix et al. } \\
\text { (1991) }\end{array}$ & $\begin{array}{l}\text { Significant decrease in nasal mucosal blood flow } \\
\text { (measured by LDF) and nasal airways resistance } \\
\text { (measured by anterior rhinomanometry) after fifth } \\
\text { capsaicin spray compared to after first capsaicin spray. }\end{array}$ \\
\hline $\begin{array}{l}\text { Van R } \\
\text { et al. }(2\end{array}$ & $\begin{array}{l}\text { No significant decrease in PNIF post-treatment. } \\
\text { Significant decrease in nasal secretion and nasal } \\
\text { patency after CDA provocation after capsaicin } \\
\text { treatment compared to baseline. }\end{array}$ \\
\hline $\begin{array}{l}\text { Jan Gerven } \\
\text { t al. (2013) }\end{array}$ & $\begin{array}{l}\text { icant difference in PNIF after CDA provocation } \\
\text { after capsaicin treatment. }\end{array}$ \\
\hline $\begin{array}{l}\text { Van Gerven } \\
\text { et al. (2017) }\end{array}$ & $\begin{array}{l}\text { Threshold for NMP response to AITC shifted toward } \\
\text { significantly higher concentrations up to } 3 \text { months, but } \\
\text { not } 6 \text { months, after treatment with capsaicin compared } \\
\text { to placebo. }\end{array}$ \\
\hline $\begin{array}{l}\text { Zebda } \\
\text { (2021) }\end{array}$ & $\begin{array}{l}\text { eant difference in OD (measured by optical OR) } \\
\text { se to capsaicin challenge after treatment with } \\
\text { compared to placebo. }\end{array}$ \\
\hline & \\
\hline
\end{tabular}

\begin{tabular}{|l|l|}
\hline $\begin{array}{l}\text { Table 3. Summary of results: analyses of nasal mucosal biopsies and } \\
\text { nasal secretions }\end{array}$ \\
\hline Study & Summary of Results \\
\hline $\begin{array}{l}\text { Lacroix et al. } \\
\text { (1991) }\end{array}$ & $\begin{array}{l}\text { Significant decrease in CGRP-LI in nasal mucosal } \\
\text { biopsies after fifth capsaicin spray compared to after first } \\
\text { capsaicin spray. }\end{array}$ \\
\hline $\begin{array}{l}\text { Blom et al. } \\
\text { (1997) }\end{array}$ & $\begin{array}{l}\text { No significant difference in the number of } \\
\text { inflammatory cells in nasal mucosal biopsies before or } \\
\text { after treatment with capsaicin or placebo. }\end{array}$ \\
\hline $\begin{array}{l}\text { Van Gerven } \\
\text { et al. (2013) }\end{array}$ & $\begin{array}{l}\text { CGRP levels in nasal secretions were below the } \\
\text { detection limit in all samples. Significant difference in } \\
\text { expression of TRPV1 and TRPM8 in nasal mucosal } \\
\text { biopsies } 3 \text { months after capsaicin treatment compared } \\
\text { to baseline. SP levels in nasal secretions in patients with } \\
\text { IR were reduced to the levels of HCs after capsaicin } \\
\text { treatment. }\end{array}$ \\
\hline $\begin{array}{l}\text { Van Gerven } \\
\text { et al. (2017) }\end{array}$ & $\begin{array}{l}\text { No significant difference in expression of TRPV1 or } \\
\text { TRPM8 in nasal mucosal biopsies } 1 \text { month or } 6 \text { months } \\
\text { after capsaicin treatment. }\end{array}$ \\
\hline $\begin{array}{l}\text { Van Gerven } \\
\text { et al. (2021) }\end{array}$ & $\begin{array}{l}\text { Significant decrease in SP levels in nasal secretions } 3 \\
\text { months after the initiation of treatment with } 0.1 \text { mmol/L } \\
\text { capsaicin and } 0.01 \text { mmol/L capsaicin compared to } \\
\text { placebo. No significant decrease in SP levels in nasal } \\
\text { secretions after treatment with } 0.001 \text { mmol/L capsaicin. }\end{array}$ \\
\hline
\end{tabular}

Calcitonin gene-related peptide-like immunoreactivity (CGRP-LI), calcitonin gene-related peptide (CGRP), transient receptor potential vanilloid (TRPV1), transient receptor potential melastatin 8 (TRPM8), substance $P$ $(S P)$, idiopathic rhinitis $(I R)$, healthy control (HC).

\begin{tabular}{|c|c|}
\hline Study & Summary of Results \\
\hline \begin{tabular}{|l|} 
Lacroix et al. \\
(1991)
\end{tabular} & $\begin{array}{l}\text { Significant decrease in individual nasal symptom VAS } \\
\text { scores immediately and } \mathbf{6} \text { months after capsaicin } \\
\text { treatment compared to baseline; VAS scores were greater } \\
6 \text { months than immediately after treatment but were still } \\
\text { lower than baseline scores. }\end{array}$ \\
\hline $\begin{array}{l}\text { Marabini } \\
\text { et al. (1991) }\end{array}$ & $\begin{array}{l}\text { Significant decrease in overall nasal symptoms VAS score } \\
\text { up to } 1 \text { month after capsaicin treatment compared to } \\
\text { baseline. }\end{array}$ \\
\hline \begin{tabular}{|l|} 
Stjärne et al. \\
(1991)
\end{tabular} & $\begin{array}{l}\text { Significant decrease in VAS scores for nasal congestion } \\
\text { and rhinorrhoea up to } \mathbf{3} \text { months after capsaicin } \\
\text { treatment compared to baseline; VAS scores increased } 6 \\
\text { months after treatment and were greater than baseline } \\
\text { scores. }\end{array}$ \\
\hline \begin{tabular}{|l|}
$\begin{array}{l}\text { Filiaci et al. } \\
\text { (1994) }\end{array}$ \\
\end{tabular} & $\begin{array}{l}\text { Significant decrease in VAS scores for overall nasal } \\
\text { symptoms, nasal congestion, sneezing, nasal itching and } \\
\text { local nasal pain up to } 6 \text { months and rhinorrhoea up to } 3 \\
\text { months after capsaicin treatment compared to baseline. } \\
\text { VAS scores were greater } 6 \text { months than } 1 \text { month after } \\
\text { capsaicin treatment but were still lower than baseline } \\
\text { scores. }\end{array}$ \\
\hline $\begin{array}{l}\text { Blom et al. } \\
\text { (1997) }\end{array}$ & $\begin{array}{l}\text { Significant decrease in overall nasal symptoms VAS score } \\
\text { up to } 9 \text { months after capsaicin treatment compared to } \\
\text { baseline; VAS score was greater } 9 \text { months than } 3 \text { months } \\
\text { after treatment but was still lower than baseline. } \\
\text { Significant decrease in overall nasal symptoms VAS score } \\
\text { in patients treated with capsaicin compared to placebo } 2 \\
\text { weeks (MD: -3.29, 95\% Cl: }-\mathbf{5 . 2 0 , - 1 . 3 8 ) , ~} 3 \text { months (MD: } \\
-\mathbf{- 3 . 6 7 , 9 5 \% ~ C I : ~ - 5 . 4 0 , - 1 . 9 4 ) ~ a n d ~} 9 \text { months after } \\
\text { treatment (MD: }-\mathbf{3 . 4 6 , 9 5 \% ~ C l : ~ - 5 . 5 1 , ~ - 1 . 4 1 ) . ~ N o ~} \\
\text { significant difference in DRC scores for individual nasal } \\
\text { symptoms or the mean sumscore before, during or after } \\
\text { treatment with capsaicin compared to placebo. }\end{array}$ \\
\hline \begin{tabular}{|l|} 
Havas and \\
Taplin (2002)
\end{tabular} & $\begin{array}{l}\text { Significant decrease in nasal congestion VAS score during } \\
\text { the last } \mathbf{3} \text { days of treatment in capsaicin group } \\
\text { compared to budesonide group. No significant difference } \\
\text { in VAS scores for headache, post-nasal drip, rhinorrhoea, } \\
\text { nasal congestion or sore throat. }\end{array}$ \\
\hline \begin{tabular}{|l|} 
Van Rijswijk \\
et al. (2003)
\end{tabular} & $\begin{array}{l}\text { Significant decrease in VAS scores for overall nasal } \\
\text { symptoms, nasal congestion, rhinorrhoea and sneezing } \\
\text { per week in both groups treated with capsaicin compared } \\
\text { to baseline; no significant constant difference in VAS } \\
\text { scores between groups. Improvement in median VAS } \\
\text { scores continued up to } 9 \text { months post-treatment. }\end{array}$ \\
\hline $\begin{array}{l}\text { Ciabatti and } \\
\text { D'Ascanio } \\
\text { (2009) }\end{array}$ & $\begin{array}{l}\text { Significant difference in resolution of symptoms in group } \\
\text { C (0.19 mmol/L capsaicin) compared to group D (placebo) } \\
\text { (RR: } \mathbf{3 . 1 7}, \mathbf{9 5 \%} \text { Cl: } \mathbf{1 . 3 8}, \mathbf{7 . 2 9}) \text {. No significant difference in } \\
\text { resolution of symptoms in group A (0.047 mmol/L } \\
\text { capsaicin) (RR: } \mathbf{1 . 5 0}, \mathbf{9 5 \%} \mathrm{Cl}: \mathbf{0 . 5 8}, \mathbf{3 . 9 1} \text { ) or group B } \\
\text { (0.094 mmol/L capsaicin) (RR: } \mathbf{2 . 0 0 , 9 5 \% ~ C l : ~} \mathbf{0 . 8 1}, \mathbf{4 . 9 3}) \\
\text { compared to group D (placebo). }\end{array}$ \\
\hline 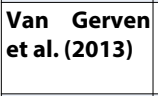 & $\begin{array}{l}\text { Significant decrease in VAS scores for nasal congestion, } \\
\text { sneezing and rhinorrhoea up to } 3 \text { months after treatment } \\
\text { compared to baseline. }\end{array}$ \\
\hline \begin{tabular}{|l|} 
Van Gerven \\
et al. (2017)
\end{tabular} & $\begin{array}{l}\text { Significant decrease in VAS scores for overall nasal } \\
\text { symptoms } 1 \text { month (MD: } \mathbf{- 8 . 9 3 , 9 5 \% ~ C l : ~} \mathbf{- 1 4 . 7 2 , - 3 . 1 4 ) , 3} \\
\text { months (MD: -8.41, 95\% Cl: } \mathbf{- 1 5 . 1 6 , - 1 . 6 6 )} \text { and } 6 \\
\text { months (MD: } \mathbf{- 1 0 . 8 2 , 9 5 \% ~ C l : ~} \mathbf{- 1 8 . 6 1 , - 3 . 0 3 ) ~ a f t e r ~} \\
\text { treatment with capsaicin compared to placebo. }\end{array}$ \\
\hline $\begin{array}{l}\text { Van Gerven } \\
\text { et al. (2021) }\end{array}$ & $\begin{array}{l}\text { Significant decrease in VAS scores for nasal congestion } 3 \\
\text { months after the initiation of treatment with } 0.1 \mathrm{mmol} / \mathrm{L} \\
\text { capsaicin and } 0.01 \mathrm{mmol} / \mathrm{L} \text { capsaicin compared to } \\
\text { placebo. No significant decrease in VAS scores after } \\
\text { treatment with } 0.001 \mathrm{mmol} / \mathrm{L} \text { capsaicin compared to } \\
\text { placebo. }\end{array}$ \\
\hline \begin{tabular}{|l} 
Zebda et al. \\
(2021)
\end{tabular} & $\begin{array}{l}\text { Significant difference in overall nasal symptoms VAS score } \\
3 \text { months, but not } 1 \text { month, after treatment with } \\
\text { capsaicin compared to placebo. }\end{array}$ \\
\hline
\end{tabular}

\section{LIMITATIONS}

A control group was not included in some studies; this may limit the reliability of the results. Sample sizes were small, therefore the results may be skewed. Van Gerven et al. (2021) did not use the same treatment regimen to compare concentrations of capsaicin and failed to report results at 24 weeks. Doses were not specified in all studies. Variation in the concentration of capsaicin, treatment regimen, setting and outcomes hinders direct comparison of results. Heterogeneity of patients also precludes direct comparison of results; inclusion and exclusion criteria varied greatly. 
We had to extract data from figures using software. We were only able to calculate measures of effect in three studies and were unable to perform a meta-analysis. 0

\section{CONCLUSION}

Capsaicin may be recommended as a treatment for NAR, given that other pharmacological therapies may be ineffective. More RCTs with larger cohorts are required to fully elucidate the therapeutic potential of capsaicin. Stringent inclusion and exclusion criteria are necessary to isolate a homogenous population of patients with NAR who may benefit from treatment with capsaicin. The lowest concentration of capsaicin shown to be effective was 0.01 $\mathrm{mmol} / \mathrm{L}$. Repeated applications of capsaicin on one day may be as effective as applications over multiple days. Capsaicin may need to be reapplied six months after treatment to maintain its therapeutic effect.

\section{REFERENCES}

1. Blom, H. M., Van Rijswijk, J. B., Garrelds, I. M. et al. (1997). 'Intranasal capsaicin is efficacious in non-allergic, noninfectious perennial rhinitis. A placebo-controlled study' Clinical and Experimental Allergy, 27(7), pp. 796-801.

2. Blom, H. M., Severijnen, L., Van Rijswijk, J. B. et al. (1998). 'The long-term effects of capsaicin aqueous spray on the nasal mucosa'. Clinical and Experimental Allergy, 28(11), pp. 1351 1358.

3. Ciabatti, P. G. and D'Ascanio, L. (2009). 'Intranasal Capsicum spray in idiopathic rhinitis: a randomized prospective application regimen trial'. Acta Oto-Laryngologica, 129(4), pp. 367-371.

4. Clavirate (2021). EndNote 20 Reference Manager.

5. Filiaci, F., Zambetti, G., Ciofalo, A. et al. (1994). 'Local treatment of aspecific nasal hyperreactivity with capsaicin'. Allergologia et Immunopathologia, 22(6), pp. 264-268.

6. Fokkens, W., Hellings, P. and Segboer, C. (2016). 'Capsaicin for Rhinitis'. Current Allergy and Asthma Reports, 16(8), p. 60.

7. Havas, T. E. and Taplin, M. A. (2002). 'Intranasal neuropeptide depletion using topical capsaicin for the control of symptoms in non-allergic, non-infectious perennial rhinitis (NANIPER)'. Australian Journal of Otolaryngology, 5(2), pp. 107-113.

8. Lacroix, J. S., Buvelot, J. M., Polla, B. S. et al. (1991). 'Improvement of symptoms of non-allergic chronic rhinitis by local treatment with capsaicin'. Clinical and Experimental Allergy, 21(5), pp. 595-600.
9. Marabini, S., Ciabatti, P. G., Polli, G. et al. (1991). 'Beneficial effects of intranasal applications of capsaicin in patients with vasomotor rhinitis'. European Archives of Oto-RhinoLaryngology, 248(4), pp. 191-194.

10. Page, M. J., McKenzie, J. E., Bossuyt, P. M. et al. (2021). 'The PRISMA 2020 statement: an updated guideline for reporting systematic reviews'. British Medical Journal, 372, n71.

11. Schünemann, H. et al. (2013). 'GRADE handbook for grading quality of evidence and strength of recommendations'. The GRADE Working Group. Available online at: guidelinedevelopment.org/handbook.

12. Stjärne, P., Lundblad, L., Änggård, A. et al. (1991). 'Local Capsaicin Treatment of the Nasal Mucosa Reduces Symptoms in Patients with Nonallergic Nasal Hyperreactivity'. American Journal of Rhinology, 5(4), pp. 145-151.

13. Van Gerven, L., Alpizar, Y. A., Wouters, M. M. et al. (2013). 'Capsaicin treatment reduces nasal hyperreactivity and transient receptor potential cation channel subfamily $\mathrm{V}$, receptor 1 (TRPV1) overexpression in patients with idiopathic rhinitis'. Journal of Allergy and Clinical Immunology, 133(5), pp. 1332-1339.

14. Van Gerven, L., Alpizar, Y. A., Steelant, B. et al. (2017). 'Enhanced chemosensory sensitivity in patients with idiopathic rhinitis and its reversal by nasal capsaicin treatment'. Journal of Allergy and Clinical Immunology, 140(2), pp. 437-336.

15. Van Gerven, L., Steelant, B., Cools, L. et al. (2021). 'Low-dose capsaicin $(0.01 \mathrm{mM})$ nasal spray is equally effective as the current standard treatment for idiopathic rhinitis: A randomized, double-blind, placebo-controlled trial'. Journal of Allergy and Clinical Immunology, 147(1), pp. 397-400.

16. Van Rijswijk, J. B., Boeke, E. L., Keizer, J. M. et al. (2003). 'Intranasal capsaicin reduces nasal hyperreactivity in idiopathic rhinitis: A double-blind randomized application regimen study'. Allergy: European Journal of Allergy and Clinical Immunology, 58(8), pp. 754-761.

17. WebPlotDigitizer Version 4.4 Released (November 28, 2020). Available online at: https://automeris.io/WebPlotDigitizer.

18. Zebda, D., Jiang, Z. Y., Gibson, M. M. et al. (2021). 'Doubleblinded randomized prospective trial of intranasal capsaicin treatment for nonallergic rhinitis'. International Forum of Allergy and Rhinology, 11(1), pp. 24-30. 


\section{Computed Tomography Analysis of the Anterior Ethmoid Genu of the Frontal Recess}

Dr. Kugan Ramen ${ }^{1}$, Dr. Revadi Govindraju ${ }^{1}$, Dr. Anish Patil², Dr. Karl James ${ }^{3}$, Dr. Mohd Zulkiflee ${ }^{1}$, Dr. Mohammad Nazri Bin Md Shah ${ }^{1}$

${ }^{1}$ Department of Otorhinolaryngology, Faculty of Medicine, University Malaya,

${ }^{2}$ New Cross Hospital, Wolverhampton,

${ }^{3}$ Sligo University Hospital

\section{BACKGROUND}

A thorough knowledge of the anatomical variations of the frontal recess and frontal sinus and recognition of the endoscopic landmarks are vital in performing safe and effective endoscopic sinus surgery. This radiological study revisits an anatomical landmark in the frontal recess that could serve as a guide to the frontal sinus.

\section{ObJective}

This study assessed the prevalence of "Anterior Ethmoid Genu" (AEG), its morphology and relationship with frontal sinus drainage pathway (FSDP). High resolution computed tomography (HRCT) scans of non-diseased sinonasal complexes were used for multiplanar reconstruction with the Horos software for this study.

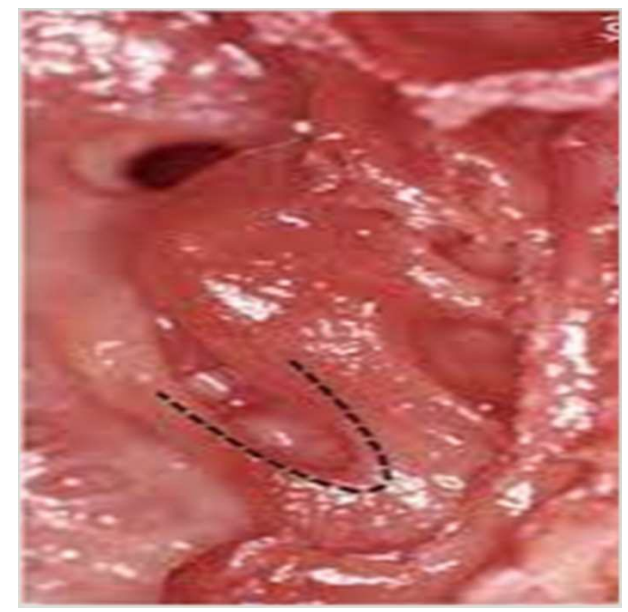

Anatomical dissection of the anterior ethmoidal genu

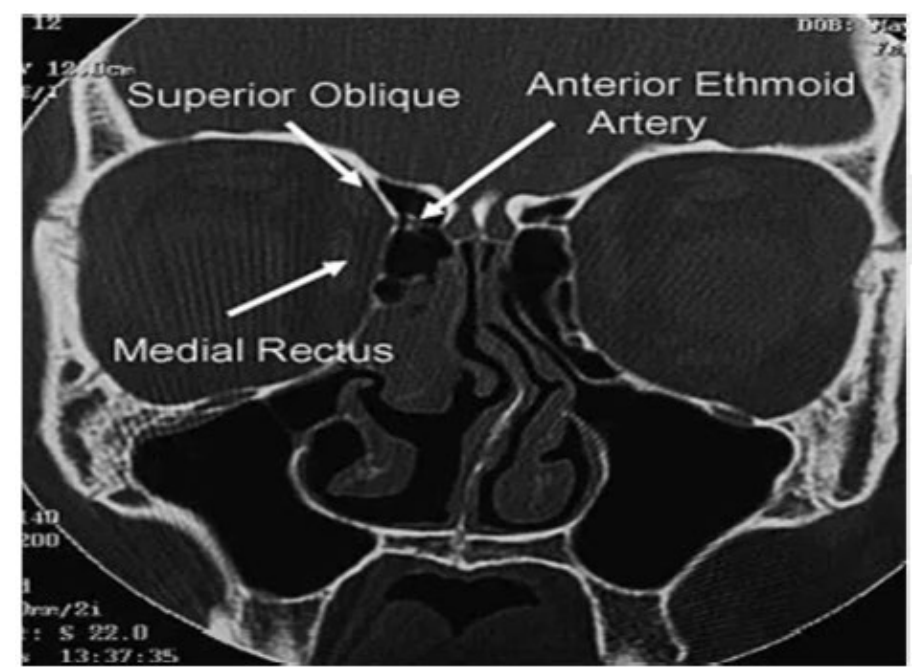

Coronal CT showing the anterior ethmoid artery exiting the orbit and crossing the ethmoid sinus at the point where the medial rectus and

\section{RESULTS} superior oblique muscles converge.

This study showed that AEG was consistently present in all 102 HRCT anatomical sides studied independent of age, gender, and race. Its position lies within the FSDP, and the drainage pathway was medial to it in 98/102 (96\%) of the cases. TheAEG sometimes formed a recess bound by the lamina papyracea laterally and anteriorly by the uncinate process and posteriorly by the bulla ethmoidalis. Further analysis showed that the distance of AEG to frontal ostia is determined by the height of the posterior wall of the agger nasi cell rather than its volume or other walls.

\section{CONCLUSION}

This study confirms AEG a constant anatomical structure positioned within FSDP. The added description of AEG found in this study explains the anatomical connection between agger nasi, uncinate process and bulla ethmoidalis and its structural organization. This complements other known landmarks in endoscopic frontal sinus surgery. 


\section{Correlation of Tegmen Height in Cholesteatoma Ear Compared to Contralateral Normal Ear}

Dr. Winton Chong ${ }^{1}$, Dr. Anish Patil2 ${ }^{2}$ Prof. Jayanthi Kulasegarah ${ }^{1}$

1 UMSC, Kuala Lumpar

${ }^{2}$ New Cross Hospital, Wolverhaton

\section{OBJECTIVE}

The Aim of this study is to correlate the tegmen height in unilateral cholesteatoma compared to the contralateral normal ear, and to classify the tegmen height in patients with unilateral cholesteatoma using the lateral semicircular canal as the landmark.

\section{METHOD}

High-resolution computed tomography (HRCT) scan of temporal bones of 56 patients with unilateral primary acquired Cholesteatoma confirmed intraoperatively were analysed. The highest, lowest and the difference of tegmen height was measured in millimetre $(\mathrm{mm})$ at the coronal plane, and compared using statistical analysis.

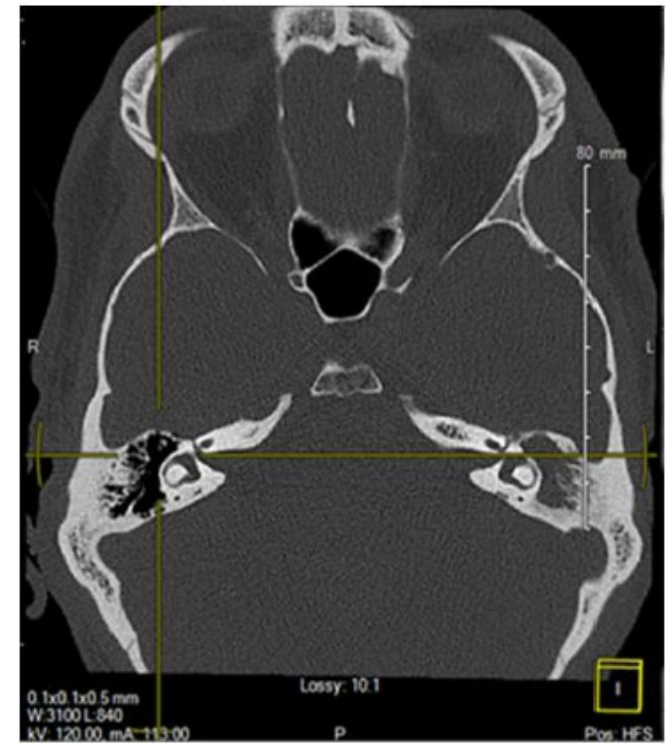

Fig. 1: Axial bone window HRCT temporal bone scan at the level of LSCC. The horizontal axis refers to the

\section{RESULTS}

coronal plane that traversed both tubes of the LSCC.

The data was normally distributed, the highest tegmen height of cholesteatoma ears and contralateral normal ears was $5.82 \pm 1.75$ and $5.99 \pm 1.63$ respectively. The lowest tegmen height of cholesteatoma ears and contralateral normal ears was $4.02 \pm 1.95$ and $4.13 \pm 1.60$ respectively. The difference tegmen height in cholesteatoma ears and contralateral normal ears was $1.80 \pm 1.21$ and $1.94 \pm 0.98$ respectively. By using independent $T$-test, there was no significant different in highest tegmen height $(p=0.601)$, lowest tegmen height $(p=0.749)$ and difference of tegmen height $(p=0.513)$ between cholesteatoma ear and the contralateral normal ear. In total, 35 (62.5\%) have low TH and 21 (37.5\%) have high TH. Whereas $34(60.7 \%)$ of the contralateral normal ears have low TH and 22 (39.3\%) have high TH. Also, $51 \%$ (29 patients) with low tegmen in the cholesteatoma ear, have low tegmen in the contralateral normal ear. Whereas, patients with high tegmen in both cholesteatoma and contralateral normal ears was $28.6 \%$ ( 16 patients).

\begin{tabular}{|l|c|c|c|}
\hline Cholesteatoma ear & Contralateral normal ear & Number of patients & Percentage \\
\hline aLow TH & Low TH & 29 & $51.8 \%$ \\
\hline bHigh TH & High TH & 16 & $28.6 \%$ \\
\hline High TH & Low TH & 5 & $8.9 \%$ \\
\hline Low TH & High TH & 6 & $10.7 \%$ \\
\hline \multicolumn{2}{|r|}{ Total } & 56 & $100 \%$ \\
\hline
\end{tabular}

Tegmen height classification of cholesteatoma ears and the contralateral ears

Abbreviations: $\mathrm{TH}$, tegmen height

aLow TH defined as the lowest TH of $\leq 4.5 \mathrm{~mm}$

bHiah $\mathrm{TH}$ defined as the lowest $\mathrm{TH}$ of $>4.5 \mathrm{~mm}$ 


\begin{tabular}{|c|c|c|c|}
\hline \multicolumn{4}{|c|}{ Tegmen Height in Cholesteatoma and Normal ears ( $\mathrm{mm})$} \\
\hline & Mean & $t$-test & p-value (2-tailed) \\
\hline TH Lowest (Cholesteatoma) (mm) & $4.02 \pm 1.95$ & -0.32 & 0.749 \\
\hline TH Lowest (Normal) (mm) & $4.13 \pm 1.60$ & & \\
\hline TH Highest (Cholesteatoma) (mm) & $5.82 \pm 1.75$ & -0.525 & 0.601 \\
\hline TH Highest (Normal) (mm) & $5.99 \pm 1.63$ & & \\
\hline *TH Difference (Cholesteatoma) & $1.80 \pm 1.21$ & -0.657 & 0.513 \\
\hline TH Difference (Normal) & $1.94 \pm 0.98$ & & \\
\hline
\end{tabular}

Dependent variables (outcomes) / Tegmen height in cholesteatoma and normal ears

\section{CONCLUSION}

Our result showed that the tegmen height in cholesteatoma and the contralateral normal ear have no significant difference.

RESEARCH POSTERPRESENTATION DESIGN @ 2015

www.PosterPresentations.com 


\section{From Kidney Stone to Parathyroid Carcinoma: A Case Presentation and Review of the Literature}

R Hill ${ }^{1,2}$, F O’Duffy 1,3

${ }^{1}$ Department of Otolaryngology Head and Neck Surgery, St Vincent's University Hospital

${ }^{2}$ The Royal College of Surgeons in Ireland

${ }^{3}$ University College Dublin School of Medicine

\section{INTRODUCTION}

Parathyroid carcinoma (PTC) accounts for less than $1 \%$ of primary hyperparathyroidism. Diagnosis is predominantly via postoperative histology following parathyroidectomy for suspected adenoma. The predominant cause of morbidity and mortality in PTC result from severe hypercalcaemia, and management of the same remains a key treatment target. Surgery remains the key treatment, and adjuvant therapies have not been found to be beneficial.

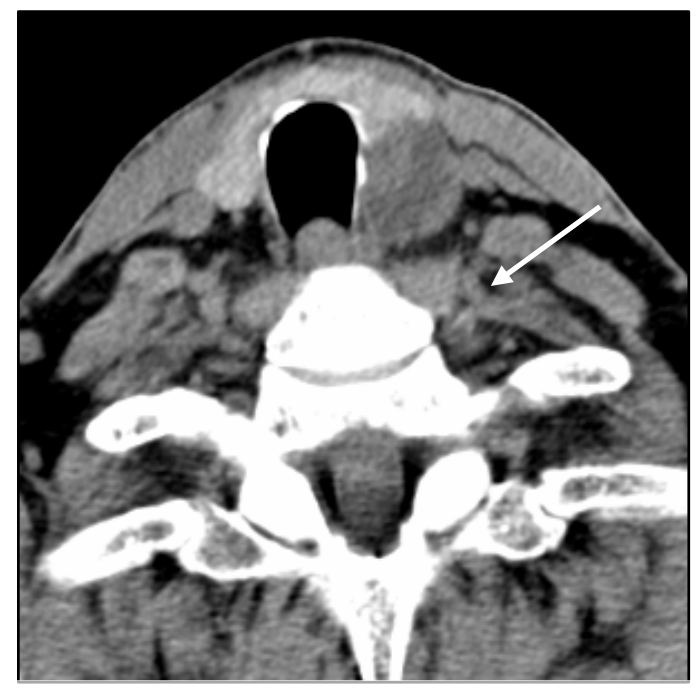

Fig. 1: 4 phase CT neck revealing a $2.8 \times 2.2 \times 3.3 \mathrm{~cm}$ mixed solid cystic lesion at the inferior pole of the left thyroid gland (arrow).

\section{Case Presentation}

We present the case of a 67 year old gentleman who was referred to the ENT clinic with systemic effects of hypercalcaema including nephrolithiasis, fatigue and malaise, and biochemical primary hyperparathyroidism. His initial serum calcium was 2.67 and a PTH of 28 on cinacalcet. His background medical history was only significant for recurrent pulmonary embolism requiring warfarin therapy.

Initial workup for his primary hyperparathyroidism included a sestamibi scan which did not reveal any functioning parathyroid adenoma, though in the context of his elevated PTH a four phase CT neck was performed revealing an extra-thyroid lesion (fig 1).

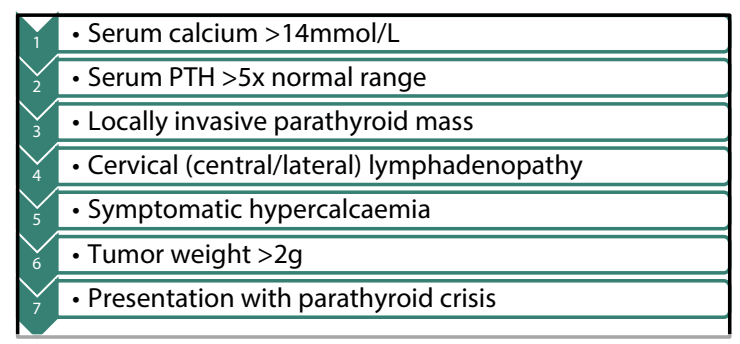

Fig . 2: Factors increasing the risk of parathyroid carcinoma ${ }^{4,5}$

\section{TREATMENT}

Following imaging findings (fig 1 ) and MDT discussion, the decision was made to proceed to surgical resection as primary treatment for his primary hyperparathyroidism. Intraoperatively a left inferior parathyroid mass was observed, and exhibited some adherence to the left thyroid lobe.

Post-operatively, he had some dysphonia attributable to the adherence of the mass and the subsequent excision of the lesion from the thyroid. Histopathology returned a diagnosis of parathyroid carcinoma, and further MDT discussion advised re-resection of the left thyroid lobe.

No adjuvant chemoradiotherapy was given, and given the indecision in the literature regarding follow up a baseline post-treatment PET-CT scan was performed revealing no residual disease or metastatic disease.

\section{LITERATURE}

PTC is an exceptionally rare cause of primary hyperparathyroidism, with incidences ranging from $0.5-1 \%$ of all cause primary hyperparathyroidism ${ }^{1}$. Unlike adenoma which has a predilection for females, PTC appears to have equal incidence in both sexes ${ }^{1}$. Predominantly, patients present with severe symptomatic hypercalcaemia, present in $90 \%$ of patients ${ }^{2}$. Figure 2 highlights key factors that raise suspicion of PTC.

Treatment of PTC is limited to surgical resection to provide optimal oncological control. Some advocate for enbloc resection of the parathyroid gland, thyroid lobe, and central level VI lymph nodes in cases of pre-operative diagnosis'. Unfortunately, PTC is relatively radioresistant, and due to the rarity of this pathology no effective chemotherapy regimens have been tested and found to be efficacious. In cases of post-operative PTC diagnosis, repeat resection is mandated.

\section{REFERENCES}

1. Rodrigo JP et al. Parathyroid cancer: An update. Cancer Treatment Reviews. 2020 86:102012

2. Akirov A. et al. The Clinicopathological Spectrum of Parathyroid Carcinoma. Frontiers in Endocrinology. 2019 10:731

3. Mohebati A. et al. Parathyroid Carcinoma Challenges in Diagnosis and Treatment. Hematol Oncol Clin N Am. 2012 26:1221-1238

4. Schaapveld $\mathrm{M}$ et al. Incidence and prognosis of parathyroid gland carcinoma: A population based study in The Netherlands estimating the preoperative diagnosis. The American Journal of Surgery. 2011 202:590-597

5. Robert JH et al. Primary Hyperparathyroidism: Can Parathyroid Carcinoma Be Anticipated on Clinical and Biochemical Grounds? Report of Nine Cases and Review of the Literature. Annals of Surgical Oncology. 2005 12(7):1-7
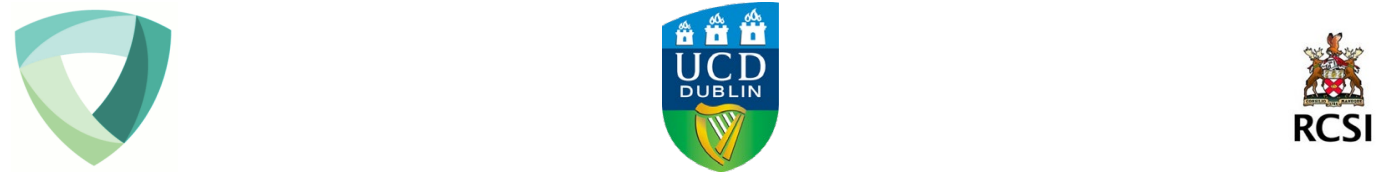


\section{Gender Differences in Irish Rhinoplasty Patients}

SL Gillanders, M Walsh, S Abdulrahman, Tallaght University Hospital

\section{OBJECTIVES}

Careful patient selection is key for ensuring cosmetic and functional satisfaction in the rhinoplasty patient cohort. For otolaryngologists functional outcomes were historically paramount however, cosmetic adjustments are becoming standard in most rhinology practices. On reviewing our service experience interestingly, we found we had a high proportion of male patients in our cohort. This encouraged us to research gender specific differences in anatomy, surgical techniques, expectations and outcomes.

\section{METHODS}

We performed a retrospective chart review of patients who have had rhinoplasty surgery under a single otolaryngology consultant with a special interest in rhinoplasty. Patient demographics, GP referrals, patient concerns/goals, treatment details, and outcomes were collected including results of the 10-Item Standardized Cosmesis and Health Nasal Outcomes Survey for Functional and Cosmetic Rhinoplasty pre and post-surgery.

\begin{tabular}{|c|c|c|c|c|c|c|}
\hline \multicolumn{7}{|c|}{ Over the past month, how much of a problem was the following: } \\
\hline & $\begin{array}{c}\text { No } \\
\text { problem }\end{array}$ & & & & & $\begin{array}{l}\text { Extreme } \\
\text { problem }\end{array}$ \\
\hline $\begin{array}{l}\text { 1. Having a blocked or obstructed } \\
\text { nose }\end{array}$ & 0 & 1 & 2 & 3 & 4 & 5 \\
\hline $\begin{array}{l}\text { 2. Getting air through my nose } \\
\text { during exercise }\end{array}$ & 0 & 1 & 2 & 3 & 4 & 5 \\
\hline 3. Having a congested nose & 0 & 1 & 2 & 3 & 4 & 5 \\
\hline $\begin{array}{l}\text { 4. Breathing through my nose } \\
\text { during sleep }\end{array}$ & 0 & 1 & 2 & 3 & 4 & 5 \\
\hline $\begin{array}{l}\text { 5. Decreased mood and self-esteem } \\
\text { due to my nose }\end{array}$ & 0 & 1 & 2 & 3 & 4 & 5 \\
\hline 6. The shape of my nasal tip & 0 & 1 & 2 & 3 & 4 & 5 \\
\hline 7. The straightness of my nose & 0 & 1 & 2 & 3 & 4 & 5 \\
\hline 8. The shape of my nose from the side & 0 & 1 & 2 & 3 & 4 & 5 \\
\hline 9. How well my nose suits my face & 0 & 1 & 2 & 3 & 4 & 5 \\
\hline 10. The overall symmetry of my nose & 0 & 1 & 2 & 3 & 4 & 5 \\
\hline
\end{tabular}

\section{Discussion}

Anatomical differences between the traditional male and female nose are important to consider when planning an individualised surgical procedure.

- Nasofrontal angle- male- $129^{\circ}$, female- $144.5^{\circ}$

- Radix-male-upper eyelid crease, female-just above the level of the pupil

- Projection- male- $34 \mathrm{~mm}$, female- $29.6 \mathrm{~mm}$

- Dorsal aesthetic lines- male- straight, female- concave

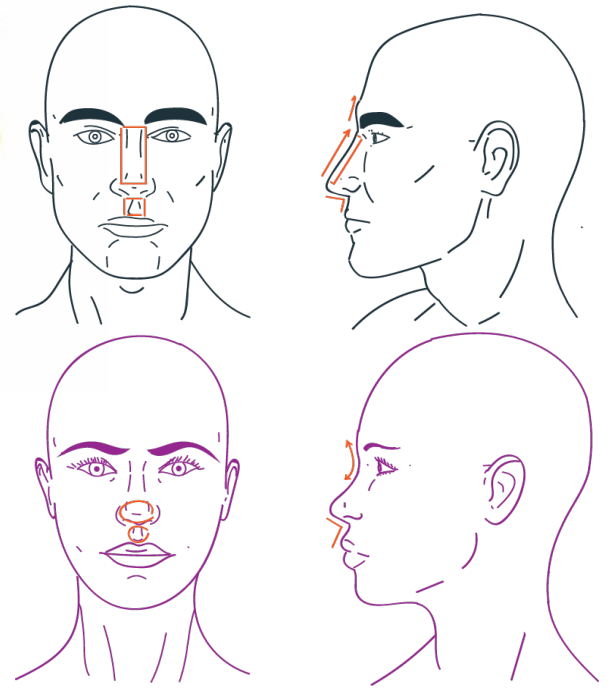

Overall, the male nose is often larger, with thicker skin and a wider base. Excessive reduction of the dorsum, narrowing of the dorsal aesthetic lines, and refinement of the nasal tip can lead to over feminisation of the male nose.

\section{RESULTS}

A total of 25 patients were identified. 5 patients were excluded due to language barriers and consent reasons. Of the 20 patients included 13 were male and 7 female. 16 cases were as a result of trauma (5 sports related, 4 assault, 7 accident) and 4 base line aesthetic complaints. All baseline aesthetic complaints were female patients (Pearson Chi-square $9.286 \mathrm{p}=0.002$ ) and all sports related injuries were male patients (Pearson Chi-square $3.59 \mathrm{p}=0.058$ ). Nasal obstruction was reported in all but one case. There was no statistically significant difference in the mean pre-operative symptom scores (29.31 vs 32.29 $p=0.559)$, change in symptom scores ( 23.25 vs 24.14 $\mathrm{p}=0.827$ ) or satisfaction score (8.69 vs $7.29 \mathrm{p}=0.089$ ) between male and female patients. The type of surgery performed did appear to have some variation between genders osteotomies were required more often in male patients $11 / 13$ versus female patients 3/7. (Pearson Chi-square $3.778 p=0.052$ ) and tip work was relatively more common in female patients $4 / 7$ versus $5 / 13$ however not significantly so. Sutures tended to be favoured in female patients and grafts in male patients.

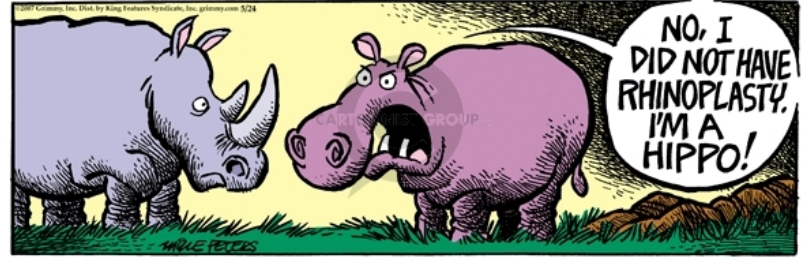

"SIMON" (single, immature, male, overly expectant, narcissistic) was coined by Gorney to warn against operating on this particularly difficult patient. In the literature the male aesthetic patient in general is known to have poorer satisfaction scores. Many authors report their male patients were more vague in both describing preoperative goals and post-operative concerns. Despite being more dissatisfied than their female counterparts, male patients were unable to specify their functional or cosmetic concern. Instead comments of emotion and regret were provided as explanation. In our study we did not find a statistical difference between male and female patients, this may be explained as the majority of cases were traumatic injuries with a heavily weighted functional concern.

\section{CONCLUSION}

Overall, both male and female patients within this group reported improved symptoms and high levels of satisfaction. There was no significant difference in any outcome analysed. Careful patient counselling and patient specific surgical planning help to achieve optimal outcomes. 


\section{REFERENCES}

1. Gorney M, Martello J. Patient selection criteria. Clin Plast Surg. 1999;26(1):37-40, vi.

2. Moubayed SP, loannidis JPA, Saltychev M, Most SP. The 10-Item Standardized Cosmesis and Health Nasal Outcomes Survey (SCHNOS) for Functional and Cosmetic Rhinoplasty. JAMA Facial Plast Surg. 2018;20(1):37-42.

3. Springer IN, Zernial O, Nölke F, Warnke PH, Wiltfang J, Russo PAJ, et al. Gender and Nasal Shape: Measures for Rhinoplasty. Plastic and Reconstructive Surgery. 2008;121(2):629-37.

4. Berli JU, Loyo M. Gender-confirming Rhinoplasty. Facial Plast Surg Clin North Am. 2019;27(2):251-60.

5. Wright MR. The male aesthetic patient. Arch Otolaryngol Head Neck Surg. 1987;113(7):724-7.

6. Khansa I, Khansa L, Pearson GD. Patient Satisfaction After Rhinoplasty: A Social Media Analysis. Aesthet Surg J. 2016;36(1):Np15 .

7. Khan N, Rashid M, Khan I, Ur Rehman Sarwar S, Ur Rashid H, Khurshid M, et al. Satisfaction in Patients After Rhinoplasty Using the Rhinoplasty Outcome Evaluation Questionnaire. Cureus. 2019;11(7):e5283-e.

8. Rohrich RJ, Janis JE, Kenkel JM. Male rhinoplasty. Plast Reconstr Surg. 2003;112(4):1071-85; quiz 86.

9. Shipchandler TZ, Sultan B, Ishii L, Boahene KD, Capone RB, Kontis TC, et al. Aesthetic analysis in rhinoplasty: surgeon vs. patient perspectives: A prospective, blinded study. American Journal of Otolarngology. 2013;34(2):93-8.

10.Spörri S, Simmen D, Briner HR, Jones N. Objective assessment of tip projection and the nasolabial angle in rhinoplasty. Arch Facial Plast Surg. 2004;6(5):295-8; discussion 9-300.

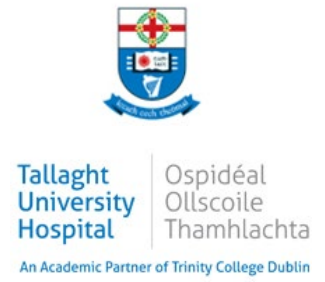


Interventions for the Prevention and Treatment of Persistent Post COVID-19 Olfactory Dysfunction - A Pair of Living Systematic Reviews

L O’ Byrne, K Webster, S Mackeith, C Philpott, C Hopkins, MJ Burton

Cochrane ENT Group

\section{ObJective}

Olfactory dysfunction (OD) is an early and sensitive marker of COVID-19 infection. Although self-limiting in the majority of cases, when hyposmia or anosmia persists it can have a profound effect on quality of life. Little guidance exists on the management of post-COVID-19 OD. We conducted two systematic reviews to identify interventions in use to either prevent or treat OD post COVID-19 infection and assess the evidence for these strategies. (O' Byrne 2021; Webster 2021)

\section{MethODS}

Using standard Cochrane methodological procedures, we included randomised controlled trials including participants who had symptoms of OD following COVID-19 infection.

- Those who had symptoms for less than four weeks were included in the Prevention review

- Those with symptoms over four weeks were included in the Treatment review Studies compared any intervention with no treatment or placebo.

\section{KEY RESULTS}

\section{Prevention review}

796 studies screened, 39 full text articles assessed $\rightarrow 1$ eligible (Abdelalim 2021)

100 participants, which compared an intranasal steroid spray to no intervention. Both groups also undertook olfactory training. Data were identified for only two of the prespecified outcomes for this review.

- Presence of normal olfactory function was self-assessed by the participants. The evidence is very uncertain about the effect of intranasal corticosteroids on recovery of sense of smell (Figure 1).

- Change in sense of smell the self-rated score for smell was reported at the endpoint of the study using a visual analogue scale. The median scores were 10 (interquartile range (IQR) 9 to 10) for the intervention group and 10 (IQR 5 to 10) for no intervention (very low-certainty evidence).

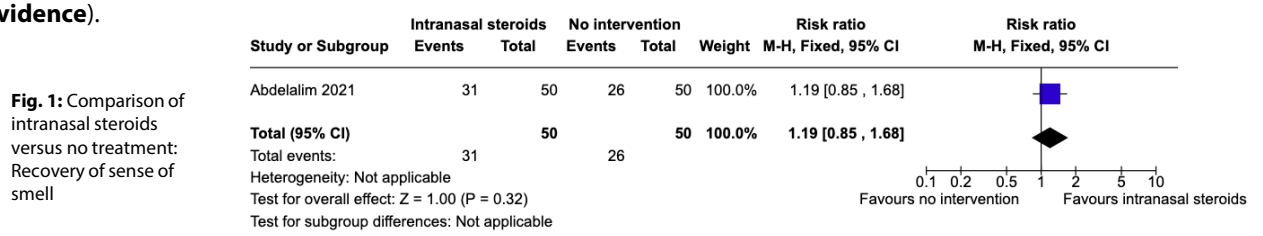

\section{Treatment Review}

\begin{tabular}{l} 
Outcomes assessed -Treatment review \\
Primary Outcomes \\
- Recovery of sense of smell \\
- Serious adverse effects \\
Secondase related quality of life \\
- Prevalence of parosmia \\
- Change in sense of smell \\
- Otherall quality of life \\
Outcomes assessed -Precention review \\
Primary Outcomes \\
The presence of normal olfactory \\
- function \\
- Cerious adverse effects \\
Secondary in sense of smell \\
- Prevalence of parosmia \\
- Change in sense of taste \\
- Oisease- related quality of life \\
\hline
\end{tabular}

796 studies screened, 39 full text articles assessed $\rightarrow 1$ eligible (Vaira 2020)

18 participants, which compared oral steroids combined with nasal irrigation (consisting of an intranasal steroid/mucolytic/decongestant solution) with no intervention. The Connecticut Chemosensory Clinical Research Centre (CCCRC) tool was used for psychophysical assessment of smell at baseline, 20 and 40 days.

- Recovery of sense of smell The evidence is very uncertain about the effect of this intervention on recovery of the sense of smell (Figure 2).

- Change in sense of smell at 40 days. This study reported an improvement in sense of smell in the intervention group from baseline (median improvement in CCCRC score 60, interquartile range (IQR) 40) compared to the control group (median improvement in CCCRC score 30, IQR 25) (1 study; 18 participants; very low-certainty evidence).

- Serious adverse events and other adverse events were not identified in any participants of this study; however, it is unclear how these outcomes were assessed.

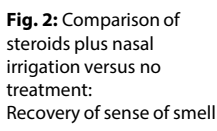

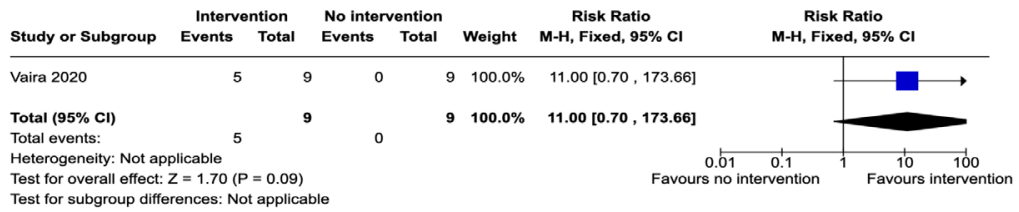

Test for subgroup differences: Not applicable

\section{CONCLUSION}

There is very limited evidence available on the efficacy and harms of prevention and treatment strategies for persistent olfactory dysfunction following COVID-19 infection. However, we have identified a number of ongoing trials in this area. As this is a living systematic review we will update the data regularly, as new results become available.

\section{REFERENCES}

1. O'Byrne 2021: O'Byrne L, Webster KE, MacKeith S, Philpott C, Hopkins C, Burton MJ. Interventions for the treatment of persistent post-COVID-19 olfactory dysfunction. Cochrane Database of Systematic Reviews 2021, Issue 7. Art. No.: CD013876. DOI: $10.1002 / 14651858$

2. Webster 2021 :Webster KE, O'Byrne L, MacKeith S, Philpott C, Hopkins C, Burton MJ. Interventions for the prevention of persistent post-COVID-19 olfactory dysfunction. Cochrane Database of Systematic Reviews 2021, Issue 7. Art. No.: CD013877. DOI: 10.1002/14651858.CD013877.pub2.

3. Abdelalim 2021 : Abdelalim AA, Mohamady AA, Elsayed RA, Elawady MA, Ghallab AF. Corticosteroid nasal spray for recovery of smell sensation in COVID-19 patients: a randomized controlled trial. American Journal of Otolaryngology 2021;422:102884. PMID: 33429174

4. Vaira 2020: Vaira LA, Hopkins C, Petrocelli M, Lechien JR, Cutrupi S, Salzano G, et al. Efficacy of corticosteroid therapy in the treatment of long-lasting olfactory disorders in COVID-19 patients. Rhinology 2020;59(1):21-5. PMID: 33290446

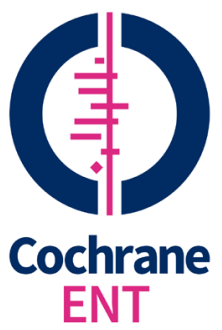


Irish Otolaryngological Head \& Neck Society (IOS)

62nd Annual Conference

October 2021

Centro Hospitalar Universitário do Porto, Portugal

Author's: Joana Raquel Costa, Sara Costa, Teresa Soares, Cecília Almeida e Sousa

\section{Obesity Risk Following Adenotonsillectomy}

\section{In Children With Down Syndrome}

\section{Objective}

Weight evolution after adenotonsillectomy is a topic that is widely debated in the literature, but with inconsistent results.

The purpose of this work is to understand if children with Down Syndrome have an increased risk for postoperative weight gain, comparing with non-syndromic children.

\section{MATERIAL AND METHODS}

This is a retrospective case-control study. Data were collected regarding age, gender, pathology that motivated the surgery and weight, at the time of the surgery and 10-12 months after the surgical intervention, in a total of 101 children (21 children with Down Syndrome - cases; and 80 non-syndromic children - controls).

\section{RESULTS}

Demographic data are shown in Figure 1. The pre- and post-operative percentiles are illustrated in Figure 2 and 3.

In general, a significant difference was observed between the percentiles in the preoperative and in the postoperative period $(p<0.001)$. However, no statistically significant difference was found when comparing children with Down Syndrome versus nonsyndromic $(p=0.123)$.

In addition, weight gain does not seem to be related to age group, children $\leq 5$ years versus $>5$ years $(p=0.682)$; with gender $(p=0.380)$; with the reason that led to the surgery, recurrent tonsillitis versus sleep-related disorders $(p=0.768)$; nor with the percentile to which they initially belong $(p=0.071)$.

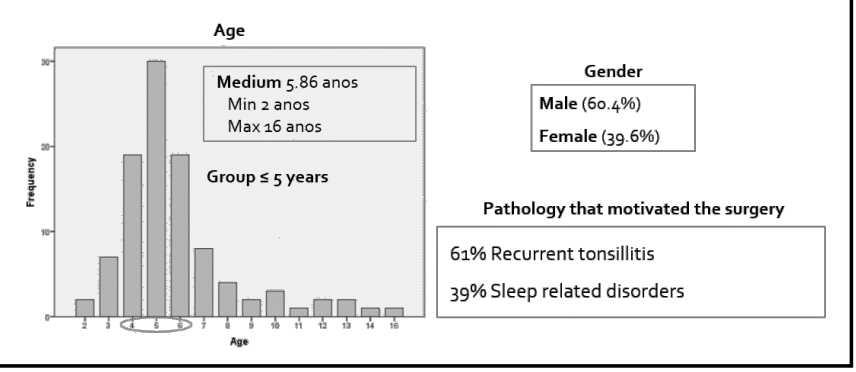

Fig. 1

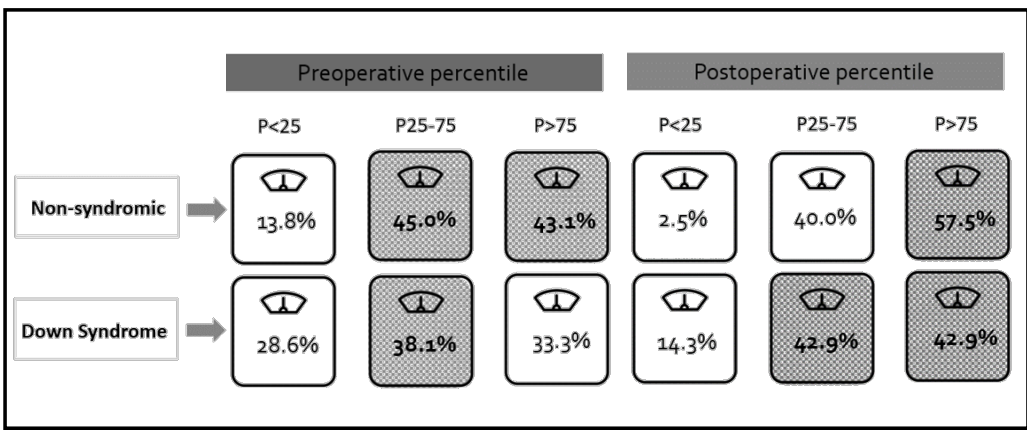

Fig. 3

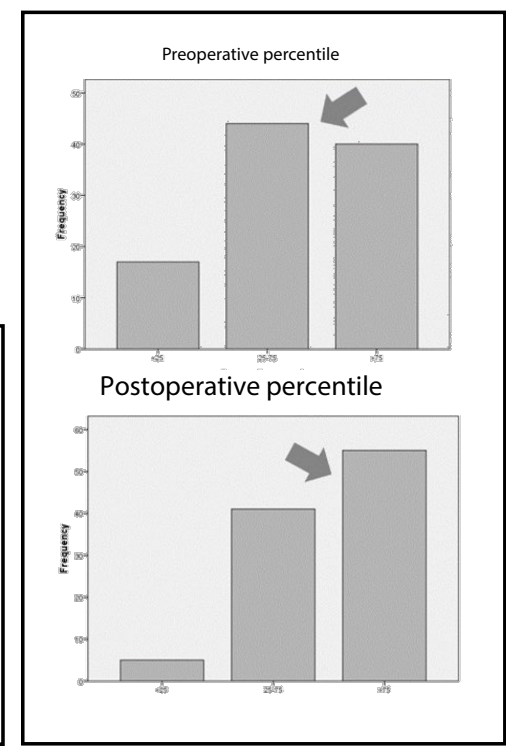

Fig. 2

\section{CONCLUSION}

Although surgical indications for adenotonsillectomy are clear and children benefit, especially parents of overweight/obese children should be aware of the possibility of significant postoperative weight gain.

Referral for nutrition consultation should be a role that must be assumed early by the otorhinolaryngologist, so that the resolution of a problem does not generate a new one in the long term.

\section{REFERENCES}

1. Bonuck K, Parikh S, Bassila M. Growth failure and sleep disordered breathing: a review of the literature. Int J Pediatr Otorhinolaryngol. 2006;70(5):769778

2. Ogden C, Carroll M, Curtin L, et al. Prevalence of overweight and obesity in the United States, 1999-2004. JAMA. 2006;295: 1549-1555.

3. Vos MB, Welsh J. Childhood obesity: update on predisposing factors and prevention strategies. Curr Gastroenterol Rep. 2010;12:280-287.

4. Roemmich JN, Barkley JE, D'Andrea L, et al. Increases in overweight after adenotonsillectomy in overweight children with obstructive sleep-disordered breathing are associated with decreases in motor activity and hyperactivity. Pediatrics. 2006;117(2):e200-e208.

5. Amin R, Anthony L, Somers V, et al. Growth velocity predicts recurrence of sleep-disordered breathing 1 year after adenotonsillectomy. Am J Respir Crit Care Med. 2008;177(6):654-659.

6. Nieminen $\mathrm{P}$, Löppönen $\mathrm{T}$, Tolonen $\mathrm{U}$, Lanning $\mathrm{P}$, Knip $\mathrm{M}$, Löppönen $\mathrm{H}$. Growth and biochemical markers of growth in children with snoring and obstructive sleep apnea. Pediatrics. 2002; 109(4):e55.

7. Wijga AH, Scholtens S, Wieringa MH, et al. Adenotonsillectomy and the development of overweight. Am J Pediatrics. 2009;123(4):1095-1101.

8. Aydogan M, Toprak D, Hatun S, Yüksel A, Gokalp AS. The effect of recurrent tonsillitis and adenotonsillectomy on growth in childhood. Int J Pediatr Otorhinolaryngol. 2007;71(11):1737-1742. 
Centro Hospitalar Universitário do Porto, Portugal

Joana Raquel Costa, Sara Costa, Teresa Soares, Cecília Almeida e Sousa

Diabetes and Healing: Role of GLycemic Control in Tympanoplasty

$$
\text { Success }
$$

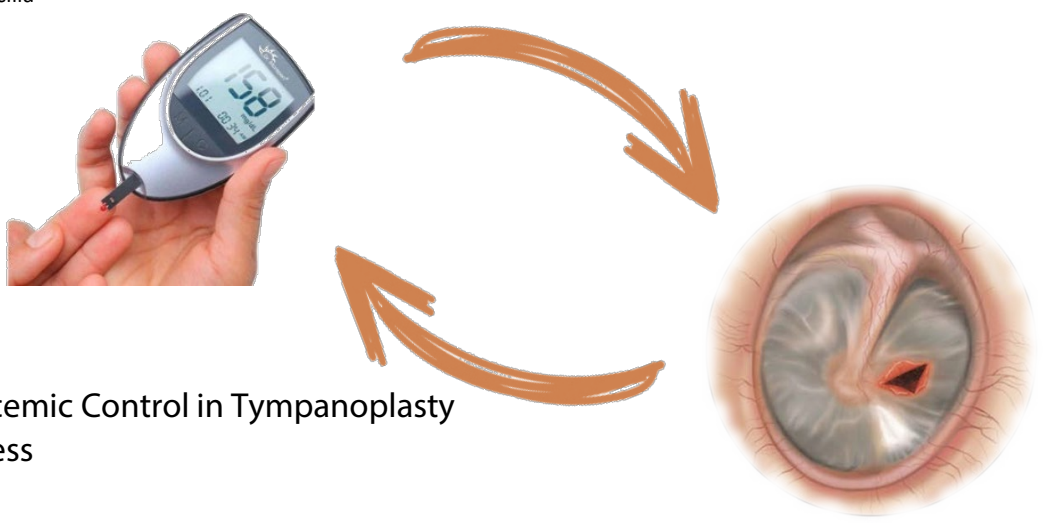

\section{INTRODUCTION}

Diabetes mellitus is a chronic metabolic disorder with important systemic implications. An often-observed clinical manifestation is poor wound repair. A significantly prolonged time to closure of tympanic membrane perforation in diabetic fatty rats has already been described in the literature.

The objectives of this study are to compare the surgical success rates of tympanoplasty comparing (1) diabetic versus non-diabetic type 2 patients and within patients with diabetes type 2 diagnosis (2) with versus without good glycemic control in the 3 months before and after surgery.

\section{Material AND MethodS}

This is a case-control study, which included 91 patients (40 patients with type 2 diabetes and 51 healthy patients). The following information was collected: age, sex, laterality, type of perforation, contralateral ear disease, Hemoglobin $\mathrm{A} 1 \mathrm{C}$ at the time of surgery and 3 months after surgery.

Hemoglobin A1c values greater than 7 were considered abnormal, that is, poorly controlled blood glucose levels. Values less than or equal to 7 were considered normal values, that is, blood glucose values within the desired range.

\section{CONCLUSION}

Good glycemic control in patients diagnosed with type 2 diabetes, with special emphasis on the postoperative period, is essential for a good surgical result in tympanoplasty.
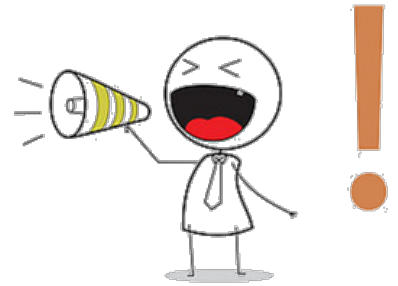

\section{RESULTS}

Demographic data and perforation types are illustrated in figure 1 and figure 2, respectively. $52.7 \%$ of the cases were operated on the left ear, and chronic otitis media was described in the contralateral ear in $35.2 \%$ of the cases.

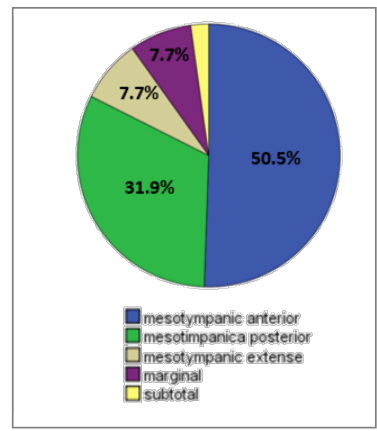

Fig. 1

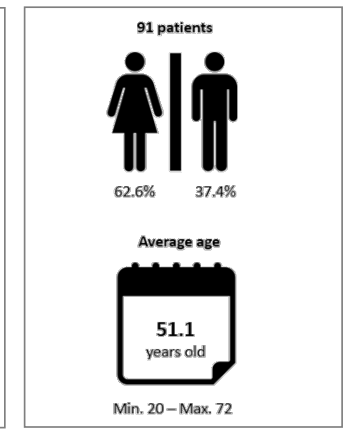

Fig. 2
No statistically significant difference was found between groups in terms of age $(p=0.971)$, gender $(p=0.684)$, type of perforation $(p=0.072)$ and laterality $(P=0.967)$.

The mean Hemoglobin A1c before surgery was $5.67 \%$ and after surgery $6.51 \%$, in patients with diabetes; and $57.1 \%$ of patients before surgery and $55.0 \%$ of patients after surgery had good glycemic control.

Surgical success rates, defined as perforation closure, in the group of patients without diabetes was $80.4 \%$ and with diabetes $67.5 \%$, with no statistically significant difference between groups $(p=0.173)$.

Regarding the glycemic control of patients with diabetes, patients with poor glycemic control prior to surgery did not present a higher risk of surgical failure $(p=0.096)$.

However, diabetes patients with poor glycemic control in the 3 months following surgery were more likely to fail to close the tympanic membrane, and this difference was statistically significant $(p=0.039)$.

\section{RefERENCES}

1. Koc A, Ekinci G, Bilgili AM, et al. Evaluation of the mastoid air cell system by high-resolution computed tomography: threedimensional multiplanar volume rendering technique. J Laryngol Otol 2003;117:595e8.

2. Luntz M, Malatskey S, Tan M, et al. Volume of mastoid pneumatization: three-dimensional reconstruction with ultrahighresolution computed tomography. Ann Otol Rhinol Laryngol 2001;110:486e90.

3. Vrabec JT, Champion SW, Gomez JD, et al. 3D imaging method for measuring temporal bone aeration. Acta Otolaryngol 2002;122:831e5.

4. Jen A, Sanelli PC, Banthia V, et al. Relationship of petrous temporal bone pneumatization to the Eustachian tube lumen. Laryngoscope 2004;114:656e60. 


\section{Validated Dysphagia Severity Outcomes in Patients with a Symptomatic Pharyngeal Pouch} Undergoing Open Approach Cricopharyngeal Myotomy.

$K$ Young, J Wareing, C Snowden, J England.

WHS

Hull University Teaching Hospital NHS Trust.

Hull University Teaching Hospitals NHS Trust

\section{BACKGROUND}

Traditionally pharyngeal pouch surgery has taken the form of endoscopic stapling or open transcervical approach with diverticulectomy.

We present a case series of 14 patients who underwent open transcervical cricopharyngeal myotomy alone without diverticulectomy who showed significant improvement in severity of dysphagia as evidenced by improvement in validated dysphagia assessment scores.

\section{METHODS}

14 open approach transcervical cricopharyngeal myotomies were performed between the dates of 21/06/2019 28/05/2021 in this single centre review.

Pre-procedure on the morning of surgery and 6 weeks post procedure (at time of post-op surgical follow up) EAT-10 questionaries were filled out by patients to assess baseline severity of dysphagia and subsequent improvement post op.

Secondary outcome measure took the form of length of hospital stay and complication rates.

\section{EAT- 10 QUESTIONNAIRE}

Validated questionnaire used to assess patient-reported symptoms of oropharyngeal dysphagia

10 questions related to the patients experience of swallowing with responses graded $0-4$

$0=$ no problem

$4=$ severe problem

A total score of $>4$ is classed as significant dysphagia

\section{RESULTS}

Total number of operations- $\mathrm{N}=14$ (12 Primary open cricopharyngeal myotomies, two revision open cricopharyngeal myotomies)

Average age- 71 (range 59-73)

Average length of stay- 2.2 days (range 1-7)

Average pre-operative EAT-10 score- 26.85 (range 15 $-40)$

Average post-operative EAT-10 score- 7.75 (range 038)

\section{Complications}

Two patients were found to have a residual pouch at follow up appointment and required second surgery.

One intraoperative pharyngeal pouch perforationrepaired intra-operatively post op contrast swallow normal.

\begin{tabular}{|l|c|c|c|c|c|}
\hline Circle the appropriate response & \multicolumn{3}{|c|}{$0=$ No problem } & $4=$ Severe problem \\
\hline $\begin{array}{l}\text { 1. My swallowing problem has caused me to lose } \\
\text { weight. }\end{array}$ & 0 & 1 & 2 & 3 & 4 \\
\hline $\begin{array}{l}\text { 2. My swallowing problem interferes with my ability } \\
\text { to go out for meals. }\end{array}$ & 0 & 1 & 2 & 3 & 4 \\
\hline 3. Swallowing liquids takes extra effort. & 0 & 1 & 2 & 3 & 4 \\
\hline 4. Swallowing solids takes extra effort. & 0 & 1 & 2 & 3 & 4 \\
\hline 5. Swallowing pills takes extra effort. & 0 & 1 & 2 & 3 & 4 \\
\hline 6. Swallowing is painful. & 0 & 1 & 2 & 3 & 4 \\
\hline $\begin{array}{l}\text { 7. The pleasure of eating is affected by my } \\
\text { swallowing. }\end{array}$ & 0 & 1 & 2 & 3 & 4 \\
\hline 8. When I swallow food sticks in my throat. & 0 & 1 & 2 & 3 & 4 \\
\hline 9. I cough when I eat. & 0 & 1 & 2 & 3 & 4 \\
\hline 10. Swallowing is stressful. & 0 & 1 & 2 & 3 & 4 \\
\hline & \multicolumn{5}{|c|}{ Total EAT-10: } \\
\hline
\end{tabular}

\begin{tabular}{|l|l|l|l|}
\hline & $\begin{array}{l}\text { Average Pre- } \\
\text { Op EAT 10 } \\
\text { Score }\end{array}$ & $\begin{array}{l}\text { Average Post- } \\
\text { Op EAT-10 } \\
\text { Score }\end{array}$ & Difference \\
\hline Total (n=13) & 26.85 & 7.75 & $\begin{array}{l}19.1 \\
(\mathrm{P}=.000018)\end{array}$ \\
\hline Question 1 & 1.62 & 0.5 & 1.12 \\
\hline Question 2 & 2.62 & 0.83 & 1.79 \\
\hline Question 3 & 1.31 & 0.58 & 0.73 \\
\hline Question 4 & 3.54 & 1.08 & 2.46 \\
\hline Question 5 & 3.15 & 0.58 & 2.57 \\
\hline Question 6 & 1.23 & 0.25 & 0.98 \\
\hline Question 7 & 3.54 & 0.92 & 2.62 \\
\hline Question 8 & 3.69 & 1.17 & 2.52 \\
\hline Question 9 & 3.23 & 1.08 & 2.15 \\
\hline Question 10 & 2.77 & 0.75 & 2.02 \\
\hline
\end{tabular}

\section{DISCUSSION}

1. Open approach transcervical cricopharyngeal myotomy shows significant improvement in patient reported dysphagia using a validated pre and post op dysphagia questionnaire.

2. We report a revision rate of $16.7 \%$ (2/12 patients).

3. Small population size and single centre nature of this study creates the potential for bias.

4. In future a multicentre study with larger patient population would further support that cricopharyngeal myotomy is a safe and effective surgical approach to pharyngeal pouches.

\section{REFERENCES}

1. Ross E, Snowden C, England R. Validated swallowing outcomes following open transcervical cricopharyngeal myotomy for the treatment of symptomatic pharyngeal pouches. Clinical Otolaryngology. 2021;46(5):1077-1081.

2. Bccancer.bc.ca. 2021 Available from: http://www.bccancer.bc.ca/managing-symptomssite/Documents/EAT\%2010.pdf 
${ }^{1}$ Department of Otolaryngology, Head and Neck Surgery, Beaumont Hospital

${ }^{2}$ Department of Otolaryngology, Children's Health Ireland at Temple Street Hospital

${ }^{3}$ University College Dublin School of Medicine

${ }^{4}$ Department of Neurosurgery, Beaumont Hospital

INTRODUCTION

- Intracranial complications of sinusitis (ICS) are rare but life-threatening events and occur frequently in children. ${ }^{1}$

- Urgent imaging based on clinical suspicion and urgent expert neurosurgical and otolaryngological input is paramount. ${ }^{2}$

- Concurrent operative neurosurgical and otolaryngological intervention has often been considered the standard of care..$^{3,4}$

- There is conflicting evidence as to whether any measurable benefit is derived from concurrent intervention. , $^{3}$

\section{AIMS \& METHODS}

- To evaluate if concurrent neurosurgical \& otolaryngological intervention improved outcomes for children with ICS.

- To further describe the population of children with ICS who required surgical management and evaluate outcome data.

- A retrospective cohort study was conducted using an existing database of children with ICS who required neurosurgical interventions from 2008-2020.

\section{Results - Baseline Characteristics}

- 47 children were identified - 31 (66\%) were male, 16 (34\%) were female.

- Mean age at presentation was 11.9 years, ranging from 16 months to 16 years.

- Most presented with headache, pyrexia, facial swelling, and altered level of consciousness.

- Mean white cell count \& C-reactive protein at presentation were 14.7x109/L (range 5.3-30) 112.8mg/L (range 1.7-377)

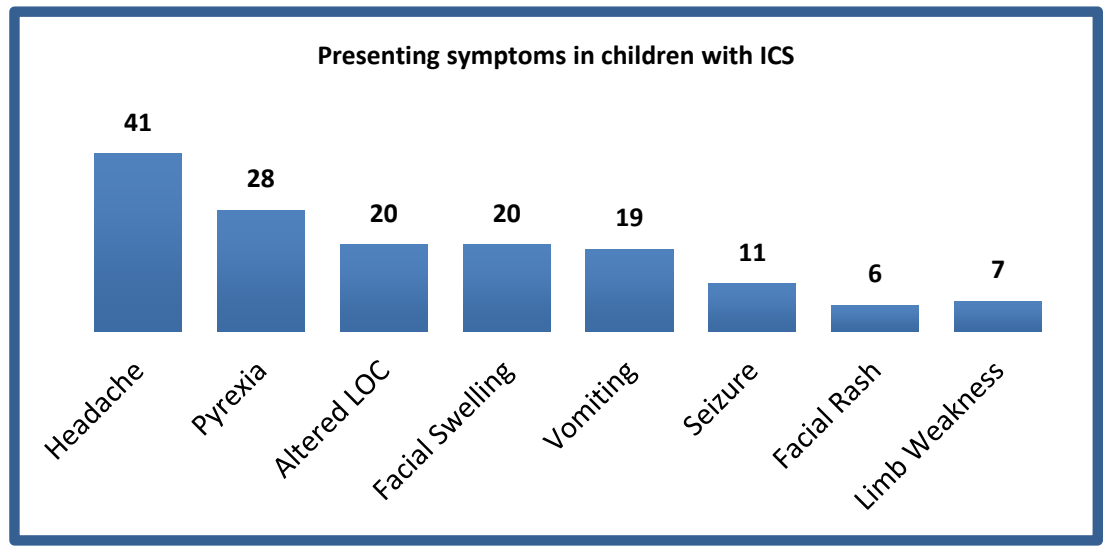

Fig. 1: Presenting symptoms in children with ICS

\section{RESULTS - IMAGING \& FINDINGS}

- Computed tomography (CT) was the primary diagnostic imaging modality ( $n=36,76 \%$ ).

- Mean Lund McKay score was 10 (range 0-24).

- Scores of 0 were observed in 3 children with recent episodes of acute sinusitis.

- Subdural empyema was the most common complication (Fig. 2).

- Other-frontoparietal abscess \& combination of subdural, extradural, and frontal pathology.

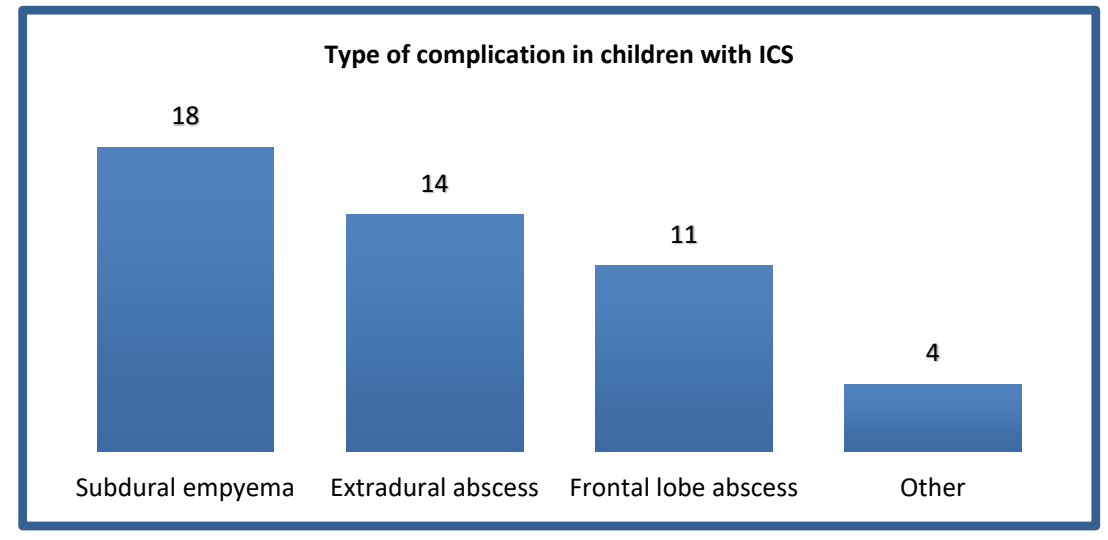

Fig. 2: Type of complication in children with ICS 


\section{Results - MANAgement}

- All patients underwent either craniotomy, craniectomy, or burr-hole drainage.

- 37 underwent ENT intervention; 33 (89.2\%) were performed concurrently or earlier.

- Endoscopic sinus surgery was the most common modality used (Fig. 3).

- All received long course antibiotics ( $>4$ weeks), at least 2 weeks intravenous.

- Primary causative organism - streptococcus intermedius in $55 \%(n=24)$.

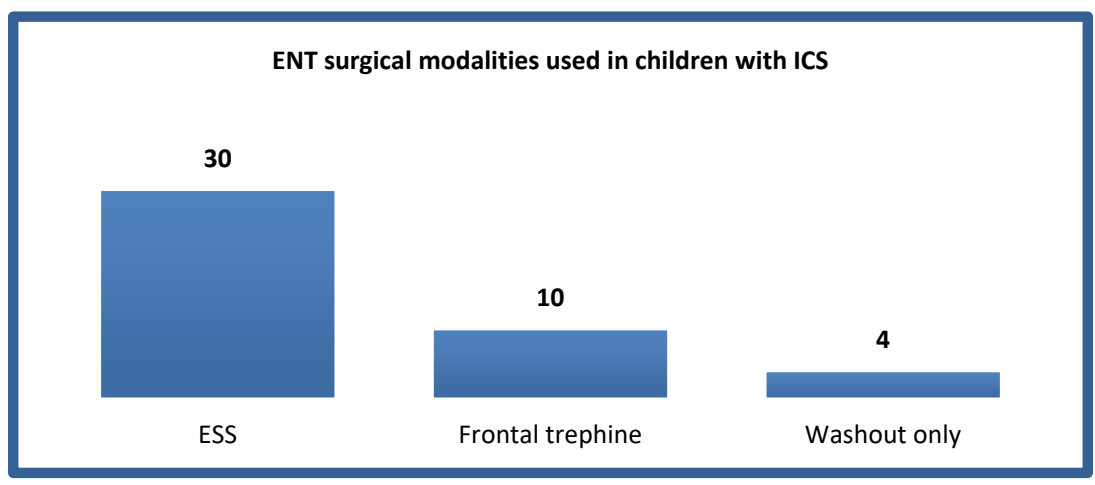

Fig. 3: ENT surgical modalities used in children with ICS

\section{MetHODS - OUTCOMES} ESS - endoscopic sinus surgery

- Pott's puffy tumour $(n=12,26 \%)$ \& cavernous sinus thrombosis $(n=5,11 \%)$, were common complications.

- Mean time to discharge was 21 days (range 6-53). Mean ICU stay was 1.2 days (0-12).

- The concurrent surgery control group was too small for meaningful analysis $(n=4)$.

- Trends for length of hospital stay (Fig. 4), permanent post op neurological deficits, abscess recurrence, and need for revision surgery favoured the concurrent group.

- Mortality was $0 \% .2$ permanent deficits were observed (epilepsy, hemiparesis).

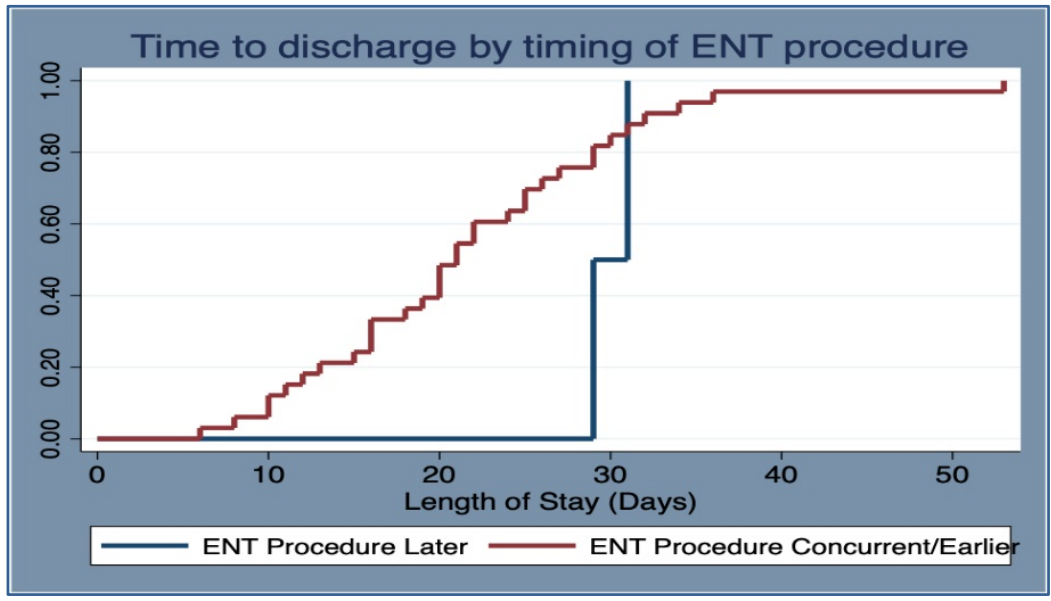

\section{CONCLUSIONS}

Fig. 4: Time to discharge by timing of ENT procedure

- ICS are life-threatening events requiring urgent surgical management in a specialist centre with multidisciplinary input.

- Endoscopic sinus surgery remains the otolaryngological approach of choice in experienced hands.

- Concurrent performance of neurosurgical and otolaryngological interventions represent the standard of care for children with ICS.

\section{REFERENCES}

1. Mameli C, Genoni T, Madia C, Doneda C, Penagini F, Zuccotti G. Brain abscess in pediatric age: a review. Childs Nerv Syst. 2019;35(7):1117-28.

2. Cantiera M, Tattevin P, Sonneville R. Brain abscess in immunocompetent adult patients. Rev Neurol (Paris). 2019;175(7-8):469-74.

3. Fenton JE, Smyth DA, Viani LG, Walsh MA. Sinogenic brain abscess. Am J Rhinol. 1999;13(4):299-302.

4. Din-Lovinescu C, Mir G, Blanco C, Zhao K, Mazzoni T, Fried A, et al. Intracranial complications of pediatric rhinosinusitis: Identifying risk factors and interventions affecting length of hospitalization. International Journal of Pediatric Otorhinolaryngology. 2020;131:109841.

5. Levy DA, Nguyen SA, Harvey R, Hopkins C, Schlosser RJ. Hospital utilization for orbital and intracranial complications of pediatric acute rhinosinusitis. International Journal of Pediatric Otorhinolaryngology. 2020;128:109696. 


\title{
Otoscopy Teaching -A Quality Improvement Project
}

\author{
J Wauchope ${ }^{1}$, S Garry ${ }^{1}$, F Guinness ${ }^{2}$, A Quigley¹, J Fitzsimons ${ }^{2}$, C Heffernan ${ }^{1}$ \\ ${ }^{1}$ Department of Otolaryngology, Children's Health Ireland at Temple Street \\ 2 Department of Paediatrics, Children's Health Ireland at Temple Street
}

\section{ObJective}

To assess and improve otoscopy examination across all medical subspecialties who perform the examination during their professional practice.

\section{METHODS}

A pre-intervention survey was created using Survey Monkey which included several preliminary questions to clarify the participant's profession and training level followed by 25 individual otoscopy images. Each question had 12 different multiple-choice answers with the task of choosing the single best answer. Following completion of the pre-intervention survey, participants were asked to watch an otoscopy lecture. This lecture was created with the aid of multidisciplinary feedback and content included a demonstration video. After completing the lecture, a post-intervention survey was circulated 4 weeks later to the same cohort of medical staff to assess for improvement.

\section{RESULTS}

- 79 pre-intervention responses - average score $\mathbf{5 3} \%$ (range of 20\%-100\%)

- Participating specialties included Paediatrics, ENT, Emergency Medicine and GP

- Training level ranged from intern - consultant

- $78.5 \%$ of responses were completed by doctors who had not worked in ENT before

- Following completion of the otoscopy lecture and at least a 4-week interval 23 post-intervention responses - average score of $66 \%$ (range $32 \%-100 \%$ )

\section{- Overall 13\% improvement}

\section{CONCLUSION}

The pre-intervention survey has shown that many doctors have difficulty with otoscopy and diagnosing otological conditions. The implementation of a 25 minute lecture has shown a $13 \%$ improvement in the otoscopy skills of medical doctors across various specialties.

\section{ReferenCES}

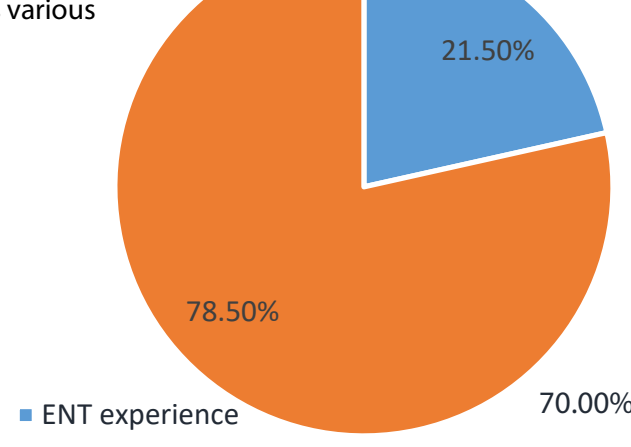

$$
\llbracket \mathrm{GP}
$$$$
\text { - ENT }
$$

$\because$ Paediatrics $\square \mathrm{A} \& \mathrm{E}$

1. Paul CR, Keeley MG, Rebella GS, Frohna JG. Teaching pediatric otoscopy skills to pediatric and emergency medicine residents: a cross-institutional study. Academic pediatrics. 2018 Aug 1;18(6):692-7.

2. Davies J, Djelic L, Campisi P, Forte V, Chiodo A. Otoscopy simulation training in a classroom setting: a novel approach to teaching otoscopy to medical students. The Laryngoscope. 2014 Nov; 124(11):2594-7.

3. Hakimi AA, Lalehzarian AS, Lalehzarian SP, Azhdam AM, NedjatHaiem S, Boodaie BD. A Call for Improved Otoscopy Training. European Archives of Oto-Rhino-Laryngology. 2020 May;277(5):1553-.

4. Wormald PJ, Browning GG, Robinson K. Is otoscopy reliable? A structured teaching method to improve otoscopic accuracy in trainees. Clinical Otolaryngology \& Allied Sciences. 1995 Feb;20(1):63-7.

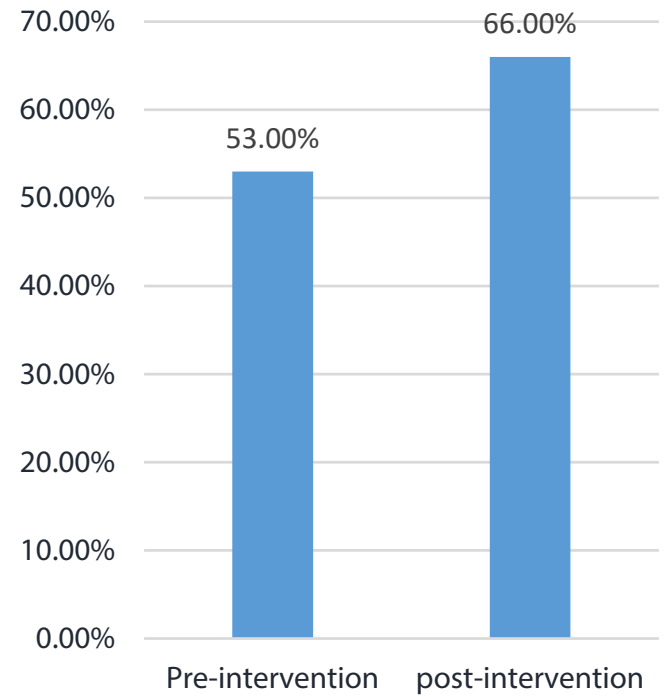




\section{Change in Institution Thyroid Nodule Radiological Scoring System and the Impact on Management of Patients with Thyroid Nodules}

Department of Otolaryngology, South Infirmary Victoria University Hospital

\section{INTRODUCTION}

- The incidence of thyroid nodules is increasing with the rise in diagnostic imaging and the subsequent discovery of "incidental findings'.

- Various scoring systems have been devised to help guide image interpretation and management, streamlining those who require additional investigation.

\section{OBJeCtives}

- As our institution has moved from 'U Score' to 'EU TIRADS', the goal of this study was to look at how this change may have impacted retrospectively on the management of patients who underwent ultrasound, cytology and thyroidectomy for thyroid nodules.

- Given that we have definitive histology on all included patients we can assess the accuracy of EU-TIRADS in this patient group

\section{METHODS}

A retrospective review of all patients who underwent total or hemithyroidectomy from January 2016 - Aug 2021, with a dominant nodule on pre operative ultrasound.

Patients who did not have a dominant nodule but underwent surgery for compression, Graves disease or completion thyroidectomy for cancer diagnosis were excluded.

Where original ultrasound reports were not available patients were excluded.

Ultrasound reports and MDT letters were reviewed and U Score noted.

A retrospective EU-TIRADS score was allocated to those who did not have one specified in accordance with EU TIRADS guidance.

Where report features were inadequate for accurate assessment patients were labelled EU-TRX

Post operative histology was compared to pre-operative imaging suspicion.

\section{EU TIRADS-Management Algorithm}

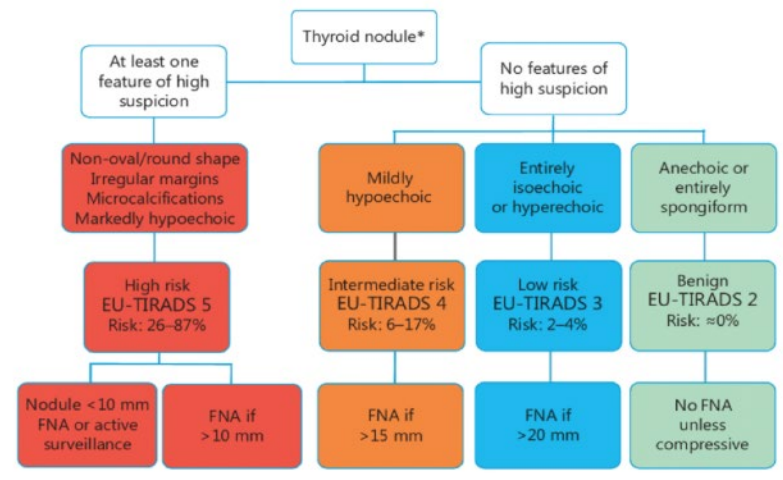

\section{RESULTS}

330 patients fit the inclusion criteria.

Many reported $\mathrm{U}$ score between categories

\begin{tabular}{|l|l|l|l|l|l|l|l|}
\hline U score & $\mathbf{U 2}$ & $\mathbf{U 2 - U 3}$ & $\mathbf{U 3}$ & $\mathbf{U 3 - U 4}$ & $\mathbf{U 4}$ & $\mathbf{U 4 - U 5}$ & $\mathbf{U 5}$ \\
\hline No. $=330$ & 35 & 38 & 131 & 26 & 60 & 12 & 28 \\
\hline $\begin{array}{l}\text { Benign } \\
\text { Histology }\end{array}$ & 33 & 32 & 91 & 22 & 28 & 5 & 4 \\
$\begin{array}{l}\text { Malignant } \\
\text { Histology }\end{array}$ & 2 & $\begin{array}{l}4 \\
+2 \text { incidental } \\
=6\end{array}$ & $\begin{array}{l}39 \\
+1 \text { incidental } \\
=40\end{array}$ & 4 & $\begin{array}{l}30 \\
+2 \text { incidental } \\
=32\end{array}$ & 7 & 24 \\
\hline
\end{tabular}

EU-TIRADS scoring, including how many would have been omitted from FNAC .

Again many were between categories 


\begin{tabular}{|c|c|c|c|c|}
\hline EU-TIRADS Score & No FNA as per size criteria & \multicolumn{2}{|l|}{ Cytology } & Histology \\
\hline $\begin{array}{l}\text { EU-TR } 2 \\
N=4\end{array}$ & 4 & $\begin{array}{l}\text { Thy } 1=2 \\
\text { Thy } 2=2 \\
\text { Thy3a }=0\end{array}$ & $\begin{array}{l}\text { Thy } 3 f=1 \\
\text { Thy } 4=0 \\
\text { Thy } 5=0\end{array}$ & $\begin{array}{l}4 \text { Benign } \\
0 \text { Malignant }\end{array}$ \\
\hline $\begin{array}{l}\text { EU-TR } 3 \\
\mathrm{~N}=83\end{array}$ & $\begin{array}{l}17 \\
\text { - nil malignant not FNAC }\end{array}$ & $\begin{array}{l}\text { Thy } 1=5 \\
\text { Thy } 2=23 \\
\text { Thy3a }=34 .\end{array}$ & $\begin{array}{l}\text { Thy } 3 f=18 \\
\text { Thy } 4=1 \\
\text { Thy } 5=2\end{array}$ & $\begin{array}{l}75 \text { benign } \\
2 \text { incidental microCa } \\
\text { (- non target lesion) } \\
6 \text { malignant }\end{array}$ \\
\hline $\begin{array}{l}\text { EU-TR 3-4 } \\
N=13\end{array}$ & $\begin{array}{l}4 \\
\text { - nil malignant not FNAC }\end{array}$ & $\begin{array}{l}\text { Thy } 1=3 \\
\text { Thy } 2=3 \\
\text { Thy } 3 a=4\end{array}$ & $\begin{array}{l}\text { Thy3f }=2 \\
\text { Thy4=0 } \\
\text { Thy5 }=1\end{array}$ & $\begin{array}{l}2 \text { malignant } \\
11 \text { benign }\end{array}$ \\
\hline $\begin{array}{l}\text { EU-TR } 4 \\
N=42\end{array}$ & $\begin{array}{l}3 \\
-1 \text { Malignant not FNAC }\end{array}$ & $\begin{array}{l}\text { Thy } 1=2 \\
\text { Thy } 2=7 \\
\text { Thy3a }=12\end{array}$ & $\begin{array}{l}\text { Thy } 3 f=11 \\
\text { Thy } 4=0 \\
\text { Thy } 5=13\end{array}$ & $\begin{array}{l}28 \text { benign } \\
14 \text { malignant }\end{array}$ \\
\hline $\begin{array}{l}\text { EU-TR 4-5 } \\
N=30\end{array}$ & 0 & $\begin{array}{l}\text { Thy1=1 } \\
\text { Thy2=2 } \\
\text { Thy3a=6 }\end{array}$ & $\begin{array}{l}\text { Thy } 3 f=11 \\
\text { Thy } 4=2 \\
\text { Thy } 5=8\end{array}$ & $\begin{array}{l}18 \text { malignant } \\
12 \text { Benign }\end{array}$ \\
\hline $\begin{array}{l}\text { EU-TR5 } \\
\mathrm{N}=69\end{array}$ & $\begin{array}{l}1 \\
\text { - nil malignant not FNAC }\end{array}$ & $\begin{array}{l}\text { Thy1 }=3 \\
\text { Thy2 }=5 \\
\text { Thy3a }=7\end{array}$ & $\begin{array}{l}\text { Thy } 3 f=14 \\
\text { Thy } 4=4 \\
\text { Thy5 }=36\end{array}$ & $\begin{array}{l}20 \text { benign } \\
49 \text { malignant }\end{array}$ \\
\hline $\begin{array}{l}E \cup T R X \\
(T R 3-5) \\
N=89\end{array}$ & $\begin{array}{l}1 \text { does not criteria regardless } \\
\text { of TR3-5. } \\
11 \text { - unknown }\end{array}$ & & & $\begin{array}{l}18 \text { malignant, } 71 \\
\text { benign }\end{array}$ \\
\hline
\end{tabular}

Comparison between final histology and published malignancy rates

EU-TIRADS categories and risk of malignancy

\begin{tabular}{|l|l|l|}
\hline Category & Malignancy risk, $\%$ & Risk in our cohort \\
\hline EU-TIRADS 1: normal & None & $\mathrm{n} / \mathrm{a}$ \\
\hline EU-TIRADS 2: benign & $\cong$ & 0 \\
\hline EU-TIRADS 3: low risk & $2-4$ & $7.2 \%$ \\
\hline EU-TIRADS 4: intermediate risk & $6-17$ & $29-33 \%$ \\
\hline EU-TIRADS 5: high risk & $26-87$ & $68-71 \%$ \\
\hline EU-TIRADS, European Thyroid Imaging Reporting and Data System; US, ultrasound.
\end{tabular}

\section{Discussion}

Of the 319 for which we know FNA status, 30 did not warrant FNA using EU-TIRADS criteria

Of these, 8 had a U2 score but underwent FNAC for another indication such as symptomology or risk factors.

Of the 30 who would not have undergone FNAC- 1 had a malignancy. An 8mm PTC in a 10mm nodule on US, TR4.

Thus we would perform 22 less FNAC using EU-TIRADS, a reduction of $6.9 \%$

U5 predicted malignancy in our department in $86 \%$, where EU TR5 was $71 \%$.

By definition U5 is termed "malignant" and EU TR5 "high risk".

Both intermediate risk categories of TR4 and U3 were comparable at 33\% and 30\%, though higher than published risk rates. 


\section{CONCLUSION}

The management of thyroid nodules remains a challenge. Selectivity is needed with performance of FNAC, which may lead to over investigation or unnecessary diagnostic thyroid surgery. .

While neither 'EU-TIRADS' nor 'U score' system was 100\% accurate, as a department moving to EU TIRADS seems to reduce FNA rate somewhat, without compromising diagnostic yield.

EU-TIRADS is intended to be a simpler scoring system that those that are presently in use which may improve compliance and help communicate risk and guide management of thyroid nodules. There is a tendency to score between categories in our department however which may cause management ambiguity.

A prospectively maintained database will help us to establish more clearly the performance and compliance with this system going forward.

\section{REFERENCES}

1. Hoang JK, Langer JE, Middleton WD, Wu CC, Hammers LW, Cronan JJ, Tessler FN, Grant EG, Berland LL. Managing incidental thyroid nodules detected on imaging: white paper of the ACR Incidental Thyroid Findings Committee. J Am Coll Radiol. 2015 Feb;12(2):143-50. doi: 10.1016/j.jacr.2014.09.038. Epub 2014 Nov 1. PMID: 25456025.

2. Perros, P., Boelaert, K., Colley, S., Evans, C., Evans, R., Gerrard BA, G., Gilbert, J., Harrison, B., Johnson, S., Giles, T., Moss, L., Lewington, V., Newbold, K., Taylor, J., Thakker, R., Watkinson, J. and Williams, G., 2014. Guidelines for the management of thyroid cancer. Clinical Endocrinology, 81, pp.1-122.

3. Russ G, Bonnema S, J, Erdogan M, F, Durante C, Ngu R, Leenhardt L: European Thyroid Association Guidelines for Ultrasound Malignancy Risk Stratification of Thyroid Nodules in Adults: The EU-TIRADS. Eur Thyroid J 2017;6:225-237. doi: 10.1159/000478927 
The Effect of the 2021 Cyber-Attack on Otolaryngology Outpatient Non-Attendance at a Model 4 Hospital in the Post-COVID ERA

Fionn Slattery ${ }^{1,2}$, Eric Farrell ${ }^{1,2}$, Peter Lacy ${ }^{1}$

${ }^{1}$ Department of Otolaryngology, Beaumont Hospital, Dublin

${ }^{2}$ Royal College of Surgeons in Ireland, Dublin
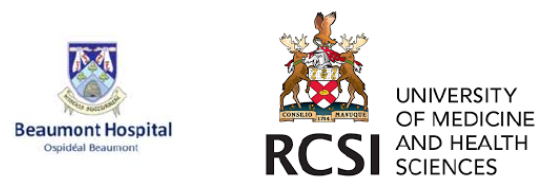

\section{Objective}

Our work investigated the impact of the cyber-attack (and the lack of a text message reminder system) on the rate of nonattendance at ENT outpatient appointments.

\section{METHODOLOGY}

A retrospective review was conducted of the rate of non-attendance at outpatient appointments comparing two time periods of two weeks. One period before the cyber attack, where the text system was in operation and another postcyberattack, where the text reminder system was disabled.

\section{RESULTS}

During the pre-attack period, 93 patients of 748 scheduled did not attend. During the postattack periods, 125 patients of 754 scheduled did not attend.

The average non-attendance rate was $13.00 \%$ for period 1 and $16.13 \%$ for period 2, representing a raw increase of 32 patients not attending their scheduled outpatient appointments. A Fisher Exact Test was carried out with a p-value set at $<0.1$ given the small sample size, with these results reached statistical significance $(p=0.0505)$.

\section{PRE-ATTACK NON-ATTENDANCE RATES}

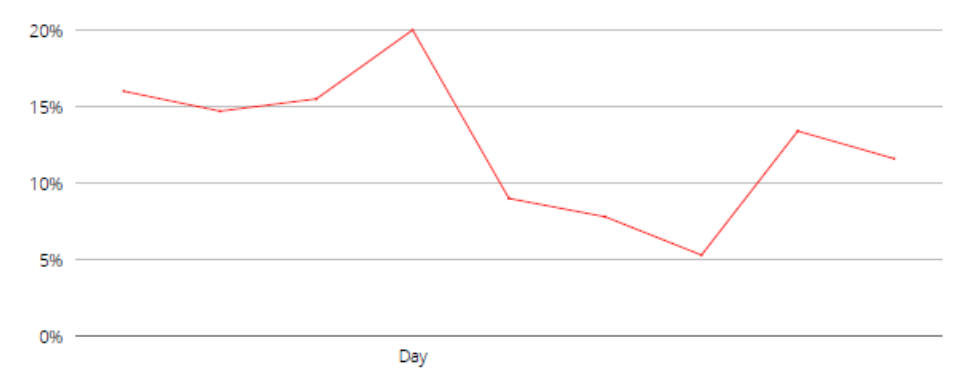

POST-ATTACK NON-ATTENDANCE RATES

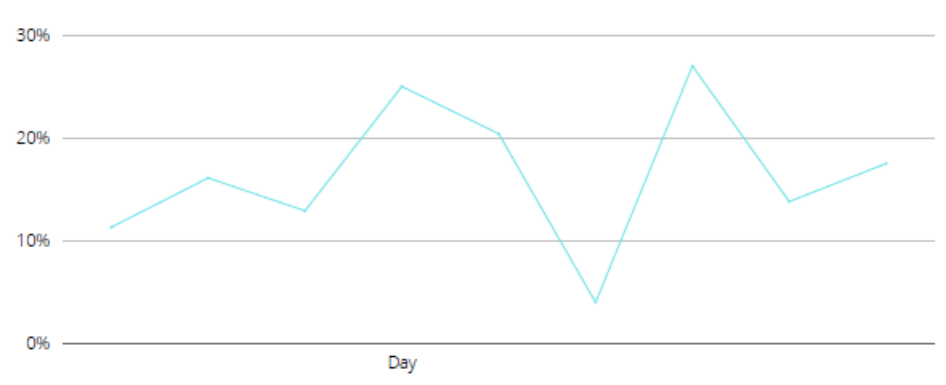

\section{INTRODUCTION}

Outpatient care was severely affected during the COVID pandemic, owing to restrictions placed on patient footfall throughout hospitals. As our health service emerged from these restrictions, a cyber-attack targeted our IT systems and caused considerable disruption to both inpatient and outpatient care.

It has been demonstrated in the past that outpatient attendance rates can be improved through personalised services such as text message reminder services and phone call reminders. ${ }^{1,2}$ This system was disabled as a result of the cyber attack.

\section{CONCLUSION}

A lack of a text reminder led to increased rates of non-attendance at outpatient appointments.

\section{FUTURE DiRECTIONS}

Increased use of personalised services to remind patients of appointments with manual reminders (such as telephone calls) for high priority patients. 
Larger studies are required to examine the effect of the cyber-attack on outpatient attendance across specialities and ultimately, guide development of more effective cybersecurity infrastructure

\section{PRE-ATTACK AND POST- ATTACK NON-ATTENDANCE RATES}

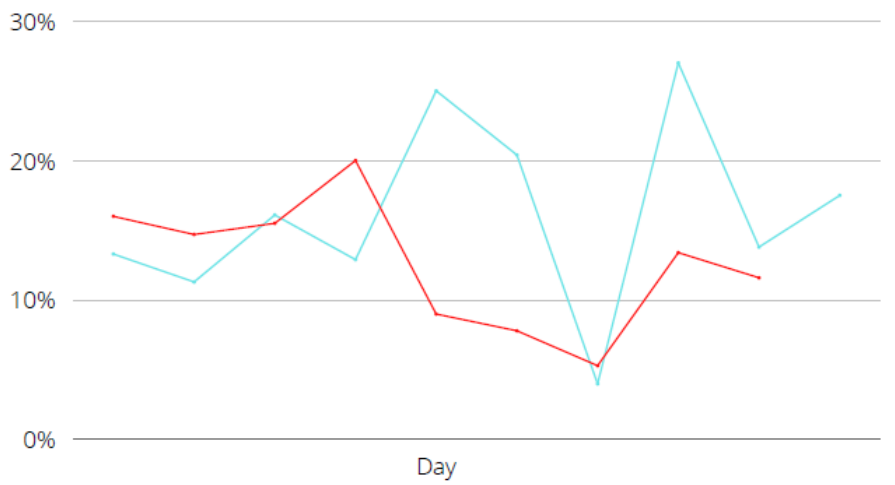

\section{REFERENCES}

1. Hasvold PE, Wootton R. Use of telephone and SMS reminders to improve attendance at hospital appointments: a systematic review. J Telemed Telecare [Internet]. 2011 Oct 20;17(7):358-64. Available from: http://journals.sagepub.com/doi/10.1258/jtt.2011.110707

2. Anthony N, Molokwu J, Alozie O, Magallanes D. Implementation of a Text Message to Improve Adherence to Clinic and Social Service Appointments. J Int Assoc Provid AIDS Care [Internet]. 2019 Jan 1;18:232595821987016. Available from: http://journals.sagepub.com/doi/10.1177/2325958219870166 
The Endoscopic Transsphenoidal Approach to Skull Base Tumours: A Single Surgeon's Experience in a Tertiary Centre

Danielle L. James, Salim A. Malik, Mohammad. H. Khan

South Infirmary Victoria University Hospital

\section{INTRODUCTION}

Endoscopic skull base surgery is becoming an increasingly accepted approach to anterior skull base tumors and pituitary tumors. It offers better cosmesis, enhanced recovery and improved quality of life post-operatively, compared with previous open approaches.
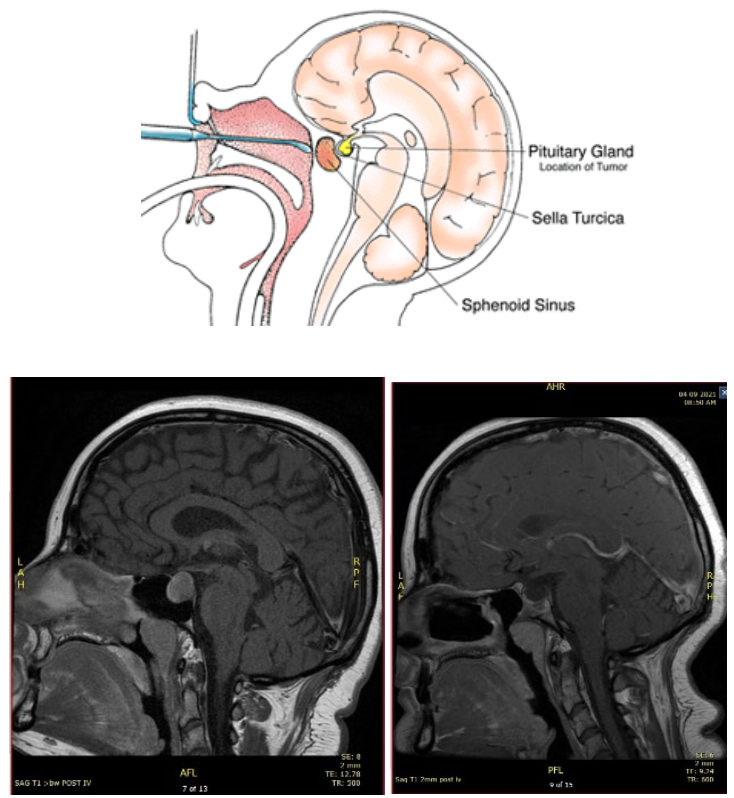

Pre and post operative MRI in a 29yo female with headache and visual disturbances showing microadenoma measuring $2 \times 1.5 \times 2 \mathrm{~cm}$ with suprasellar extension. Post operative imaging shows pituitary tissue without recurrent disease.

\section{AIMS}

Our study purpose was to assess our institutions outcomes of transsphenoidal surgery resection with both the endonasal transsphenoidal approach (TSA) and the extended endonasal approach (EEA) for skull base tumors and compare them to those published in the international literature.

\section{METHODS}

Following local ethical approval, a retrospective study investigating a single surgeon database was performed in our department from 2019 to the present. Patient demographics, tumor size, histopathology, complications and recurrence rate and were all assessed.
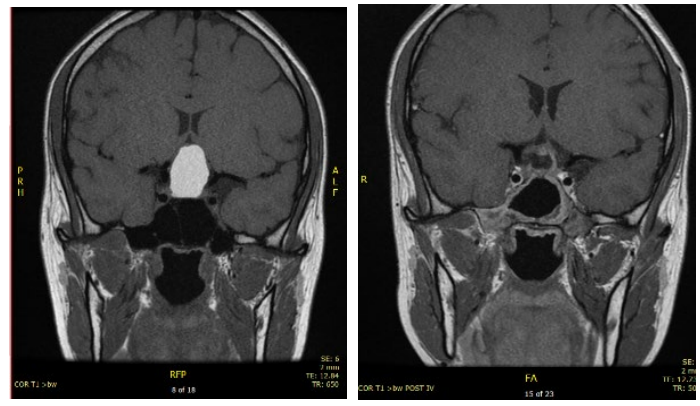

Pre and post-operative imaging of a 29yo male who underwent Transsphenoidal Rathke Pouch Excision.

\section{RESULTS}

37 patients $(M=20, F=17)$ were included in this database. In our cohort, there were no reports of post-operative CSF leak or other complications. All patients were followed up in both ENT and Neurosurgical OPD with post-operative surveillance imaging.. 


\begin{tabular}{|l|l|l|l|}
\hline Type of Surgery & Number of Patients & $\begin{array}{l}\text { Number of Recurrence } \\
\text { Based on Imaging (CT/MR) }\end{array}$ & Histopathology \\
\hline $\begin{array}{l}\text { Endoscopic } \\
\text { Transsphenoidal } \\
\text { Hypophysectomy }\end{array}$ & 32 & $0 / 32$ & $\begin{array}{l}\text { Pituitary Adenoma 29 } \\
\text { Craniopharyngioma 2 } \\
\text { Chordoma 1 }\end{array}$ \\
\hline $\begin{array}{l}\text { Extended Endonasal } \\
\text { Approach }\end{array}$ & 3 & $0 / 3$ & $\begin{array}{l}\text { Rathke Pouch 1 } \\
\text { Optic Schwannoma 1 } \\
\text { Pituitary Adenoma 1 }\end{array}$ \\
\hline $\begin{array}{l}\text { Malignant } \\
\text { Craniofacial Tumour } \\
\text { Resections }\end{array}$ & 2 & $1 / 2$ & $\begin{array}{l}\text { Sinonasal Chondrosarcoma } \\
1 \\
\text { Maxillary SCC 1 }\end{array}$ \\
\hline
\end{tabular}

\section{CONCLUSIONS}

The endoscopic approach is becoming increasingly popular approach for anterior skull base tumors. A systematic review of skull base surgery reported an overall complication rate of $17.1 \%$ (range $0 \%-68.0 \%$ ) and a mortality rate of $0.4 \%(0 \%$ $10.0 \%){ }^{1}$ Our database shows a $0 \%$ post-operative complication rate and $0 \%$ mortality rate. These rates compare favorably to those in international literature. However, we acknowledge the size limitations of our database compared with those figures produced internationally. We will continue to log our operative activity and compare with international standards.

\section{REFERENCES}

1. Borg A, Kirkman MA, Choi D. Endoscopic Endonasal Anterior Skull Base Surgery: A Systematic Review of Complications During the Past 65 Years. World Neurosurg. 2016 Nov;95:383-391. doi: 10.1016/j.wneu.2015.12.105. Epub 2016 Mar 4. PMID: 26960277.

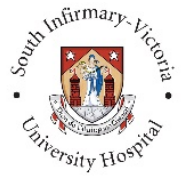




\section{INTRODUCTION}

Necrotising otitis externa (NOE) is a rare complication of acute otitis externa, most commonly seen in the elderly, diabetic and immunocompromised. ${ }^{1}$ It is an invasive infection of the external auditory canal, spreading to involve the skull base, resulting in temporal bone osteomyelitis. ${ }^{2}$ The most commonly isolated micro-organism is psuedomonas aeruginosa. ${ }^{1}$ Once infection and subsequent granulation occurs, the facial nerve (CNVIII) may be compromised, resulting in palsy. As infection progresses, however, cranial nerves IX, X, XI and XII may be affected, resulting in dysphagia, dysphonia, and shoulder weakness. ${ }^{3}$

\section{Aims}

The aim of our study was firstly to evaluate our cohort of patients treated for necrotizing otitis externa from January 2018 to June 2021, and secondly to determine variations in presentations with this condition between these time periods.

\section{METHODS}

A single-centre, retrospective, observational study of all patients treated for necrotising otitis extern at our institution over a period of 42 months, from January 2018 to June 2021 was carried out. Patients were identified using HIPE records. Overall, ten patients treated for twelve separate episodes of necrotizing otitis externa in this time period were identified. No patients were excluded. Data regarding patient demographics, presentation, treatment and outcomes were collected from electronic patient records. Presentations over this time frame were grouped by year to allow comparison between those presenting since the onset of the COVID-19 pandemic and the preceding two years.

\section{RESULTS}

Ten patients were treated at our institution for twelve episodes of necrotising otitis externa were identified during this time period, with one developing infection of the contralateral ear following initial treatment. The male:female ratio was 9:1 with the mean age being $72.32 \pm 9.46$ years.

$80 \%$ of patients treated had diabetes mellitus, $87.5 \%$ of whom had Type II. All patients presented with severe unilateral otalgia, with $70 \%$ reporting otorrhoea from the affected ear.

Two patients were treated in both 2018 and 2019. Presentations decreased in 2020, with one patient treated. However, between January and June $2021,50 \%$ of the total cases $(n=5)$ presented. Of these, $33 \%$ had CNVII palsy at presentation. In the previous three years, there were zero patients presenting with CNVII palsy.

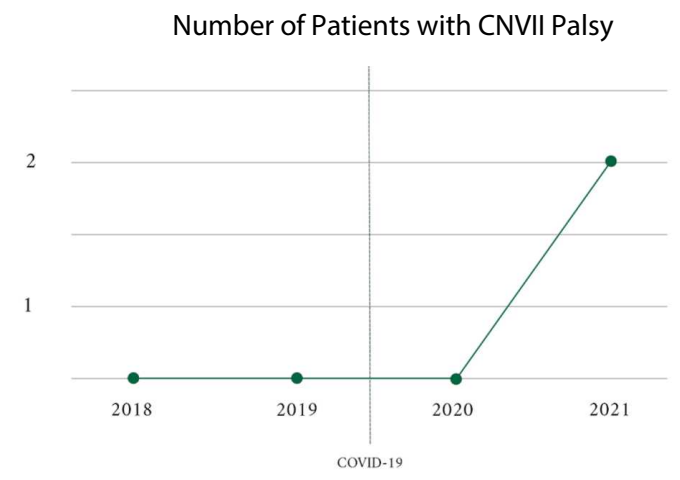

Similarly, the mean duration of symptoms preceding presentation was longer in 2020 and 2021 compared with 2018 and 2019 - 34.7 vs 20.5 days. No patients treated in 2020 or 2021 received topical treatment in the community, compared with $75 \%$ in 2018 and 2019.

Mean Duration of Symptoms

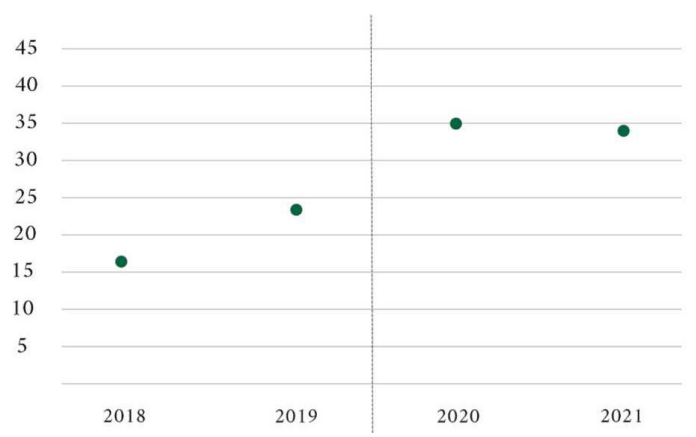




\section{DisCUSSION}

Until recently, there were no formal published guidelines on the investigation, diagnosis and management of necrotising otitis externa. This was perhaps a result of the heterogenous nature of its presentation and debate among health professionals regarding its diagnosis. ENT UK published their guidelines in May 2020 which details outpatient, inpatient, radiological, medical and surgical managment of this condition. ${ }^{4}$

Our data shows that when there is a long time-to-treatment, patients have greater complications such as CNVII palsy. This correlates with the guideline's emphasis on prompt investigation of those at risk and establishment of a pathway for management once a diagnosis has been made. The guideline also stresses that patient management should be with a multi-disciplinary team including ENT, infectious disease, medical teams and allied healthcare professionals.

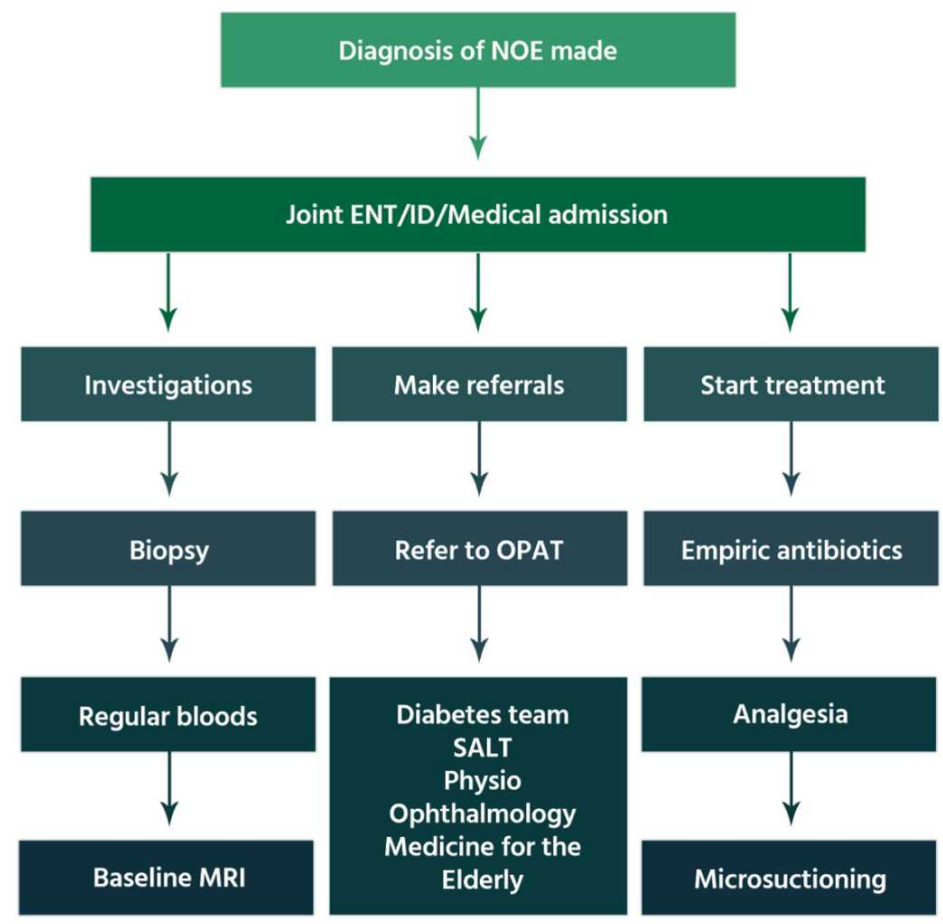

\section{CONCLUSION}

This study demonstrates that patients presenting with necrotitising otitis externa following onset of the COVID-19 pandemic had a longer duration of symptoms and presented with more advanced disease. Timely recognition of symptoms and treatment of patients at risk of developing necrotising otitis externa is imperative to prevention and management.

\section{REFERENCES}

1. Treviño González, J., Reyes Suárez, L. and Hernández de León, J., 2021. Malignant otitis externa: An updated review. American Journal of Otolaryngology, 42(2), p.102894.

2. Chawdhary, G., Liow, N, Democratis, J. and Whiteside, O., 2015. Necrotising (malignant) otitis externa in the UK: a growing problem. Review of five cases and analysis of national Hospital Episode Statistics trends. The Journal of Laryngology \& Otology, 129(6), pp.600-603.

3. Hopkins, M., Bennett, A., Henderson, N, MacSween, K., Baring, D. and Sutherland, R., 2020. A retrospective review and multi-specialty, evidence-based guideline for the management of necrotising otitis externa. The Journal of Laryngology \& Otology, 134(6), pp.487-492.

4. ENT UK, 2020. ENT UK guideline on Necrotising Otitis Externa. United Kingdom: ENT UK. 